\title{
Perceived Clinician Competence to Work with Spiritual Issues in Supervision
}

\author{
Brittany J Shannon
}

Follow this and additional works at: https://researchrepository.wvu.edu/etd

\section{Recommended Citation}

Shannon, Brittany J, "Perceived Clinician Competence to Work with Spiritual Issues in Supervision" (2018). Graduate Theses, Dissertations, and Problem Reports. 7251.

https://researchrepository.wvu.edu/etd/7251

This Dissertation is protected by copyright and/or related rights. It has been brought to you by the The Research Repository @ WVU with permission from the rights-holder(s). You are free to use this Dissertation in any way that is permitted by the copyright and related rights legislation that applies to your use. For other uses you must obtain permission from the rights-holder(s) directly, unless additional rights are indicated by a Creative Commons license in the record and/ or on the work itself. This Dissertation has been accepted for inclusion in WVU Graduate Theses, Dissertations, and Problem Reports collection by an authorized administrator of The Research Repository @ WVU.

For more information, please contact researchrepository@mail.wvu.edu. 


\title{
Perceived Clinician Competence to Work with Spiritual Issues in Supervision
}

\author{
Brittany J. Shannon, Ph.D.
}

Dissertation submitted

to the College of Education and Human Services at West Virginia University

in partial fulfillment of the requirements for the degree of

Doctor of Philosophy in

Counseling Psychology

\author{
Christine J. Schimmel, Ed.D., Chair \\ David Allen, Ph.D. \\ Jeffrey Daniels, Ph.D. \\ Deborah Hendricks, Ed.D. \\ Lisa F. Platt, Ph.D.
}

Department of Counseling, Rehabilitation Counseling, and Counseling Psychology

\author{
Morgantown, West Virginia \\ 2018
}

Keywords: Supervision, competence, religion, spirituality, doctoral training

Copyright 2018 by Brittany J. Shannon, Ph.D. 


\section{ABSTRACT \\ Perceived Clinician Competence to Work with Spiritual Issues in Supervision}

\section{Brittany Shannon}

A lack of training around religious and spiritual issues in formalized mental health professional programs has placed the responsibility to ensure clinicians are prepared to work with clients in this area on clinical supervisors. This study measured supervisors' perceived competence to address issues of spirituality in supervision as well as frequency and type of religious/spiritual conversations in supervision. Additionally, this study evaluated the relationship between perceived competence and frequency of conversations around religious/spiritual issues. Finally, in the service of measurement-based supervision, the constructs delineated in the Spiritual Competency Scale (SCS) were evaluated next to the factors in the SACRED model as a way of providing supervisors a model and measurement to enhance supervision competence. Threehundred and four participants completed a survey assessing perceived competence and types of spiritual discussions held in supervision. A total of $46 \%$ of supervisors scored below the cutoff for perceived competence as measured by the SCS. There was no significant difference between student and supervisor scores on the SCS and the average score across groups fell below the cutoff for competence. Additionally, a large positive correlation existed between scores on the Spiritual Issues in Supervision Scale (SISS) and the SCS for both groups. Finally, the SCS could effectively be used as a competency-based measure for supervisors utilizing the SACRED model of supervision to help foster student's spiritual competence. The results of this study hold implications for the importance of training, supervision, and course work devoted to religious and spiritual concerns. 


\section{DEDICATION}

There are many individuals whose support and encouragement made this work possible. First and foremost, I would like to dedicate this dissertation to my husband. His unwavering patience and encouragement have made this journey less daunting. I cannot express how grateful I am for his many sacrifices, as I pursued this career path. I am truly lucky to have such an incredible partner and friend with which to move through life.

I would also like to dedicate this work to my mom and dad who have shown me through their example the importance of perseverance, hard work, and determination. They have dedicated their lives to helping others both personally and professionally. Their example has, and will continue to be, a true inspiration.

Lastly, I would like to dedicate this dissertation to my brothers who have been a constant source of comedic relief, support, and encouragement. Through their actions they have shown me the tenacity of the human spirit and the resilience to conquer every challenge that is placed in front of them. Their kindness, concern, and positive spirit has been unmatched. 


\section{ACKNOWLEDGEMENTS}

Graduate school and the dissertation process require a great deal of tenacity and I am grateful for the village of people who have offered their support, expertise, and guidance. I would like to acknowledge two people who served as the catalysts for this entire doctoral process, Dr. Julia Wernz and Dr. Jonathan Leggett. You showed me the healing power of holistic, integrated, collaborative care. Thank you for challenging me to grow as a clinician, specifically in the areas of religious/spiritual integration, this dissertation would not have been possible without your wisdom.

I would also like to thank my dissertation chair, Dr. Christine Schimmel for her guidance and support. Your passion for teaching and mentoring has been apparent from our first meeting. I cannot express enough how grateful I am for your organization, guidance, availability, and unwavering support. Most of all, I would like to thank you for your collaborative, strengths focused approach. I will strive to implement all of these wonderful characteristics into my own supervisory style.

Finally, I would like to thank the many faculty and staff that have made my time at West Virginia University truly memorable, Dr. Jeffrey Daniels, Dr. James Bartee, Dr. Lisa Platt, Dr. David Allen, and Vicki Railing. From the moment I arrived in Morgantown I felt welcomed and included. Thank you for opening your homes and offices to me throughout my time in the program. It is very clear how passionate and dedicated you are to each of the students and the work to which you have devoted your lives. As I move into my career as a health service psychologist I will strive to approach my work with the same level of dedication and care that I experienced at WVU. 


\section{TABLE OF CONTENTS}

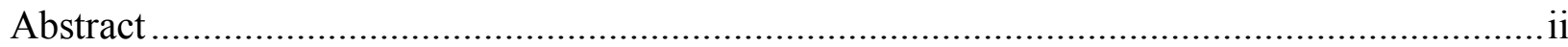

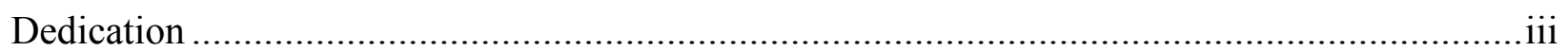

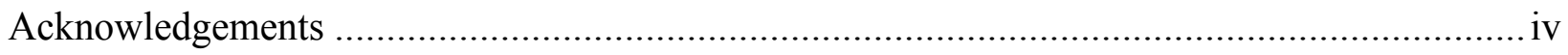

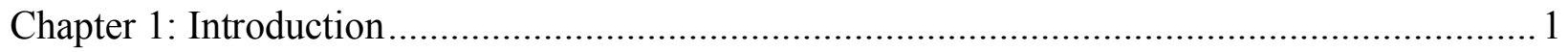

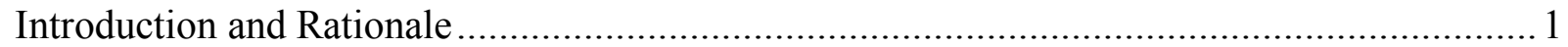

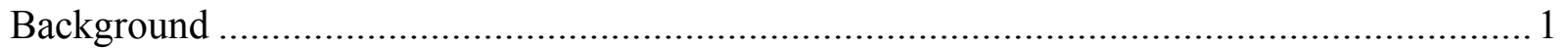

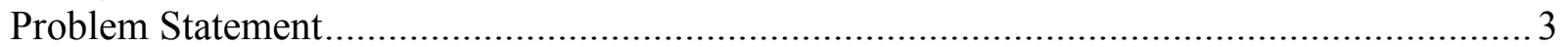

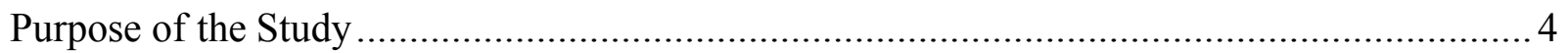

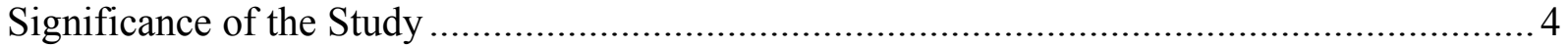

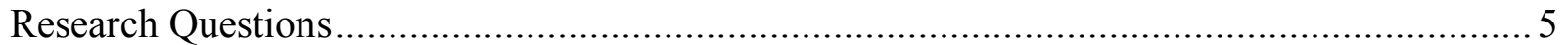

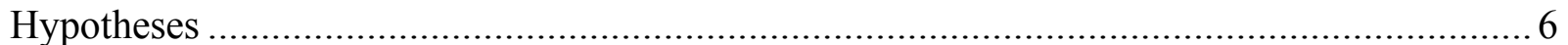

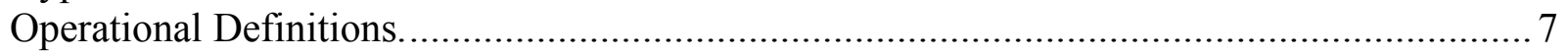

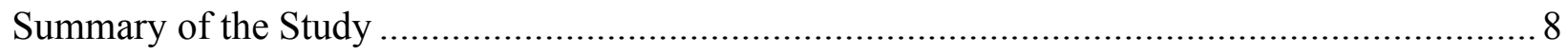

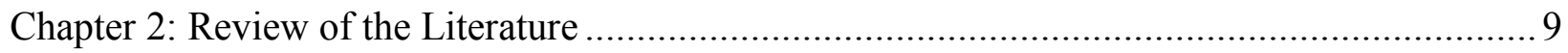

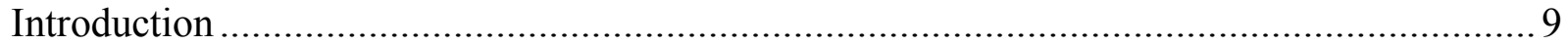

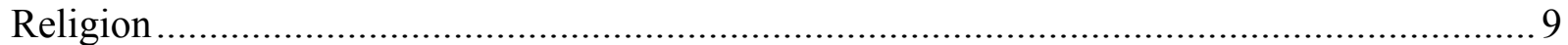

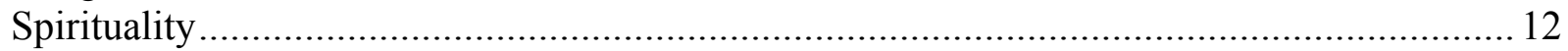

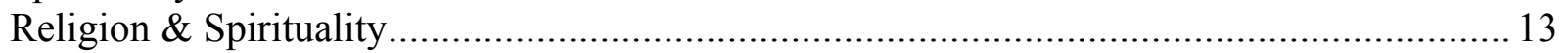

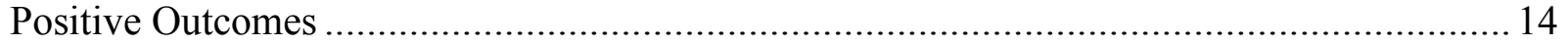

Religion and Spirituality from a Client's Perspective ........................................................ 18

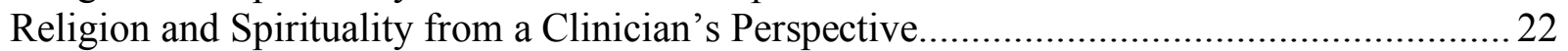

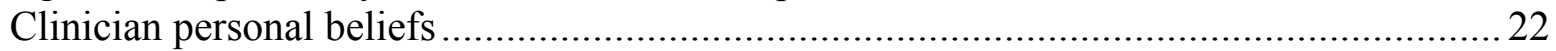

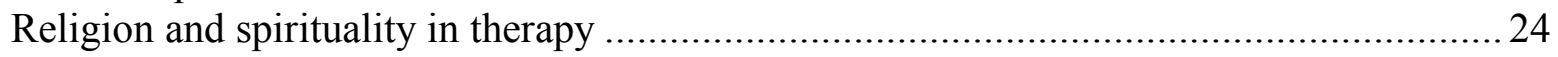

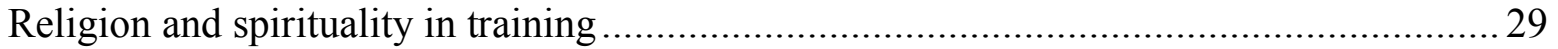

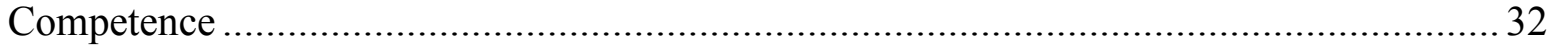

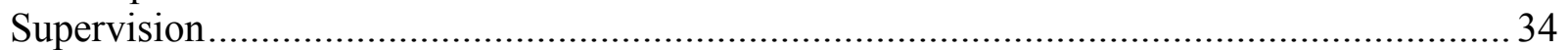

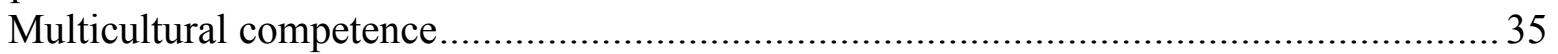

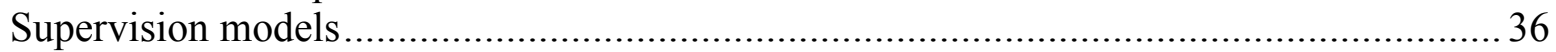

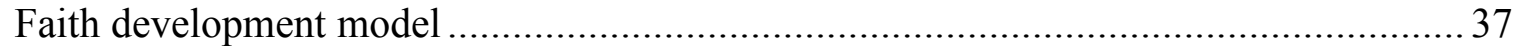

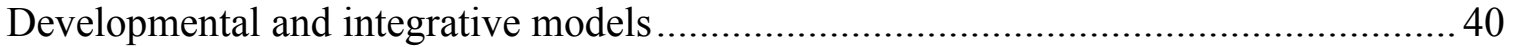

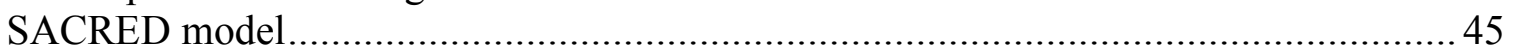

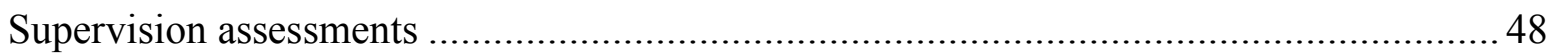

Spiritual issues in supervision scale (SISS)............................................................ 48

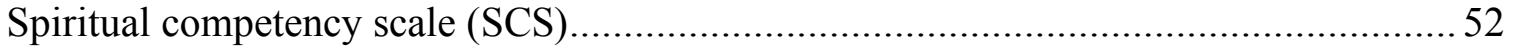

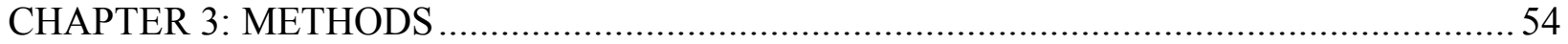

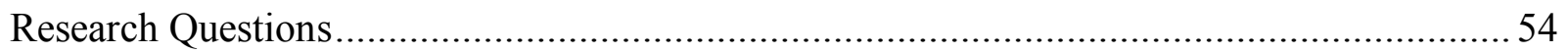

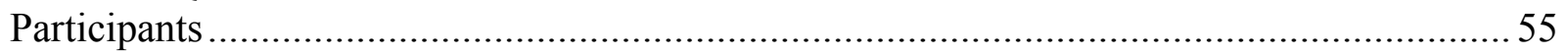

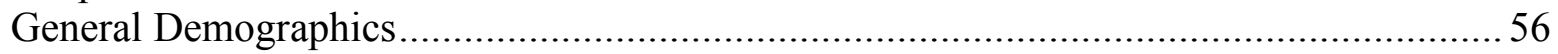

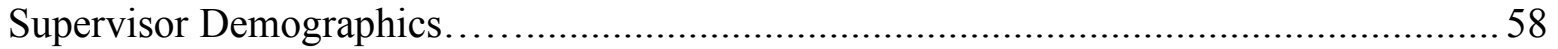

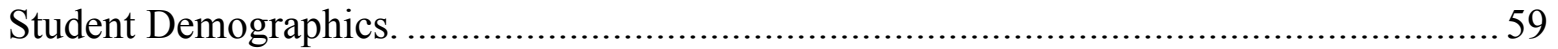

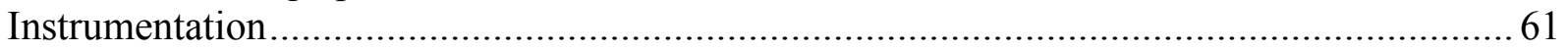




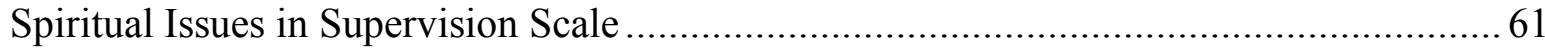

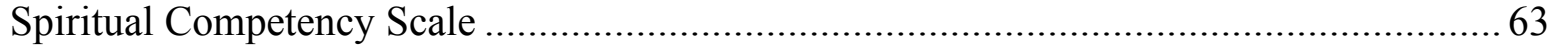

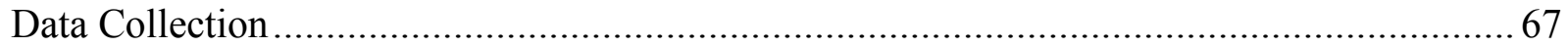

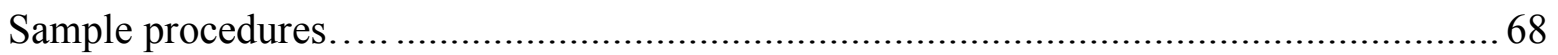

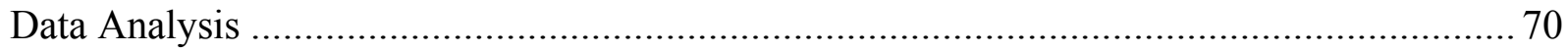

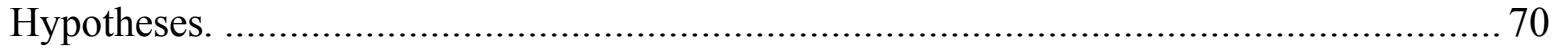

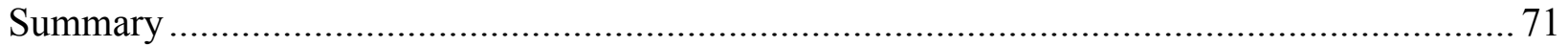

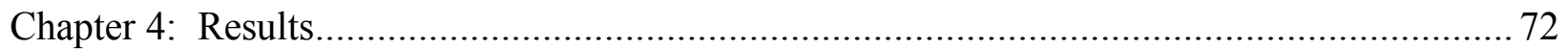

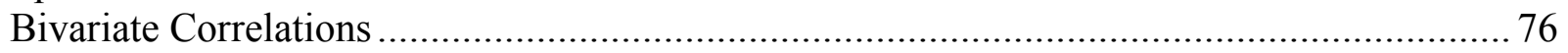

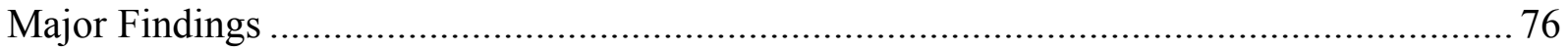

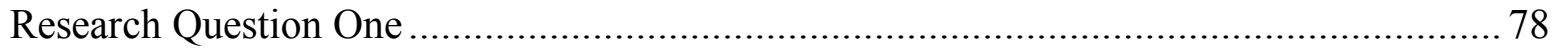

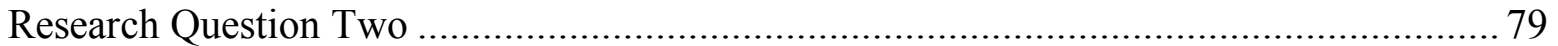

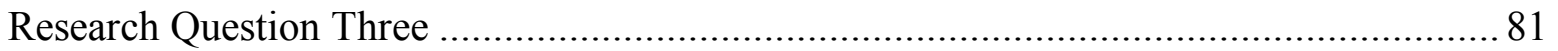

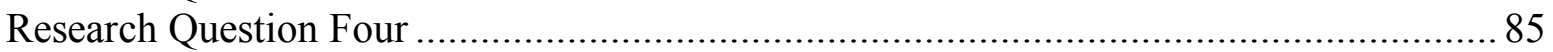

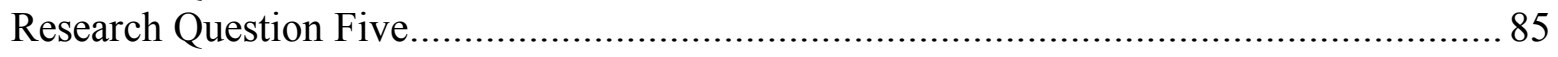

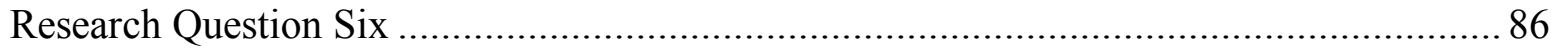

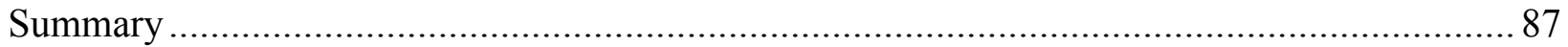

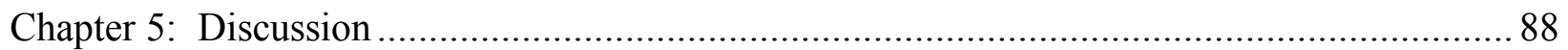

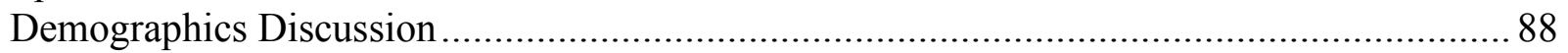

Supervisors' Scores on Spiritual Competency Scale (SCS) Discussion.................................. 92

Difference in Supervisor and Student Spiritual Competency Scale (SCS) Score Discussion .. 93

Spiritual Issues in Supervision Scale Discussion .............................................................. 94

Spiritual Competency Scale (SCS) as a Measure for SACRED Model Implementation......... 95

Relationship between SISS Scores and SCS Scores for Supervisors Discussion ..................... 99

Relationship between SISS Scores and SCS Scores for Students Discussion ....................... 100

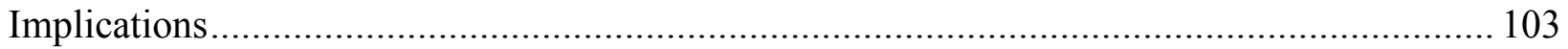

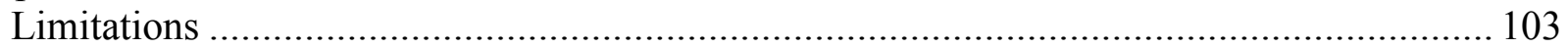

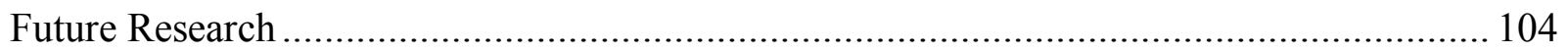

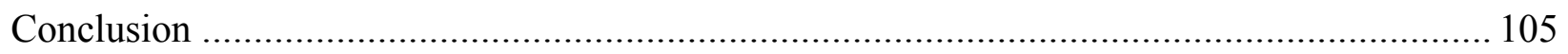

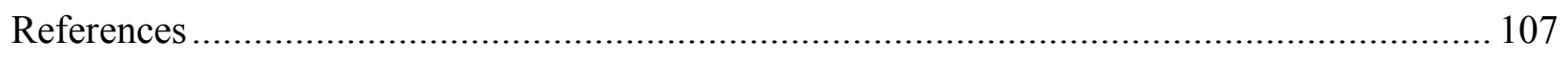

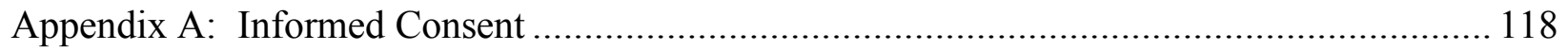

Appendix B: Participant Invitation Request ………........................................................... 120

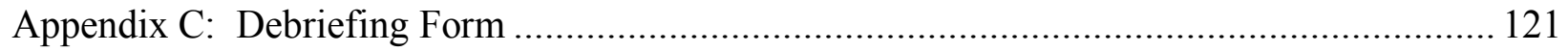

Appendix D: Demographic Information Questionnaire (Supervisors).................................... 125

Appendix E: Demographic Information Questionnaire (Students) ........................................ 129

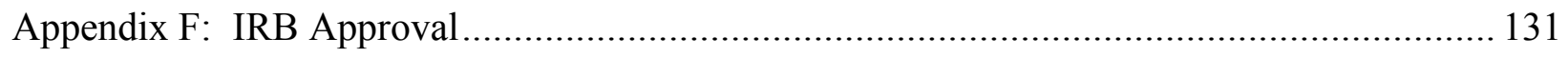

Appendix G: Permission to Use the Spiritual Competency Scale........................................... 132

Appendix H: Spiritual Competency Scale …….............................................................. 135

Appendix I: Spiritual Issues in Supervision Scale (Supervisors) ........................................... 139 
Appendix J: Spiritual Issues in Supervision Scale (Students) ........................................ 142

Appendix K: 2 Week Participation Reminder......................................................... 143

Appendix L: 4 Week Participation Reminder................................................................... 144

Appendix M: Facebook Advertisement ..................................................................... 145

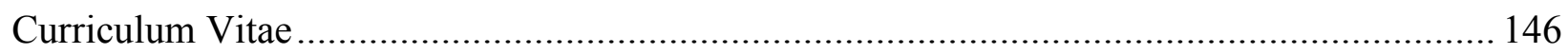




\section{CHAPTER 1: INTRODUCTION}

\section{Introduction and Rationale}

Multicultural competence is an area of emphasis for the training of counseling psychologists according to the American Psychological Association (2002). Within these guidelines is a requirement to address the multidimensionality of the client including their religious and spiritual beliefs. In response to this requirement, the literature has identified a deficit in training (Adams, 2012; Burke, Hackney, Hudson, Miranti, Watts, \& Epp, 1999; Delaney, Miller, \& Bisonó, 2013; Hall, Dixon \& Mauzey, 2004; Saunders, Petrik, \& Miller, 2013; van Asselt, \& Senstock, 2009; Walker, Gorsuch, \& Tan, 2004; Young, Wiggins-Frame, \& Cashwell, 2007). This deficit in training has led to increased emphasis on fostering competent clinicians through the use of supervision (Plumb, 2011; van Asselt, \& Senstock, 2009; Walker, Gorsuch, \& Tan, 2004; Young et al., 2007). This dissertation is an examination of how supervisors implement religious and spiritual topics into supervision. Additionally, this dissertation will evaluate supervisors' perceived levels of competence to discuss religion and spirituality as well as students' perceived levels of competence to implement religion and spirituality into therapy.

\section{Background}

Religion and spirituality have a place in counseling (Koenig, 2009; McCullough, Hoyt, Larson, Koenig \& Thoresen, 2000; Rogers, Skidmore, Montgomery, Reidhead, \& Reidhead, 2012; Worthington, Hook, Davis, McDaniel, 2011), and clinicians need to be competent to address these concerns with clients (Mrdjenovich, Dake, Price, Jordan, \& Brockmyer, 2012; Shafranske \& Malony, 1990; Souza, 2002; Young et al., 2007). Chapter two of this study examines the nuances of what it means to be religious and what it means to be spiritual. 
However, with such ambiguity surrounding the definitions of these constructs (Crossley \& Salter, 2005; Delaney, Miller \& Bisonó, 2013; Frazier, \& Hansen, 2009; Gockel, 2011; Hall, Dixon, Mauzey, 2004; Knox, Catlin, Casper, \& Schlosser, 2005; Morrison, Clutter, Pritchett, \& Demmitt, 2009; Post \& Wade, 2014; Richards, Bartz \& O’Grady, 2009; Rose, Westefeld, \& Ansley, 2008; Souza, 2002; van Asselt \& Senstock, 2009; Walker, Gorsuch, \& Tan, 2004; Worthington, Hook, Davis, \& McDaniel, 2010; Worthington, \& Sandage, 2001; Young et al., 2007), it stands to reason that empirical support is limited for religion and spirituality in counseling. While solidifying a definition for the constructs might prove elusive, several benefits of implementing religion and spirituality clinically will be explored (Koenig, 2009; McCullough, Hoyt, Larson, Koenig \& Thoresen, 2000; Rogers, Skidmore, Montgomery, Reidhead, \& Reidhead, 2012; Worthington, Hook, Davis, McDaniel, 2011).

Within the clinical realm, both clients and clinicians agree on the utility of religious and spiritual discussions (Diallo, 2013; Gockel, 2011; Knox et al., 2005; Morrison et al., 2009; Post \& Wade, 2014; Rose et al., 2008). However, clinicians report training deficits (Adams, 2012; Burke et al., 1999; Delaney et al., 2013; Hall et al., 2004; Saunders et al., 2013; Walker et al., 2004; Young, Wiggins-Frame, \& Cashwell, 2009) resulting in feelings of incompetence as far as addressing religious and spiritual concerns with clients (Mrdjenovich et al., 2012; Shafranske \& Malony, 1990; Souza, 2002; Young et al., 2007). It is suggested that supervisors take on the role of educator and use supervision as a place to foster competent clinicians (Souza, 2002).

There are several theoretical models that suggest ways of implementing religion and spirituality into supervision (Aten \& Hernandez, 2004; Gingrich \& Worthington, 2007; Ogden \& Sias, 2011; Parker, 2009; Ripley, Jackson, Tatum, \& Davis, 2007; Ross, Suprina, \& Brack, 2013; Tan, 2009). There also exist assessments that measure perceived competence to work on 
religious and spiritual concerns as well as whether those concerns are brought up in supervision; however, none of the available competence assessments have been evaluated to see if they correspond to the suggested models of supervision. In addition, the literature has not addressed feelings of supervisors' competence to serve as teachers or supervisees' feelings of competence to implement religious or spiritual discussions. If supervisors are going to be tasked with teaching clinicians competent implementation of religious and spiritual discussions, empirical literature would ideally support that endeavor.

\section{Problem Statement}

Due to a lack of training on religious and spiritual issues in formalized programs (Adams, 2012; Burke et al., 1999; Delaney et al., 2013; Hall et al., 2004; Saunders et al., 2013; Walker et al., 2004; Wiggins-Frame, \& Cashwell, 2007; Young et al., 2009) the responsibility to ensure clinicians are prepared to work with clients has fallen to the clinical supervisors (Plumb, 2011). However, there is currently no literature focused on assessing supervisors' feelings of competence in their work with supervisees on religious and spiritual concerns. Furthermore, there is no literature focused on how supervisors actually attend to spiritual issues in supervision. A necessary step to ensure culturally competent treatment of clients is to evaluate the skills and competence of the clinician's supervisor. This study will attempt, through the use of formalized assessments, to measure supervisors' perceived competence to address issues of spirituality in session. This study will provide empirical, outcome data to support the perceived level of competence of supervisors to address these multicultural concerns, or there will be evidence to support the need for increased training. 


\section{Purpose of the Study}

In 2002, the American Psychological Association (APA) released a foundational document that outlined multicultural competence as an important area of training for clinicians (APA, 2002). Attention to religion and spirituality is one aspect of multicultural competence. While attention has been given to the lack of training clinicians receive in higher education (Adams, 2012; Burke et al., 1999; Delaney et al., 2013; Hall et al., 2004; Saunders et al., 2013; Walker et al., 2004; Wiggins-Frame, \& Cashwell, 2007; Young et al., 2009), there has been very little research about how supervision can act as a platform to foster multiculturally competent clinical practice (Souza, 2002). The purpose of this study was to determine the role of religion and spirituality in supervision. Additionally, this study addressed if supervisors perceive themselves to be competent to address issues of spirituality with supervisees. Finally, this study expands the literature further by breaching a gap between theory and assessment through evaluating a theoretical model of addressing religion and spirituality in supervision.

\section{Significance of the Study}

The literature calls for more research and examination of supervision as a modality for increasing clinician competence to address clients' religious and spiritual concerns (Berkel, Constantine, \& Olson, 2007; Bishop, Avila-Juarbe, \& Thumme, 2003; Coyle \& Lochner, 2011; Gilliam \& Armstrong, 2012; Gubi, 2007; Hull, Suarez, \& Hartman, 2016; Soheilian, Inman, Klinger, Isenberg, \& Kulp, 2014; Souza, 2002). Additionally, there is no published research on supervisors' perceived level of competence to teach supervisees about religion and spirituality. Finally, several models of supervision have been proposed to address the task of teaching supervisees, however there is no measurement that would suggest effectiveness of these models. 
Identifying and lending empirical support for the use of a supervision model could provide supervisors with a template for implementing religion and spirituality with their supervisees. In addition, providing empirical support for supervisors' feelings of competence could shed light on areas where growth and increased training are needed. A suggested way to address perceived training deficits was to work with the clinician in supervision (Souza, 2002). While this seems to be a viable solution, it is possible that supervisors are not equipped to take on this task. Empirical support is necessary to continue to foster competent clinicians.

The information gleaned from this study will be beneficial to clinicians, supervisors, and educators. Clinicians may benefit from this information in the sense that they will know what to expect from supervision with regard to religious and spiritual training. Supervisors may gain insight into ways to implement religion and spirituality discussions into supervision as well as their perceived competence to do so. Additionally, individuals who read this study will gain an awareness of the ASERVIC competencies. Finally, this study holds implications for educators. As illustrated in the literature, clinicians have expressed that training is insufficient when it comes to preparing them to work with a client's religious and spiritual concerns. The results of this study may provide additional support for the importance of course work devoted to religious and spiritual concerns.

\section{Research Questions}

The following research questions were addressed in this study:

1. Do supervisors' scores on the Spiritual Competency Scale (SCS) fall within the competent range?

2. Are supervisors' scores on the SCS significantly different than students' scores on the SCS? 
3. Are supervisors addressing issues pertaining to facets of spirituality, as measured by the Spiritual Issues in Supervision Scale (SISS) with supervisees?

4. How do the constructs in the SACRED model of supervision compare to the constructs measured on the SCS?

5. To what extent are supervisor scores on the SISS related to their scores on the SCS?

6. To what extent are student scores on the SISS related to their scores on the SCS?

\section{Hypotheses}

The following hypotheses were addressed in this study:

1. $50 \%$ or more of supervisors will score in the competent range (at least 105 points) to implement spirituality as examined by the Spiritual Competency Scale (SCS). Analysis: Descriptive statistics

2. Supervisors will score significantly higher on the SCS than students. Analysis: Independent samples $t$-test.

3. Supervisors will report addressing issues of spirituality in less than $50 \%$ of the provided situations on the Spiritual Issues in Supervision Scale (SISS). Analysis: Descriptive statistics.

4. Constructs measured by the Spiritual Competency Scale (SCS) will map onto constructs discussed in the SACRED model of supervision. Analysis: Confirmatory factor analysis.

5. There will be a significant, positive correlation between supervisors' scores on the Spiritual Competency Scale (SCS) and their reports of topics discussed in supervision as measured by the Spiritual Issues in Supervision Scale (SISS). Analysis: Pearson correlation. 
6. There will be a significant, positive correlation between students' scores on the Spiritual Competency Scale (SCS) and their reports of topics discussed in supervision as measured by the Spiritual Issues in Supervision Scale (SISS). Analysis: Pearson correlation.

\section{Operational Definitions}

1. Spirituality - according to the definition used on the SISS, spirituality is defined, "in the broadest sense as an overarching construct that includes a personal journey of transcendent beliefs and a sense of connection with other people, experienced either within or outside of formal religious structures" (Miller, 2004, p. 144).

2. Religion — "beliefs, practices, behaviors, and feelings that are expressed in institutional settings or ways associated with a denominational affiliation, including attendance at church, synagogue, or mosque; participation in public religious rituals; participation in public prayer, and publicly reading scriptures or sacred writings" (Richards, Bartz, \& O’Grady, 2009, p. 66).

3. Supervision — individual guidance about clinical work and professional development which can take the form of self-report, process notes, case notes, live observation, or audio and video recordings as delineated by Bernard and Goodyear (2014).

4. Supervisor - a doctoral level provider who assumes the role of educator, consultant, and resource to the doctoral level counseling or clinical psychology student supervisee while they are practicing counseling.

5. Student - a doctoral level clinical or counseling psychology student who holds a clinical position and consults with a more experienced doctoral level individual during a scheduled, structured time as a way of learning and developing perceived competence in counseling. 


\section{SUMMARY OF THE STUDY}

This study attempted to identify ways in which spirituality is discussed and developed in supervision. All clinicians receive supervision during their training and at the beginning of their careers. As clinicians become more experienced they move into supervisory roles and are tasked with helping develop beginning clinicians. Ensuring clients receive the most effective treatment is the result of competent practice from the clinician and competent supervision. This study attempted to provide a way to measure the effectiveness of supervision when the focus of supervision is on religious and spiritual issues. In addition, this study assessed feelings of perceived competence to work with religious and spiritual presenting concerns. This study provides information to supervisors and students in the hope of increasing the quality of care for clients. 


\section{CHAPTER 2: REVIEW OF THE LITERATURE}

\section{Introduction}

When examining religious preference among a sample of 4,820 Americans, $71.6 \%$ reported a belief in God and 42.8\% reported that they are at least somewhat strongly religious. Approximately $44.8 \%$ of participants surveyed indicated they attended services at least once a month (Ulmer, 2012). From a clinical perspective, psychologists report $60 \%$ of their clients often use religious language to describe their personal experiences (Rose, Westefeld, \& Ansley, 2008). These statistics illuminate just how many people deem religion and spirituality a significant part of their lives. Knowing this information, it is necessary that clinicians are able to address religion and spirituality with their clients.

The American Psychological Association (APA) indicates the importance of multicultural competence. Clinicians are encouraged to provide treatment that is inclusive and sensitive to all different groups of people, including people with distinct religious and spiritual convictions (APA, 2002). Walker, Gorsuch, and Tan (2004) reported that $90 \%$ of Americans claimed either a Protestant or Catholic religious affiliation. With such emphasis placed on the importance of religion and spirituality by the public (Gallup \& Lindsay, 1999), it is highly likely that clinicians will work with clients on presenting problems around their belief systems. It is necessary that clinicians are competent to address these concerns.

\section{Religion}

The psychological community has been largely divided in their beliefs surrounding religion as a liability or an asset. This division has made arriving at a definition of religion difficult. Wulff (1996) discussed the theoretical differences that have contributed to modern psychology's understanding of religion. Several early theorists believed that religion was a 
liability. B.F. Skinner suggested that people engaged in religious practices because the practices were followed by reinforcing stimuli. He suggested that religious practices were essentially exploitative and aversive because their primary goal was to be controlling (Wulff, 1996). In addition to Skinner, Freud believed religion was an infantile response. He asserted that religion served two purposes. First people had a need to believe in a father through the use of elaborate and obligatory rituals. Second, Freud suggested that people are driven to engage in religious rituals because they are prone to feelings of guilt. These feelings were akin to the obsessive symptoms associated with neurosis. Freud suggested that the only way to overcome this infantile response was to abandon "religion and its dogmatic teachings" (Wulff, 1996, p. 51). John Watson and Albert Ellis also believed that religious expression and experiences should be regarded as pathological and as a sign of neurosis (Knox et al., 2005).

In stark contrast to Freud, Skinner, Watson, and Ellis, several theorists believed religion could be an asset. William James believed that religion was the way to human excellence. He asserted that "religion is an essential organ of our life, performing a function which no other portion of our nature can so successfully fulfill” (Wulff, 1996, p. 53). Jung asserted that religion was a way to wholeness. He believed religion was an essential function of the human psyche and contributed to his conceptualization of the collective unconscious. Jung expressed the importance of considering the full range of human experience which includes religion (Wulff, 1996). A third psychology pioneer, Erik Erikson, viewed religion as an avenue of hope for people asserting that it was the path to "the most fundamental needs, fears, and longings of humankind" (Wulff, 1996, p. 58).

When trying to arrive at a definition for religion the literature has not yet reached consensus (Delaney, Miller \& Bisonó, 2013; Hall, Dixon, Mauzey, 2004; Knox, Catlin, Casper, 
\& Schlosser, 2005; Morrison, Clutter, Pritchett, \& Demmitt, 2009; Post \& Wade, 2014;

Richards, Bartz \& O’Grady, 2009; Rose, Westefeld, \& Ansley, 2008; van Asselt \& Senstock, 2009; Walker, Gorsuch, \& Tan, 2004; Worthington, Hook, Davis, \& McDaniel, 2010;

Worthington, \& Sandage, 2001; Young, Wiggins-Frame, \& Cashwell, 2007). The definitions range in complexity and specificity. Van Asselt and Senstock (2009) utilized a more general explanation for religion, articulating that religion is a set of "institutional beliefs and behaviors that are a part of the broader concept of spirituality" (p. 412). By contrast, Richards, Bartz, and O’Grady (2009) presented a more nuanced definition, stating that being religious, refers to beliefs, practices, behaviors, and feelings that are expressed in institutional settings or ways associated with a denominational affiliation, including attendance at church, synagogue, or mosque; participation in public religious rituals; participation in public prayer, and publicly reading scriptures or sacred writings. (p. 66)

Many definitions fall within these two broad and specific examples.

While there is no agreed upon definition, there are many similarities among definitions. The hypothesis that religion is organized and institutional is a common theme (Knox et al., 2005; Post \& Wade, 2014; Rose et al., 2008; van Asselt \& Senstock, 2009; Walker et al., 2004). In addition, religion is viewed as having specific beliefs and practices associated with it (Knox et al., 2005; Rose et al., 2008; Worthington et al., 2010). Finally, religion takes place within the context of an identifiable community (Frazier, \& Hansen, 2009; Post \& Wade, 2014). Within the empirical realm it is speculated that religion is emphasized more often than spirituality due to the ease of measurement (Hall, Dixon, \& Mauzey, 2004). While there is no agreed upon definition of religion, there are many commonalities across definitions and measurable actions that make religion a relatively easy to measure construct. 


\section{Spirituality}

In contrast to the definitions of religion, spirituality is much more diversely defined and much less quantifiable (Crossley \& Salter, 2005; Frazier, \& Hansen, 2009; Gockel, 2011; Knox et al., 2005; Post \& Wade, 2014; Richards et al., 2009; Souza, 2002; van Asselt \& Senstock, 2009; Worthington et al., 2010; Worthington, \& Sandage, 2001; Young et al., 2007). Crossley and Salter (2005) delved into the many ways spirituality can be defined. They suggested that focusing on the issue of transcendence is one way to define spirituality. Individuals can focus on how their beliefs or relationship with powers transcend the present reality. Another way to define spirituality is through a dualistic approach that is not linked to transcendent forces. Through this lens, individuals search for meaning beyond materialistic things. A third way to conceptualize spirituality is through a present focused lens. Finally, spirituality can be defined through the values an individual holds. Each of these ways to define spirituality are subjective and allow for a unique construction of what it means to be spiritual (Crossley \& Salter, 2005).

In an attempt to narrow the definition of spirituality, Young, Wiggins-Frame, and Cashwell (2007) offered a general definition of spirituality. They suggested Spirituality is a capacity and tendency that is innate and unique to all persons. The spiritual tendency moves the individuals toward knowledge, love, meaning, peace, hope, transcendence, connectedness, compassion, wellness, and wholeness. Spirituality includes one's capacity for creativity, growth, and the development of a value system. (p. 48)

This definition encompasses several components addressed by other authors attempting to study spirituality. A common theme among definitions of spirituality is the emphasis on the individual's unique experience (Frazier, \& Hansen, 2009; Knox et al., 2005; van Asselt \& 
Senstock, 2009). The individual emphasis compared to the institutional emphasis is what separates spirituality from religion for many individuals (Richards et al., 2009; Worthington et al., 2010). A testament to the ambiguity that surrounds defining spiritualty are the results of a study conducted by Souza (2002). One of the research questions asked master's level counseling students to define spirituality. The participants demonstrated difficulty defining the construct of spirituality, reporting that it was difficult to put what they thought and felt about spiritualty into words. This struggle to define spirituality is a direct reflection of the broad definitions of spirituality found in the literature.

\section{Religion \& Spirituality}

When comparing religion and spirituality, Knox, Catlin, Casper, and Schlosser (2005) offered an inclusive conceptualization of the two constructs, suggesting "the two are neither mutually exclusive nor wholly overlapping, because religion may act as a platform for expressing spirituality but may also act as an inhibition for the expression of one's individual spirituality" (p. 287). The hypothesis that religion and spirituality are similar, yet distinct, is a common belief among researchers (Post \& Wade, 2014; Worthington et al., 2010; Worthington \& Sandage, 2001). Gall, Malette, and Guirguis-Younger (2011) asked 234 students to define religion and spiritualty. Several themes emerged from the definitions. Spirituality was viewed as an integral part of one's identity. Spirituality was seen as a defining feature of how the individual is viewed and how the individual relates to others and to the world. Overall, spiritualty "was seen as the nucleus of the self or the core self”' (Gall, Malette, \& GuirguisYounger, 2011, p. 176). In addition, spiritualty provided a perspective on life. Individuals also connected spiritualty to a divine presence. By contrast, religion was viewed as an external construct through which individuals could tap into their spirituality. Religion served as a 
framework for spiritualty. Some core components of religion that participants identified were, an affiliation with an organization, belief in a higher power, and perspective. When looking at the two constructs, the greatest difference in the definitions appears around the amount of structure as well as the guidelines for perspective.

Because of the overlap in the two concepts the hypothesis of being only religious or only spiritual is not accurate. Delaney, Miller, and Bisonó (2013) reported that people can meaningfully describe themselves as spiritual without being religious. Blando (2006) asserted that people can be religious, spiritual, or both. Finally, Worthington, Hook, Davis, and McDaniel (2010) discussed that many people experience spirituality within the context of religion. When working with clients, Worthington and Sandage (2001) placed more emphasis on the importance of asking the client how they identify as opposed to trying to apply a definition to a client. The authors suggested that some religious clients might resist a discussion about spirituality without the use of religious language. Conversely, clients might resist religious language but be open to spiritual language. Overall, the therapist is responsible for engaging in a sensitive discussion with the client about his or her religious or spiritual beliefs.

\section{Positive Outcomes}

The relationship between religion/spirituality, mental health, and physical health has been found to be more positive than negative (Gartner, Larson, \& Allen, 1991; Koenig, 2009; McCullough, Hoyt, Larson, Koenig, \& Thoresen, 2000; Rogers, Skidmore, Montgomery, Reidhead, \& Reidhead, 2012; Worthington et al., 2011). When looking at longevity of life McCullough, Hoyt, Larson, Koenig, and Thoresen (2000) conducted a meta-analysis of the data measuring religious involvement and mortality. In their study of 125,826 hospitalized patients, those with a religious belief system were more likely to be alive at a follow-up appointment than 
people who reported lower levels of religious involvement. In addition, Rogers et al. (2012) utilized the Spiritual Integration Scale to evaluate the perceived mental and physical health of 167 participants ranging in age from 56-96 years old. The results demonstrated increased mental and physical health in participants who held a spiritual belief system. Finally, there is a body of work that examines at the positive impact of religious coping. Olson et al. (2012) defined religious coping as "the use of religious behaviors and practices to adapt to or deal with difficult and stressful situations" (p. 174). The hypothesis of religious coping has been associated with increased mental health in pregnant women (Puente, Morales, \& Monge, 2015), survivors of intimate partner violence (Abu-Raiya, Sasson, Plachy, Mozes, \& Tourgeman, 2016), the elderly (Heydari-Fard, Bagheri-Nesami, Shirvani, \& Mohammadpour, 2014) and caregiver wellbeing (Pearce, Medoff, Lawrence, \& Dixon, 2016).

Looking specifically at positive outcomes in the context of counseling, Koenig (2009) conducted a meta-analysis of the outcome literature on religion and spirituality and mental health. Five mental health diagnoses were researched further; depression, suicide, anxiety, psychosis, and substance use. Within the context of depression, two thirds of the 93 observational studies found that rates of depression were lower for participants identifying as more religious. Findings were more robust when the suicide literature was consulted. Koenig (2009) found that 57 of the 68 studies reviewed found fewer suicide attempts in more religious participants than nonreligious participants. When reviewing the anxiety literature, 76 studies were evaluated. Religious participants in 35 of the studies reported less anxiety as compared to the non-religious participants. The author indicated a dearth of literature around the relationship between psychosis and religious beliefs. However, 16 studies were evaluated and 10 of them indicated less psychosis or psychotic tendencies among the religious participants. Finally, the 
literature on substance use was reviewed. Ninety percent of the 138 studies indicated less substance use in participants who identified as more religious. These findings indicate a positive impact of religion and spirituality on depression, hope, suicide, anxiety, psychosis, and substance abuse.

While much of the literature reports positive physical and mental health outcomes as a result of holding religious and spiritual beliefs, it is worth noting there are some ambiguous or complex outcomes. Gartner, Larson, and Allen (1991) conducted a review of more than 200 studies seeking to discover trends in the outcomes of holding religious beliefs. They identified four trends that exist between religion and mental health. First, the authors indicated that the use of inconsistent measures might contribute to discrepant findings across many studies. They discussed the use of soft mental health measures and hard variables. The soft measures are things like paper-and-pencil personality tests. These tests have limited reliability and validity and are more subjective. Conversely, hard variables constitute real-life behavioral events, things that can be observed and are unquestionable. For example, "physical health, mortality, suicide, drug use, alcohol abuse, delinquency, and divorce" (Gartner, Larson, \& Allen, 1991, p. 15). The hard variables are value-neutral whereas the soft variables are reflective of a value bias.

The authors noted that most studies that found a positive relationship between religion and mental health utilized hard variables. Additionally, when looking at how religiosity is represented across disorders those high in religiosity had disorders associated with over control as opposed to those with low levels of religiosity, who were more likely to have disorders related to under control. Next, the authors found that behavioral measures of religious participation were better associated with mental health than attitudinal measures. Lastly, it is important to 
note differences between intrinsic and extrinsic religiosity as that impacts the relationship between mental health and religiosity.

There is compelling evidence in support of tailoring therapy to be inclusive of a client's religious and spiritual beliefs. Worthington, Hook, Davis, and McDaniel (2011) compared intervention types across three groups of participants. In their meta-analysis, they compared the therapeutic outcomes of religious and spiritually accommodated therapy versus nonaccommodated therapy across 46 studies. First, they analyzed was whether participants receiving religious or spiritual interventions had better therapy outcomes than those receiving notreatment (control group). A statistically significant difference was found between the two types of treatment, indicating that participants receiving religious or spiritual interventions reported more improvement than those receiving no intervention.

The second question considered was how treatment outcomes differed between participants receiving religious or spiritual interventions and participants receiving secular interventions. The results indicated a significant difference between the two groups; those in the religious or spiritual intervention group reported greater treatment outcomes than those in the secular intervention group.

Finally, the authors considered the relationship between theoretical orientations. They compared treatments that had similar theoretical foundations and duration with religious or spiritual interventions. Holding theory and duration constant, participants in the religious or spiritual groups outperformed the other treatment groups. The physical and mental health benefits of having a religious or spiritual belief system are apparent from an outcome perspective. While this evidence provides support for the positive outcomes of religion and 
spirituality in session, religion and spirituality need to be of value to the client if they are going to be addressed in session.

\section{Religion and Spirituality from a Client's Perspective}

While reaching a consensus on the definitions of religion and spirituality have proven to be challenging, there is overwhelming consensus about how clients feel about the role of religion and spirituality in counseling (Diallo, 2013; Gockel, 2011; Knox et al., 2005; Morrison et al., 2009; Post \& Wade, 2014; Rose et al., 2008). These six empirical studies provide an overview of how clients feel about the implementation of religion and spirituality in counseling.

Knox et al. (2005) gathered information about the role of religion and spiritualty in participants' lives. In addition, they sought information about the role of religion and spirituality in therapy. They also tried to understand how the participants experienced religious or spiritual discussions with secular clinicians. Using Consensual Qualitative Research (CQR) design, 12 clients between the ages of 21 and 56 were interviewed. The results of the interviews suggested a foundation for the importance of religion and spirituality. All 12 participants engaged in religious and spiritual activities and those activities were important facets of their lives. In the context of therapy, participants reported talking about existential concerns such as meaning and purpose or anger at God. When religious and spiritual topics came up in session they typically came up organically and were not the primary presenting problem. These religious or spiritual discussions were related to the participants' psychological problems and participants reported that the conversations were helpful. The discussions were facilitated by the fact that clinicians were open, accepting, and created a safe space. Participants were also asked to reflect on unhelpful therapy discussions that occurred around religion and spirituality. Participants reported they were uncomfortable when the clinician initiated a conversation about religion or 
spirituality they were uncomfortable. In addition, the conversations were perceived as being more negative if therapists were judgmental or imposed their own beliefs (Knox et al., 2005).

Building on the findings discussed by Knox et al. (2005), Plumb (2011) discussed the role of self-disclosure in religious and spiritual discussions. In the instance where a client decides to share their beliefs with the clinician it is not typically important to the client that the therapist reciprocate by sharing their own personal beliefs. While there is support for some selfdisclosure of religion and spirituality in treatment, it has not been found effective to self-disclose (Plumb, 2011). Overall, clients reported religious and spiritual concerns were appropriate for discussion in treatment and preferred to have these discussions with clinicians.

Providing additional support for the findings of Knox et al. (2005), Morrison, Clutter, Pritchett, and Demitt (2009) interviewed 73 clients about their feelings on the use of spirituality in counseling. Clients were recruited from both a Christian counseling practice and a secular private practice. When looking at the degree to which spirituality was incorporated into counseling, $31 \%$ of clients from the secular practice noted the implementation of spirituality into session and that they were responsible for bringing up the topic. This finding is significantly lower than the experiences of the Christian counseling participants, where approximately $93 \%$ of participants reported the use of spirituality in session. A total of 50 participants indicated the use of spirituality in session regardless of location. Among those 50 clients, $73 \%$ indicated that they wanted spirituality to be included their treatment. In addition, $74 \%$ reported that the inclusion of spirituality had been instrumental to their progress in therapy. None of the participants reported that the implementation of spirituality into treatment had been unhelpful.

The preference for spiritual discussion in treatment is bolstered by findings from Gockel (2011). In a qualitative study, 12 clients were interviewed about their counseling experiences 
discussing spirituality. Several common themes emerged. Clients believed spirituality to be integral to effective counseling. They reported that spirituality was foundational to the healing process. In addition, spirituality was deemed necessary for change. The participants discussed how their spiritual beliefs helped them shift thought processes, adjust feelings, and adapt behaviors that were contributing to difficulties in their lives. In addition to facilitating the change process, spirituality was listed as a key ingredient in the therapeutic alliance. Many therapist qualities were conceptualized through a spiritual lens by the clients such as, "warmth, empathy, openness, acceptance, and genuineness" (p. 160). Clients identified effective counselors as being able to understand and respond to their needs spiritually. Integration of spiritual beliefs was a critical concept that impacted clients' ratings of clinician effectiveness. Finally, counselor effectiveness was linked to the clinician's own spiritual integration and healing. It was important for the clients to know a clinician had embarked on their own spiritual journey. Overall, clients reported terminating services when counseling lacked spiritual integration. These results support the implementation of spirituality into counseling but also emphasize the importance of competent practice.

As was demonstrated by Gockel (2011), it is not enough to talk about spirituality with a client. Clients want to discuss spirituality in a meaningful, intentional way. The clinician needs to demonstrate an ability to facilitate these discussions. Diallo (2013) expanded these findings to include the importance of overall knowledge of religion and spirituality. In contrast to Gockel's (2011) findings that clinicians needed to embark on their own spiritual journeys, Diallo (2013) found that all 84 participants were willing to talk about religion or spirituality with their counselor if the clinician was knowledgeable about the client's religious or spiritual beliefs. This knowledge was cited as being more important than the clinician's religious background. 
Much of the literature surrounding appropriateness to implement religion and spirituality in session is conducted in the context of individual therapy sessions (Diallo, 2013; Gockel, 2011; Knox et al., 2005; Morrison et al., 2009; Rose et al., 2008). However, Post and Wade (2014) provided support for the appropriateness of having religious or spiritual discussions in a group setting. They surveyed 164 group members and found that $84 \%$ of participants deemed religious and spiritual discussions were appropriate to have. In addition, these discussions were welcomed by participants. Several factors contributed to feelings of comfortability with religious or spiritual discussions, the first being client's spirituality or religious commitment. The more devout or vested the client was the more open they were to have these discussions. In addition, the degree to which the client was struggling with their religious or spiritual identity affected willingness to engage in conversations. If a client was experiencing more difficulty they were more likely to engage in the discussion. Finally, having experience discussing religion and spirituality contributed to an increased desire to talk about religious or spiritual issues. These findings suggest that the more exposure to the topics of religion and spirituality the client has, the more comfortable they will be discussing those issues in a group setting.

The findings from these studies suggest numerous ideas about how clients feel regarding the implementation of religion and spirituality into counseling. Overall, the results suggest that clients want to have religious and spiritual discussions in individual (Diallo, 2013; Gockel, 2011; Knox et al., 2005; Morrison et al., 2009; Rose et al., 2008) and group treatment (Post \& Wade, 2014). Clients perceived religious and spiritual interventions as meaningful, supportive, and effective (Morrison et al., 2009). In addition, when clients identified religious or spiritual components to their presenting concerns they expected to address those concerns with secular counselors (Knox et al., 2005). 
It is also noteworthy that clients have some hesitations about discussing their beliefs with their counselors. There is fear that the clinician will either make a conversion attempt (Morrison et al., 2009) or will not be able to understand the client's perspective (Gockel, 2011). These fears are not unfounded. Ankrah (2002) surveyed twenty participants about their experiences discussing religion and spirituality with clinicians and found that $25 \%$ of the participants were pathologized or dismissed by the clinician. Despite these fears, clients report a desire to discuss religion and spirituality in treatment, which stands in contrast to the hypothesis that religion and spirituality should only be discussed in pastoral counseling. Rose, Westefeld, and Ansley (2008), as well as Post and Wade (2014), offered support for the idea that having a history of positive discussions about religion and spirituality will help clients feel more comfortable to continue having those discussions across individual and group therapy. It is also indicative of the need to have clinicians who are competent at implementing spiritually appropriate interventions. Having established the foundational assertion that religion and spirituality have an important place in counseling from the client's perspective, the perspective of the clinician will be addressed.

\section{Religion and Spirituality from a Clinician's Perspective}

Clinician personal beliefs. When considering the role of religion and spirituality in counseling, it is important to have an understanding of the religious and spiritual demographics of clinicians. Historically, members of the American Psychological Association (APA) are less religious than the general public (Bergin \& Jensen, 1990; Delaney, Miller, \& Bisonó, 2013). Bergin and Jensen (1990) conducted a survey with APA members to learn how closely the demographics of religiosity and spirituality mapped onto the general population of the United States. Their findings indicated that clinicians were far less religious than the general 
population. Delaney, Miller, and Bisonó (2013) replicated the study to see if beliefs had shifted and the gap between clinicians and the rest of the population had closed. Their findings suggested that psychologists are still far less religious than clients. However, $82 \%$ of the 258 psychologists surveyed indicated that religion is important and not harmful to the client. Unfortunately, $83 \%$ of participants reported religious and spiritual issues were rarely or never discussed in their training programs.

With the foundation established that clinicians are typically less religious than the general population, Cummings, Ivan, Carson, Stanley, and Pargament (2014) chose to review the literature surrounding the relationship between a therapist's religious and spiritual beliefs and a variety of different factors such as therapy attitudes and behaviors, the therapeutic relationship, and treatment outcomes. Upon reviewing 29 qualitative studies several themes emerged. With regard to the impact of religious and spiritual beliefs on therapy attitudes and behaviors, they found that a therapist's religious and spiritual beliefs are positively correlated with favorable attitudes toward implementing religion and spirituality into therapy. Additionally, a therapist's religious and spiritual beliefs are also positively correlated with confidence in one's ability to implement religion and spirituality into therapy. With confidence comes action and the literature suggests that clinicians who reported strong religious or spiritual beliefs were more likely to actually integrate religion and spirituality into treatment as opposed to clinicians who reported a low level of religious or spiritual beliefs. Additionally, therapists typically preferred clients who share their religious or spiritual beliefs and values. However, there is not strong evidence that would suggest this commonality affects the therapeutic relationship.

Taking the results of Cummings et al. (2014) one step further, Walker, Gorsuch, and Tan (2004) evaluated the impact of a clinician's religious and spiritual beliefs on the implementation 
of religion and spirituality in therapy. Their review of 26 studies including 5,759 clinicians demonstrated that most therapists considered themselves to be spiritual but rarely engaged in spiritual practices or organized religion. In addition, the clinician's religious faith was associated with the use of religious or spiritual techniques in treatment. The clinician's beliefs were also associated with a willingness to discuss religion in therapy.

Mrdjenovich, Drake, Price, Jordan, and Brockmyer (2012) found that the impact of personal beliefs on treatment were going unnoticed by clinicians. When asked, only nine of the 306 participants endorsed the idea that their personal beliefs were a perceived barrier to having religious or spiritual discussions with clients. The qualitative results indicated this number is much higher. The authors suggested that personal conviction served as a barrier to discussing religion and spirituality with clients.

Although Mrdjenovich et al. (2012) found minimal awareness among clinicians with regard to the impact of their personal beliefs on the implementation of religion and spirituality in session, van Asselt and Senstock (2009) identified the impact of personal spiritualty, spiritual experience, and training on treatment focus. They found that all three factors significantly impacted treatment focus as well as perceived level of competence. These outcomes hold implications for working with clients as well as for the importance of implementing religion and spirituality into session. These results suggest a foundation for how clinicians feel about religion and spirituality in therapy.

Religion and spirituality in therapy. The first step to implementing religion and spirituality into therapy is to assess for it. Richards, Bratz, and O'Grady (2009) articulated the importance of assessment as a way to ensure religion and spirituality are addressed in treatment. When looking at how religion and spirituality actually get integrated into therapy there exists a 
disconnect between what clinicians report is important versus what they actually do (Frazier \& Hansen, 2009; Morrison et al., 2009; Plumb, 2011). One explanation for the lack of implementation is the impact of the clinician's religious and spiritual beliefs (Cummings, Carson, Stanley, \& Pargament, 2014). Another explanation for this could be a lack of understanding of what spirituality means (Crossley \& Salter, 2005). A final explanation for not implementing religion and spirituality into treatment is a lack of training (Mrdjenovich et al., 2010).

Richards et al. (2009) articulated the importance of assessing a client's religious and spiritual identity. They asserted that these constructs are often overlooked during the intake assessment. According to the authors, there are several reasons why assessing religion and spirituality would be relevant in counseling. First, through having a better understanding of the client's views, clinicians are better able to join with the client. Clinicians are also better able to respect the client's values if those values are known. In addition, knowing the client's religious or spiritual preferences help the clinician know if spiritual interventions would be appropriate for treatment. The assessment process can also help the clinician determine if there are unresolved religious or spiritual concerns. Finally, through the assessment process clinicians can obtain a better understanding of any pathology that exists in conjunction with the client's religious or spiritual identity.

While assessment of a client's religious or spiritual identity is deemed a necessary first step to implementation by Richards et al. (2009), there seems to be a disconnect between clinicians' thoughts and actions when it comes to addressing religion and spirituality in session. Morrison et al. (2009) evaluated clinicians' feelings about the role of religion and spirituality in treatment as well as implementation of religious or spiritual interventions. The sample of 34 
clinicians unanimously agreed on the importance of incorporating religion and spirituality into session. However, there was a divide in terms of implementing actual religious or spiritual interventions. Approximately half of the 34 clinicians reported implementing religious or spiritual interventions with their clients. Based on these findings, awareness of importance is not enough to result in implementation.

Other studies revealed similar issues of disconnect between importance and implementation in treatment. Plumb (2011) wanted to understand how therapists view and integrate religion and spirituality into their practice. To address this question, 341 clinicians completed a survey. When asked about the importance of religious versus spiritual work, the group reported spiritual work was more important than religious work. However, only $46 \%$ of the 341 clinicians indicated that they implemented spirituality into their clinical work. When asked about their comfortability discussing spirituality and God in session, $98 \%$ of the 341 clinicians reported they would feel comfortable if the client initiated the process. The belief is that if the client brings up the discussion the inherent ambiguity that surrounds the issue is eliminated. When evaluating therapist comfort with initiating a conversation about God in treatment, just $42 \%$ of the 341 clinicians reported a willingness to do that. The results of this study lend further support to the dissonance that exists between thoughts and actions with regard to clinicians implementing religion and spirituality into session.

The final, and starkest, evidence to support the disconnect between clinicians' thoughts and their lack of action initiating discussion in session comes from Frazier and Hansen (2009). The purpose of this study was to discern if clinicians are consistent in practicing what they preach. Three hundred psychologists were given a list of 29 recommended religious and spiritual psychotherapy behaviors. The results indicated that overall, clinicians believed these 
behaviors were important. For $90 \%$ of the individual items, clinicians reported using them far less than their reported use ratings would indicate. Only $30 \%$ of participants indicated they would discuss religious or spiritual topics with their clients, however, $57 \%$ reported they would not refer their client to a more qualified provider. In addition, the greater the clinician's religious or spiritual self-identification the more likely they were to report implementing the recommended behaviors. Analysis of the frequency of practiced items indicated that the five least frequently practiced items were making a DSM diagnosis for religious or spiritual problems, the use of prayer as an intervention, citation of religious texts in treatment, developing a professional development plan to improve religious or spiritual competence, and seeking feedback from colleagues. The lack of attention to these five components suggested to the authors that clinicians would implement the items they deemed personally important but not the others. This study demonstrates a disconnect between what clinicians value and what clinicians are doing. Very few clinicians are entering into discussions about religion and spirituality with clients but at the same time clinicians are not referring clients to more qualified providers. Additionally, it seems as though the clinician's belief system dictates the types of interventions in which they engage. Those clinicians with a stronger belief system are more likely to utilize religious or spiritual interventions, whereas clinicians without a strong belief system are implementing interventions based on what they deem important.

The work of Cummings et al. (2014) offers support for the hypothesis that a clinician's belief system dictates the types of interventions in which they engage. The authors chose to review the literature surrounding the relationship between therapists' religious and spiritual beliefs, therapy attitudes and behaviors, the therapeutic relationship, and treatment outcomes. Their review of 29 studies yielded several themes. The therapist's religious or spiritual beliefs 
were positively correlated with favorable attitudes toward implementing religion and spirituality into therapy. The therapist's beliefs were also positively correlated with confidence in one's ability to implement religious or spiritual interventions. The authors asserted that with confidence comes action. The literature suggests that clinicians who report strong religious or spiritual beliefs are more likely to actually integrate religion and spirituality into treatment than clinicians who do not hold equally strong beliefs.

An additional explanation for the lack of conversation about religion and spirituality stems from the work of Crossley and Salter (2005). The purpose of this study was to understand how clinical psychologists address spirituality in therapy. Overall, the eight participants had a difficult time defining, operationalizing, and understanding spirituality as a construct. In addition to not understanding the construct fully, participants reported avoiding the subject altogether. Some other reasons for avoidance were that a discussion of spirituality was culturally inappropriate, it did not resonate as important to the clinician and therefore was not addressed with the client, clinicians found the topic a source of personal discomfort, and clinicians did not feel like they used the right language to talk about spirituality.

A final explanation for the lack of spiritual and religious discussions is proposed by Mrdjenovich et al. (2012). They examined the kinds of religious and spiritual discussions providers were having with their clients as well as what barriers were preventing these discussions. In accordance with the literature (Frazier \& Hansen, 2009; Morrison et al., 2009; Plumb, 2011), participants reported positive feelings about religion and spirituality. Participants also identified several barriers in explaining why providers did not choose to talk with clients about their religious and spiritual identity. Many of these barriers lend additional support to the aforementioned works. One barrier to this discussion was accessibility of the topic; providers 
reported that issues of religion and spirituality did not come up organically in treatment. The clinicians reported they did not bring up religion and spirituality because they did not want to impose a personal agenda on the client. Additionally, clinicians themselves did not identify as being religious or spiritual and as such did not deem these topics important to discuss. Finally, the second largest predictor of avoidance of religious and spiritual discussions was inadequate training. Clinicians identified that they had not been adequately trained to competently engage in religious or spiritual discussions. Feelings of competence to implement religious and spiritual topics into counseling emerge from the clinical training clinicians receive. Clinical training is an area where clinicians' ideas about the importance of implementing religion and spirituality into counseling are either fostered or extinguished. Based on training experiences, feelings of competence are developed or halted.

Religion and spirituality in training. A major theme that emerges across the literature is the lack of training for clinicians to implement religion and spirituality into counseling (Adams, 2012; Burke, Hackney, Hudson, Miranti, Watts, \& Epp, 1999; Hall, Dixon, \& Mauzey, 2004; Magaldi-Dopman, 2014; Saunders, Petrik, \& Miller, 2013; Walker, Gorsuch, \& Tan, 2004; Wiggins-Frame, \& Cashwell, 2007; Young, van Asselt, \& Senstock, 2009;). The seminal work of Kelly (1994) found that only 25\% of the 341 schools surveyed included religious and spiritual issues as course components. Saunders, Petrik, and Miller (2013) provided an update to the literature surrounding training to implement religion and spirituality in session. They interviewed 543 doctoral clinical and counseling students about their training experiences with religion and spirituality. Upon comparing the work of Saunders et al. (2013) to the results from Kelly (1994), Saunders et al. (2013) found that 25\% of participants reported no discussion of religious or spiritual issues in coursework. 
In addition to these findings, Schafer, Handal, Brawer, and Ubinger (2011) followed up with American Psychological Association (APA) - accredited programs eight years after an initial survey of education and training practices around religion and spirituality. Training directors were asked how their programs had improved over the eight years. The results indicated that supervision on the topic increased between $77-84 \%$ across schools. The number of courses devoted to religion and spirituality increased between 13-25\%. Finally, the number of publications by faculty on the topics of religion and spirituality increased $30-43 \%$ across schools. These results are promising in terms of increased training available to clinicians.

Magaldi-Dopman (2016) sought to gain an understanding of counseling trainees’ experiences with spiritual/religious issues. Eight counseling trainees participated in a semistructured interview and through the use of grounded theory the results of the interviews were compiled. The participants discussed feeling ill prepared to discuss issues of spirituality/religion as they came up in session. The trainees completed multicultural counseling courses, however spirituality and religion were not discussed. As far as skills to work with clients the participants indicated that they felt comfortable exploring, however participants were unsure how to handle the content that emerged after exploring. Additionally, participants stated they "had no opportunity to examine their own spiritual/religious/nonreligious self-awareness" (p. 201). Finally, participants indicated that the topics of religion and spirituality "were noticeably absent from multicultural training" (p. 201).

Coursework is not the only training opportunity available to clinicians. Practical experiences in the form of internships are a requirement for many masters and doctoral level degrees. Russell and Yarhouse (2006) surveyed APA - accredited pre-doctoral internship sites to gauge availability of religious and spiritual training opportunities. Of the 139 surveyed 
placements, $65 \%$ reported that they did not offer training in religious or spiritual issues. Only 49 sites offered didactic training on the topic of religion and spirituality. When site training directors were asked if they might add religion and spirituality to their training program, $68 \%$ of directors reported that they never foresee training being offered at their site. It appears as though the importance of religion and spirituality in practice has not reached many clinical sites.

In addition to a lack of coursework devoted to religious and spiritual issues, Adams (2012) reported that $40 \%$ of the 188 student participants received mixed messages from faculty about religion and spirituality. Counselors in training were surveyed in an attempt to understand what messages they received about religion and spirituality in their training programs. They were also asked about their behaviors when working with a client on these issues. The results suggest that the students are receiving mixed messages. Explicitly, clinicians were told it is appropriate and ethical to discuss religion and spirituality in session with the client. However, implicitly, approximately $40 \%$ of students received the message that it is inappropriate or unethical to discuss issues of religion and spirituality. Students were also implicitly taught that providing a referral to the client when values or a spiritual conflict occurred was unethical. The result of these deficits in training is that clinicians have to decide for themselves how to deal with religious and spiritual issues. As a result of the implicit and explicit messages, as well as lack of coursework, students are left on their own to make sense of how they will or will not integrate religion and spirituality into their work. In many instances, the student will fall back on what they know, their personal experiences with religion and spirituality (van Asselt \& Senstock, 2009; Walker et al., 2004), which may not be helpful to the client.

Walker, Gorsuch, and Tan (2004) addressed what happens when clinicians are not taught how to implement religion and spirituality into session. The purpose of their study was to 
examine how therapists integrate religion and spirituality into session through consulting 26 different studies. They found that $80 \%$ of the 5,759 therapists rarely discussed spiritualty or religious issues in training. They also found that the therapists' religious faith was related to the use of religious and spiritual techniques. Participants reported that due to a lack of training they used intrapersonal experiences as a way to work with clients. Similar clinician behavior was noted by van Asselt and Senstock (2009). They found that a clinician's personal beliefs impacted their choice of interventions. As was demonstrated by Plumb (2011), clients are not receptive to the clinician self-disclosing or bringing their personal beliefs into session.

Competence. As a result of a lack of training and support, clinicians have reported feelings of incompetence when it comes to addressing a client's religious and spirituals beliefs in session (Mrdjenovich et al., 2012; Shafranske \& Malony, 1990; Souza, 2002; Young et al., 2007). In a similar way to Delaney, Miller, and Bisonó (2013), who found that clinicians believe discussions of religion and spirituality are important, Young, Wiggins-Frame, and Cashwell (2007) assessed participants to ascertain if competence to implement religion and spirituality into session was important. The purpose of their study was to gauge how important it is to be competent to implement religious and spiritual interventions. When looking at what it means to be competent the authors consulted the literature on religious and spiritual competence in counseling. In 1995, nine competencies were created by the Association for Spiritual, Ethical, and Religious Values in Counseling (ASERVIC) (ASERVIC, 2009), a division of the American Counseling Association. These competencies were created to improve counselor training. Young and colleagues assessed 505 participants across the ASERVIC's nine different categories of competency. 
These categories indicate that a counselor should be able to talk about the similarities between religion and spirituality. The clinician should be able to describe different religious and spiritual beliefs within a cultural context. In addition, the clinician should engage in selfexploration with regard to their own beliefs as a way to foster acceptance and sensitivity. Fourthly, the clinician should be able to describe several different models of religious/spiritual development across the lifespan. The counselor should be accepting of different ways the client expresses their religious and spiritual beliefs. Also, a counselor should note the limits of their competence and utilize appropriate referral skills. Additionally, the clinician should be able to evaluate the relevance of religious and spiritual domains in the client's presenting concerns. Counselors should be respectful of the religious/spiritual themes that emerge in the counseling process and address them according to client preference. Finally, the ASERVIC competencies indicate that the clinician should use the client's religious/spiritual beliefs to help them achieve their therapeutic goals as they prefer (ASERVIC, 2009). The results of their study found that the 505 participants deemed that religious and spiritual competency is important, however they did not feel competent to work with the client's religious or spiritual beliefs.

Feelings of incompetence are demonstrated among students (Saunders et al., 2013) as well as licensed professionals (Morrison et al., 2009). In a survey of recent graduates, Saunders, Petrik, and Miller (2013) found that $76 \%$ of the 543 participants surveyed felt their graduate programs inadequately addressed training related to religion and spirituality. When looking at competence among licensed professionals, $73 \%$ of participants reported they did not feel competent to implement religious or spiritual interventions (Morrison et al., 2009).

One of the reoccurring themes that is offered by clinicians to explain feelings of incompetence to implement religion and spirituality into session is a lack of training (Morrison et 
al., 2009; Saunders et al., 2013; Young et al., 2007). Mrdjenovich et al. (2012) assessed barriers to the implementation of religion and spirituality in session. One of the barriers discussed by the 306 participants was not feeling competent to implement religious or spiritual interventions as a result of inadequate training. One explanation for the perceived lack of competence to implement religion and spirituality into session is a lack of formal training (Adams, 2012; Burke, Hackney, Hudson, Miranti, Watts, \& Epp, 1999; Hall, Dixon, \& Mauzey, 2004; Saunders, Petrik, \& Miller, 2013; Walker, Gorsuch, \& Tan, 2004; Wiggins-Frame, \& Cashwell, 2007; Young, van Asselt, \& Senstock, 2009).

Additional barriers are discussed by Adams, Puig, Baggs, and Wolf (2015). Ten experts in religion and spirituality were consulted to identify common barriers to implementing religion and spirituality into counselor training. Two themes emerged from the interviews in this qualitative study. The experts agreed that educators lacked information to effectively teach about religion and spirituality. In addition to a lack of knowledge, it was suggested that educators lacked interest in the topic. While it appears as though higher education has some work to do in the way of adapting curriculum and making clinical opportunities available, Souza (2002) suggested an alternate way to foster competence among clinicians. Deficits in religious and spiritual training could be addressed in supervision.

\section{Supervision}

To address the training deficits among clinicians to implement religion and spirituality into session it has been suggested that supervision be used as a platform to train competent clinicians (Souza, 2002). There is evidence to suggest that supervision is an appropriate context to develop religious and spiritual competence (Bishop, Avila-Jurabe, \& Thumme, 2003; Sperry, 2014), however, supervisors need to be competent to facilitate that growth (Berkel, Constantine, 
\& Olson, 2008; Coyle \& Lochner, 2011; Gilliam \& Armstrong, 2012; Hull, Suarez, \& Hartman, 2016; Soheilian, Inman, Klinger, Isenberg, \& Kulp, 2014).

Multicultural competence. When looking at the role of supervision in the supervisee's religious and spiritual development, Bishop, Avila-Juarbe, and Thumme (2003) identified important factors of which supervisors should be aware. First and foremost, counselor competence is addressed. Supervision is an avenue where competence can be fostered and as such is an appropriate venue to address religious and spiritual concerns. Next, the authors suggested fostering an understanding of spirituality from a personal perspective as well as from a place of general understanding. Finally, values and culture should be taken into consideration when helping a supervisee develop competence to implement religious and spiritual discussions. Creating this open, holistic environment will help supervisees feel safe to discuss religious and spiritual concerns.

Creating an environment for discussing religious and spiritual clinical concerns is necessary in supervision. Gubi (2007) surveyed clinicians about their willingness to bring up religious concerns in supervision. All of the nineteen participants reported that their supervision experiences did not foster a culture of openness and as a result they did not feel comfortable discussing interventions such as prayer with a client. Participants reported feeling misunderstood, judged, losing credibility, and condemned by supervisors for bringing up the use of religious interventions. Several participants reported finding two supervisors, a secular supervisor and a religious supervisor, with which to address cases. Overall, the results lend support for fostering an open and accepting environment to have religious and spiritual discussions in supervision. 
Supervisor multicultural competence is an area that is addressed in the supervisory literature (Berkel et al., 2007; Coyle \& Lochner, 2011; Gilliam \& Armstrong, 2012; Hull et al., 2016; Soheilian et al., 2014). Berkel, Constantine, and Olson (2007) provided a list of ways supervisors can foster multicultural competence when addressing religious and spiritual issues with supervisees. Some of the suggested guidelines are to ensure self-understanding, continued education, willingness to address cultural issues, utilize community resources, and a willingness to initiate religious and spiritual discussions with supervisees. Another way to ensure multiculturally competent supervision around religious and spiritual issues is to implement the use of the Association for Spiritual, Ethical, and Religious Values in Counseling (ASERVIC) competencies. Hull, Suarez, and Hartman (2016) suggested supervision interventions that can be utilized with each of the 14 competencies. Through implementation of these concepts supervisors can begin to facilitate multiculturally competent supervision with their supervisees around religious and spiritual concerns.

Culturally competent supervision is not only valued by the supervisor. Research has shown that the supervisee is also vested in receiving culturally competent supervision. Soheilian, Inman, Klinger, Isenberg, and Kulp (2014) surveyed supervisees' experiences in supervision and asked supervisees to identify constructs that indicated competence in their supervisors. The 102 supervisees identified several common themes in competent supervision. Supervisors who facilitated exploration of specific cultural issues, implemented culturally appropriate interventions, the facilitation of self-exploration and awareness as well as encouraging openness, were representative of a competent supervisor.

Supervision models. The use of theory to guide supervisors in developing competent supervisees has been expressed by several researchers. Supervision in religion and spirituality 
has been conceptualized through the lens of Fowler's model of faith development (Parker, 2009), the developmental model (Gingrich \& Worthington, 2007; Ripley et al., 2007), the integrative developmental model (Aten \& Hernandez, 2004; Ogden \& Sias, 2011; Tan, 2009), and the SACRED model (Ross et al., 2013). Each of these models will be looked at in closer detail and the SACRED model will be discussed with implications for competent supervision.

Faith development model. Fowler's (1981) model of faith development has been identified as a seminal work in helping clinicians address religious and spiritual issues in counseling. Parker (2009) suggested the framework of this model be used by supervisors to "understand and work with some of the dynamics that emerge when client and counselor values diverge regarding spirituality and religious issues" (p. 40). Fowler's model offered a growthoriented approach that avoids pathologizing issues that have historically been pathologized. It is also noted that Fowler's model can be conceptualized within the Integrated Developmental Model (IDM) of supervision framework. The IDM is "the best known and most widely used stage developmental model of supervision” (Bernard \& Goodyear, 2014, p. 35). A strength of using Fowler's model within the framework of the IDM is the empirical validation of the IDM.

When implementing Fowler's (1981) model within a supervision context there are seven stages that are moved through based on the presentation of the seven structures of faith. The first structure of faith evaluates logic. Heavily influenced by Piaget's cognitive developmental model, the development of logic happens in a similar way in faith development. Individuals move from concrete thinking to more abstract conceptualizations. Moral reasoning is the second structure of faith. Fowler paid tribute to Kohlberg with his use of moral reasoning, asserting that individuals move from a concrete inflexible moral understanding to a more complex and abstract understanding of what is right and wrong. The third structure of faith is perspective taking. This 
structure was influenced by Selman's work on perspective taking. As an individual grows and develops, they move from an egocentric viewpoint to an ability to understand many different perspectives. The fourth structure of faith deals with world coherence. Fowler asserted that this structure is characterized by how an individual makes sense of the world. The trajectory a person might take could be an understanding of the world through their parents' eyes versus an understanding of the world based on self-reflection and life experiences.

An individual's locus of authority is the fifth structure of faith in Fowler's (1981) model. This structure is similar to the second structure that was influenced by Kohlberg in the sense that individuals seek to understand whether their beliefs and actions are right or wrong. This structure is characterized by either an outward understanding of right and wrong or an inward understanding of right and wrong. With development people move from an external perspective to an internal perspective. The sixth structure deals with social awareness. This concept evaluates how an individual either includes or excludes others in meaning making. With age and experience people tend to be more inclusive of others as opposed to individually focused.

The final structure in Fowler's (1981) model that is used to help identify an individual's developmental stage is symbolic function. "This structure refers to how and what symbols one uses to refer to transcendent values and experience" (Parker, 2009, p. 41). The greater the amount of sophistication present in the symbols, the further the person is developmentally. When conceptualizing the concept of faith, it is not reducible to just one of the structures. These structures were designed to encompass the complexity of faith development and represent the cognitive, affective, and relational development of an individual (Parker, 2009).

Fowler's (1981) stages of faith development occur over an individual's lifespan. Similar to Erik Erikson's psychosocial model of human development, an individual does not 
automatically progress through each stage and the experiences in the previous stage have an impact on the subsequent stages. Parker (2009) asserted that in the context of supervision the first and last stages of spiritual development are unlikely to be encountered. The first stage is thought to occur in the first year of life. An individual's faith is built on trust and how that is fostered might impact the remainder of their development. While this stage is critical, it is not likely to be experienced in the context of supervision. The final stage is also not likely to be present in supervision and is reminiscent of Maslow's self-actualization stage. Parker (2009) described this stage as "inclusiveness of all being[s], while maintaining commitments to values such as universal justice and love" (p. 42). The remaining five stages are likely to materialize in supervision and can be navigated by supervisors.

The first stage of spiritual development that might show up in supervision, according to Fowler (1981), is the intuitive-projective stage. In this stage individuals have a rudimentary understanding of their faith that is characterized by spontaneity and irregularity. Faith may be defined by images in stories or relationship figures. The second stage is the mythic-literal stage. This stage is characterized by the use of concrete logic. An individual rigidly, and literally interprets the meaning of rules, fairness, and reciprocity. Stage three is the syntheticconventional stage. The main component of this stage is an interpersonal focus. Relationships become a central focus and the individual gains an ability to make sense of another person's perspective. In addition, the individual spends time critically reflecting on their own beliefs and values. The individuative-reflective stage emerges from the self-reflection of the third stage. There are two things that happen in the fourth stage: distancing from one's previous value system, and the emergence of the executive ego. The executive ego emerges when an individual takes responsibility for their own beliefs and lifestyle. A move towards independence and 
objectivity occurs in this stage. The final stage that might emerge in supervision is the conjunctive faith stage. In this stage, the individual is able to move beyond the black and white thinking of previous stages. Situations are no longer mutually exclusive. The individual also moves into a deeper understanding of the self and how social influences impact them.

As a supervisor, Fowler's (1981) model can provide developmental guidance for working with supervisees. Knowing the stage and the structures of faith the supervisee is presenting can help the supervisor facilitate growth. This model can also help the supervisor glean insight into how the supervisee might conceptualize a client. While Fowler's (1981) model of spiritual development was not originally developed to use in the context of supervision, it provides supervisors a viable, empirically supported option to work with supervisees.

Developmental and integrative models. While Parker (2009) suggested that the faith development model can be used alone to supervise an individual's religious/spiritual concerns, two other theorists proposed developmental and integrative approaches that combine Fowler's (1981) theory with other conceptualizations.

Fowler's (1981) six stages are: intuitive-projective faith, mythic-literal faith, syntheticconventional faith, individuative-projective faith, conjunctive faith, and universalizing faith. These stages are paired with the corresponding stages in Kohlberg's moral development model: punishment and obedience, instrumental hedonism, good child morality, authority and social order maintaining morality, morality of contract, individual rights, and democratically accepted law, morality of individual principles of conscience. Ripley, Jackson, Tatum, and Davis (2007) suggested an integration of Fowler's (1981) model and Kohlberg's stages of moral development. Their developmental theory postulated six different stages a supervisee can move through that coincide with the six stages of each contributing theory. 
In the first stage of their integrated approach, Ripley et al. (2007) suggested that supervisors will likely have supervisees who are in the beginning stages of their clinical work. These might be practicum students who have done minimal work exploring their own strengths and weaknesses. The goal of the supervisor when working with a supervisee in the first stage is to provide education, support, and direct feedback about how to appropriately navigate religious/spiritual concerns their clients might have. Role playing, and imitative learning are suggested during this stage.

Supervisees in the second stage of development will likely exhibit black and white thinking with regard to religious/spiritual matters. This stage is characterized by the supervisee's egocentric focus on their own development, often at the cost of the client's needs. The supervisee might have a difficult time working with clients who have a different belief system and will be reliant on the supervisor for guidance. The role of the supervisor in this stage is to help alleviate anxiety and foster autonomy within the supervisee. Redirecting the supervisee to focus on the needs of the client will be a large focus of this stage (Ripley et al., 2007).

The third stage of development combines Kohlberg's and Fowler's third stages. The result is a supervisee who is trying to merge their professional identity with their religious/spiritual identity. The supervisee might find grounding in their theoretical orientation, to the point of being rigidly tied to that orientation. They demonstrate an ability to understand other theoretical perspectives but are tied to their own. The supervisee will likely be very concerned with interpersonal relationships with their clients as well as supervisor. The authors suggest that supervisees in this stage are difficult to work with due to their sensitivity and rigidity. A supervisor can work with the supervisee to integrate the professional and religious/spiritual identities while also fostering a sense of autonomy in the supervisee. Direct 
feedback is not encouraged by the authors in this stage due to the heightened levels of interpersonal concern. As a result, it is suggested that the supervisor use Socratic questioning methods to help guide the supervisee to insight about working with clients who have a different belief system (Ripley et al., 2007).

Newfound confidence and critical analysis characterize the fourth stage of growth. While in previous stages the supervisee might have been unquestioning and receptive of information, they are now critically reviewing and evaluating information. The result of this critical review is the formulation of their own perspective on addressing religious/spiritual issues in therapy. Ripley et al. (2007) suggested that successful completion of this stage is necessary before a clinician seeks independent licensure. This stage marks the beginning of one's ability to conceptualize religious/spiritual concerns from the client's perspective. When supervising a client in this stage of development the supervisor is tasked with attending to the supervisee's overconfidence. The supervisor should continue to help the supervisee develop their religious/spiritual awareness and competence.

Stages five and six have been combined for similar reasons similar to Parker (2009)'s discussion. The last stages in both Fowler and Kohlberg's theories are more difficult to achieve and are unlikely to be present in the supervisory relationship. Ripley et al. (2007) included them for the sake of being thorough; however, they are not likely to be prevalent. Supervisees in this final stage of development demonstrate an acceptance of multiple truths. The anxiety of previous stages around the presentation of values that were different than their own is now gone. The supervisee will likely seek out knowledge and understanding of traditions that are different than their own and would not feel threatened by these differences. 
In addition to presenting a six-stage integrated developmental model of supervision focusing on religious and spiritual development, Ripley et al. (2007) offered empirical support for their theoretical model. A survey of 22 supervisors indicated that "supervisors do appear to address and incorporate religious and spiritual issues differently into clinical supervision, depending on a multitude of factors" (p. 304). As a result, a developmental model would likely be the most appropriate way to attend to the needs of the supervisee.

Ogden and Sias (2011) built on the integrated developmental model presented by Ripley et al. (2007), adding a few novel, key components. They offered support for the combination of Fowler's (1981) and Kohlberg's stages with the addition of an assessment component. Ogden and Sias (2011) suggested that the Spirituality Self-Rating Scale (SSRS) and the Defining Issues Test (DIT) be used in supervision to aid the supervisor in meeting their supervisee at the appropriate level. The SSRS is a measure of the supervisee's views on spirituality and the DIT assesses level of moral reasoning. Both of these measures have adequate empirical support, reliability, and validity and would serve as adequate pre- and post-measures of supervisee development. The use of assessment in supervision could be helpful to lend support to the models that have remained theoretical.

Within the context of supervision models, the IDM has been one of the most widely adopted and used models of supervision (Bernard \& Goodyear, 2014). Aten and Hernandez (2004) suggested that the eight domains from the IDM can be applied to work with supervisees on religious/spiritual development.

The first and second domains that a supervisor should focus on fit together and impact each other. The first domain focuses on intervention skills and the second domain focuses on assessment approaches and techniques. The supervisor's role in the first domain is to introduce 
supervisees to religious and spiritual interventions. The rationalization for the focus on interventions is two-fold. There is a practical benefit, the supervisee will gain applicable knowledge about ways to implement different religious/spiritual interventions. There is also an intrinsic benefit, through a discussion of interventions the supervisee can "begin the process of examining their own understanding of religion and the usefulness of religion-based interventions" (Aten \& Hernandez, 2004, p. 155). The assessment approaches and techniques domain focus on the act of assessing a client's belief system. Again, this domain has a practical focus on the supervisor teaching the supervisee how to sensitively assess a client's belief system. By processing these opportunities in supervision, the supervisor and supervisee can process the feelings of anxiety or hesitation the supervisee might have about assessing a possibly sensitive topic.

The third domain that should be attended to is individual and cultural differences. The supervisor's role in this domain is to foster multicultural sensitivity. Supervisors should encourage the supervisee to self-reflect on their own beliefs and values, their religious experiences, gaining knowledge about different religious traditions, and facilitate insight into the unique religious/spiritual experiences of their clients. The third and fourth domains build off of each other and fit together nicely. The fourth domain emphasizes interpersonal assessment. This construct is characterized by the supervisee learning to differentiate between themselves and the client. Gaining an awareness of perspective is a critical component of this domain and will tie directly to the previous domain of gaining cultural competence.

The next three domains build off of each other as well. The fifth domain emphasizes theoretical orientation. The sixth domain focuses on problem conceptualization and the seventh domain emphasizes treatment goals. With regard to theoretical orientation, the supervisor should 
explore with the supervisee how the supervisee's theoretical orientation conceptualizes issues of religion and spirituality. This conceptualization will directly impact how a supervisee identifies a client's presenting concern, which is the sixth domain. Following an understanding of how to conceptualize what is happening the supervisee will focus on the treatment goals. The supervisor will assist the supervisee in creating plans that are consistent with the client's religious/spiritual beliefs.

The final domain that should be addressed within the framework of the IDM is professional ethics. The supervisor's role is to ensure the supervisee understands the professional expectations and responsibilities they have to practice competently. While this model provides supervisors with a framework for how to supervise religious/spiritual topics, it lacks the depth of the other integrated approaches. There is a large focus on practical approaches for how the supervisor should navigate supervision with a supervisee who has a client with religious/spiritual concerns. However, there is little direction given about how to work with the supervisee's religious/spiritual development. The strengths of the models proposed by Parker (2009) and Ripley et al. (2007) were the emphasis on attention to both the supervisee and the client. A holistic approach seems like it would be most effective in fostering a sense of competence as well as ethical practice.

SACRED model. The SACRED model of development was created from a synthesis of the theoretical literature (Ross, Suprina, \& Brack, 2013). Ross et al. (2013) reviewed the literature looking at spirituality in supervision. From the surveyed literature, the SACRED model is an amalgamation of several existing supervision models (Integrated Developmental Model and Fowler's model of faith development), as well as the themes that emerged from the review of the relevant literature. 
Ross et al. (2013) created the SACRED model of supervision through the synthesis of nine articles dealing with religion and spirituality in supervision, which resulted in six domains of attention for competent supervision: safety, assessment, conceptualization, reflection, emerging congruence, and development (Table 1).

The component of safety includes establishing an environment where a discussion about spirituality can occur. The assessment construct deals with assessing the supervisee's understanding and knowledge of spirituality, which can be done formally or informally. The conceptualization part of the model is broken into three different components. Broadening the view of the supervisee includes reflection on the many relationships happening within supervision. The supervisor-supervisee relationship, the supervisee-client relationship, and the supervisor-client relationship are being evaluated and discussed. The integrating portion of conceptualization includes case conceptualizations that utilize the client's religious and spiritual beliefs. Finally, the personalizing portion of the conceptualization stage includes addressing countertransference reactions to topics that come up in session as well as in supervision.

The fourth stage of the SACRED model is the reflection stage, which is broken into four components. The first component of this stage is promoting diversity and cultural sensitivity. During this time, the supervisor helps the supervisee to process any anxiety that arises as a result of increased awareness. The second component of this stage is to address parallel process. This includes guidance from the supervisor to foster insight for the supervisee about how supervision processes can be applied to clinical work. The third component is to foster ideological consistency. In this part of the reflection stage the supervisee is encouraged to identify ways in which their theoretical orientation accommodates religion and spirituality. The final component 
of the reflection stage is to attend to self-examination, self-care, and self-growth. The overall goal of this component is to "teach the counselor how to be a caring person" (p. 79).

The next stage is the emerging congruence stage, which is centered on finding a balance between religious or spiritual beliefs and the presenting issues. This stage involves formulating interventions that are congruent with the client's beliefs, having discussions about hope, love, compassion, and remembering, as well as learning congruence. The supervisee is encouraged to help their client foster a sense of congruence. These skills will help the client create authentic change.

The final stage in the SACRED model is development. This stage emphasizes the importance of lifelong learning. Supervisees are encouraged to continue to develop their personal and professional spiritual identities through scholarship. The SACRED model provides an inclusive framework for the facilitation of competent supervision. To increase the empirical validity of the SACRED model, its effectiveness should be formally assessed. Table 1

\begin{tabular}{|l|l|}
\hline SACRED Domains & Definition \\
\hline Safety & $\begin{array}{l}\text { Emphasizes establishing an open, safe environment in which } \\
\text { supervisees can discuss spirituality }\end{array}$ \\
\hline Assessment & $\begin{array}{l}\text { Importance of the supervisor understanding the supervisee's } \\
\text { knowledge of spirituality }\end{array}$ \\
\hline Conceptualization & $\begin{array}{l}\text { Awareness of the many relationships present in supervision, } \\
\text { self-reflection (specifically as it pertains to } \\
\text { countertransference), and holistic case conceptualization }\end{array}$ \\
\hline
\end{tabular}




\begin{tabular}{|c|c|}
\hline Reflection & $\begin{array}{l}\text { - Diversity component } \\
\text { Supervisors should assist supervisees as they process } \\
\text { their increased awareness of the cultural complexity } \\
\text { that surrounds issues of religion and spirituality. } \\
\text { - Parallel process component } \\
\text { Importance of the supervisory relationship and how } \\
\text { supervision processes can be applied to clinical work } \\
\text { - Ideological integration component } \\
\text { Importance of understanding the ways in which a } \\
\text { supervisee's theoretical orientation accommodates } \\
\text { religion and spirituality } \\
\text { - Self-examination component } \\
\text { Self-reflection and integration to "teach the counselor } \\
\text { how to be a caring person" (Ross et al., 2013, p. 79) }\end{array}$ \\
\hline Emerging Congruence & $\begin{array}{l}\text { - Importance of finding a balance between a client's } \\
\text { presenting concerns and their spiritual beliefs } \\
\text { - Focus on tailoring the interventions used in treatment to } \\
\text { the individual }\end{array}$ \\
\hline Development & $\begin{array}{l}\text { - Importance of life-long learning and continued growth } \\
\text { as it relates to spiritual understanding both personally } \\
\text { and professionally }\end{array}$ \\
\hline
\end{tabular}

Table 1. Brief overview of the six SACRED domains and definitions of each domain.

Supervision assessments. The Spiritual Issues in Supervision Scale (SISS; Miller, 2004;

Miller, Korinek \& Ivey, 2006) and the Spiritual Competency Scale (SCS; Robertson, 2008;

Robertson, 2010) measure spirituality and were used in the current study. Both measures

provide empirical support for supervisory models being used and facilitating goal setting within supervision.

Spiritual issues in supervision scale (SISS). The SISS was created to assess the extent to which spiritual issues are discussed in supervision from the supervisee's perspective (see Appendices I \& J). The instrument was created by Miller (2004) as part of her dissertation research. The author was examining the relationship between supervisor and supervisee gender, supervisory style, and frequency of spiritual issues addressed in supervision. As there was not a measure of spiritual issues addressed in supervision the author created one. 
The SISS is comprised of 29 items that represent potential areas to be addressed in supervision (e.g., assessment, divorce, culture). Participants rate each item as to the degree it is addressed in supervision. The items were created by a panel of experts recruited by the author. Following the creation of the items a pilot test was completed which resulted in the emersion of seven different factors that make up the SISS. These factors accounted for $72.7 \%$ of the sample variance and produced a Cronbach's alpha coefficient of .94, indicating adequate consistency among the scales. The original seven factors were related to gender and identity, acceptance, family roles, morality and loss, diversity, values of life, and supervisory process. Each individual scale had appropriate reliability coefficients which resulted in the use of the scale in the study.

The SISS was used in conjunction with several other measures to address the primary research questions of her dissertation. The SISS was completed by 153 participants in the primary study which served to increase the robustness of the test (Miller, 2004). Analyses of the SISS were completed on a total of 257 cases, as many participants chose to rate several supervisory experiences.

Miller (2004) noted several limitations to the SISS. First, the pilot test did not achieve a large enough sample. When looking at the appropriate sample size for a study utilizing factor analysis, Tinsley and Tinsley (1987) suggested a ratio of 5-10 participants per item, Miller's pilot study only had 51 respondents. While the use of the SISS as a part of the larger research project helped increase reliability and validity, the author emphasized the importance of continued validation. In addition, Miller (2004) noted the use of convenience, nonprobability sampling methods has its limitations. While it holds a strength in terms of higher response rate, a 
drawback is the increased sample bias that could occur as a result of participants holding similar group affiliations.

Weinstein (2006) sought to address some of the limitations delineated by Miller (2004) and expand the use of the SISS. The purpose of the study was to examine the extent that counseling psychology graduate students discussed spiritual issues in supervision, as measured by the SISS. Additionally, the author wanted to assess the impact of multicultural awareness and the supervisory working alliance on discussion of spiritual issues in supervision. One hundred and one counseling psychology graduate students were asked to complete the SISS along with several other measures. While the author recognized and attempted to address the sample size limitation another limitation was discussed. Weinstein (2006) asserted that the 1 to 5 Likert scale utilized on the SISS assumed that all of the presented topics were addressed in supervision. There was no way for the participant to indicate if the topic had never been discussed. To address this limitation Weinstein (2006) added a question before each Likert response eliciting whether or not the topic had been discussed in supervision. This addition served to increase clarity and depth of information.

The results of this study indicate that overall spiritual issues are not consistently addressed in supervision. However, discussions of spirituality increased if the individual had previous experience discussing religion and spirituality. In addition, as satisfaction with the supervisory relationship increased, discussion of spiritual issues increased. A reported limitation was the use of the Multicultural Counseling, Knowledge, and Awareness Scale (MCKAS; Ponterotto et al., 2002) to ascertain competence among participants. It was noted that this measure assesses more heavily for competence related to race and gender as opposed to religious 
and spiritual competence. Overall, the results offer support for the use of the SISS as a reliable and valid measure.

While Weinstein (2006) sought to address some of the foundational limitations of the SISS, Miller, Korinek, and Ivey (2006) aimed to provide a more detailed examination of the measure. The SISS was given to 153 masters and doctoral level students. These students came from 12 different accredited programs in marriage and family therapy. The authors utilized factor analysis and found four factors as opposed to seven that were originally postulated by Miller (2004). The first factor looked at the client system which encompassed problems clients brought to therapy. The second factor dealt with the supervisory system which included discussions in supervision. The third factor was labeled a diversity lens as it related to aspects of treatment that were not necessarily discussed by the client but were considered by the clinician such as race and culture. The final factor was termed the lens of meaning and values. This factor addressed concepts related to meaning making and purpose. The results suggest that the SISS is a reliable measure with four major factors.

A final empirical look at the use of the SISS was conducted by Hull, Suarez, Sells, and Miller (2013). The purpose of the study was to look at the frequency of spiritual discussions in supervision among supervisor/supervisee dyads. This was the first study to look at pairs of supervisors and supervisees. Upon surveying 54 supervisory dyads, support for the four factors asserted by Weinstein (2006) emerged. The results also illustrated the significant impact of each individual's religious or spiritual affiliation. The authors noted a high correlation between religious affiliation and scores on the SISS. When that variance was removed there was a significant difference between supervisor and supervisee perceptions. This indicates the importance of recognizing the impact of each individual's personal beliefs on the results of the 
SISS. Hull et al. (2013) echoed the results of previous authors who support the use of the SISS as a reliable measure.

Spiritual competency scale (SCS). The SCS (Appendix H) was developed to meet the needs of the clinical community by providing an assessment for perceived spiritual competence. As previously discussed, ASERVIC created nine Spiritual Competencies to help guide educators and clinicians in the task of developing religious and spiritual competence (Miller, 2004). Two pilot tests using 100 participants at each administration were conducted with a two-week interval between administrations. The final study utilized 662 participants from a mixture of secular and religiously-based universities across 17 states. The pilot test-retest reliability was favorable. In addition, the measure included tests for socially desirable responses and there was no evidence that participants were responding in socially desirable ways. The results of the final study suggested that participants from religiously oriented schools had higher scores on the SCS than those from secular schools. The 90-question assessment yielded six factors that directly corresponded to each of the nine Spiritual Competencies. The competencies that were represented on the SCS were diagnosis and treatment, cultural and worldview, counselor selfknowledge, assessment, communication, as well as human and spiritual development. The findings overall suggest the utility of the SCS in education, as an outcome measure, and as a way to evaluate perceived competence.

A follow up study was conducted by Dailey, Robertson, and Gill (2015) in an effort to expand the literature from the original work. The purpose of the study was to confirm the sixfactor structure of the 90 item SCS. The authors revised the question presentation, changing the use of pronouns like "I" to "counselors" to further decrease any socially desirable responses. In addition, the authors utilized a 6-point Likert scale, eliminating the neutral option (e.g., don't 
know) as the literature from the seminal work supported clear answers to each of the items. The overarching goal of the study was to provide a cutoff point for competency as that was not addressed in the original work. Finally, the authors sought to survey a sample that would be expected to be competent. The original sample was comprised of graduate students who were not expected to have competency in spiritual issues. Dailey et al. (2015) chose to survey ASERVIC members to establish results for allegedly competent individuals. The 90 -item version of the SCS was administered and support for a 6-factor solution was found. A mean score of 106 was found from the sample, lending support for the hypothesized score of 105 as an indicator of spiritual competency. The sample was comprised of members of ASERVIC that were a mixture of students and licensed professionals. The results indicated that ASERVIC student members scored higher on the SCS than the original sample, which could suggest that membership in ASERVIC increases clinician competency. Finally, Dailey et al. (2015) asserted, as a result of their findings, the utility of the SCS as a measure of perceived clinician competence. 


\section{CHAPTER 3: METHODS}

The goal of improving clinician competence to implement religion and spirituality into session begins with ensuring clinicians have an avenue to learn the skills necessary to work competently with a client on religious or spiritual concerns. As the literature suggests, this teaching responsibility is often passed to supervisors (Bishop, Avila-Jurabe, \& Thumme, 2003; Souza, 2002; Sperry, 2014). The purpose of this study was to understand how spiritual discussions impact clinician perceived competence. Perceived competence was measured through the use of the Spiritual Issues in Supervision Scale (Miller, 2004) and the Spiritual Competency Scale (Robertson, 2008).

A second goal of this study was to suggest a method of empirically measuring the theoretical assertions made in the SACRED model through the use of the Spiritual Competency Scale (Robertson, 2008). What follows is a review of the questions examined in this study, an in-depth discussion of the instruments used, and the process by which this research was conducted.

\section{Research Questions}

This in-depth, descriptive-correlational design surveyed spirituality in supervision and examined the following questions:

1. Do supervisors' scores on the Spiritual Competency Scale (SCS) fall within the competent range?

2. Are supervisors' scores on the SCS significantly different than supervisees' scores on the SCS?

3. Are supervisors addressing issues pertaining to facets of spirituality, as measured by the Spiritual Issues in Supervision Scale (SISS) with supervisees? 
4. How do the constructs in the SACRED model of supervision compare to the constructs measured on the Spiritual Competency Scale (SCS)?

5. To what extent do supervisor scores on the Spiritual Issues in Supervision Scale (SISS) relate to their scores on the Spiritual Competency Scale (SCS)?

6. To what extent do supervisee scores on the Spiritual Issues in Supervision Scale (SISS) relate to their scores on the Spiritual Competency Scale (SCS)?

\section{Participants}

The population in this study included doctoral level clinicians at least 18 years of age or older, in clinical or counseling psychology programs, and clinical supervisors across the United States. Through recruiting both supervisors and supervisees the limitation of only looking at supervisees' perspectives when administering the SISS suggested by Miller, Korinek, and Ivey (2006) was addressed. First, participation was sought through solicitation of American Psychological Association (APA) - accredited clinical and counseling psychology programs' training directors. Second, participation was sought through solicitation of training directors of the Association of Psychology Postdoctoral and Internship Centers (APPIC) internship sites. The training directors were asked to forward the invitation to participate to their students and supervisors. In addition, participants were recruited through online and social media convenience sampling; recruitment and sampling procedures are outlined in further detail in the following sections.

General demographics. The sample of this study consisted of 362 total individuals. Of those participants, 148 identified as supervisors and 214 identified as students. In order to ensure a 95\% confidence level with a 5.0\% margin of error, 120 supervisors and 120 students were needed to participate. Of the 362 total respondents, 286 returned the survey after the initial 
contact. Following the first reminder, an additional 42 participants responded. After a third and final reminder was distributed electronically 34 additional participants responded. Thus, the total number of respondents was 362 .

Upon examination of the responses, 58 participants were excluded from the analysis for three reasons. Participants who took less than four minutes, completed less than $75 \%$ of the survey, or did not complete entire assessment portions (i.e., left the SCS or SISS blank) were excluded. A total of 304 participants 115 supervisors (37.8\%) and 189 students $(62.2 \%)$ were included in the analysis.

Supervisor demographics. The 115 supervisors included in the analysis were comprised mostly of women (65\%) and ranged in age from 26 to 73 years with an average age of 42. The majority of supervisors identified as European-American, Caucasian (82.6\%) with 9.6\% identifying as Latino/a and 3.5\% identifying as African-American (Black) (See Table 2). Supervisors had an average of 7-9 years of clinical experience post-doc with $29.6 \%$ of the sample having 15 or more years of clinical experience. Supervisors more often reported being spiritual (66.1\%) than religious (37.4\%). As a group, 59.1\% of supervisors reported they did not feel adequately prepared by their graduate programs to work with a client's spiritual identity. However, 92.2\% reported that they would feel comfortable working with a client on spiritual concerns. Finally, $95.7 \%$ of supervisors reported they were not aware of the ASERVIC spiritual competencies (See Table 3).

Table 2

Demographic Information of Supervisors

\begin{tabular}{lccc}
\hline & Demographics & Number of & \\
Participants & Percentage \\
\hline Gender & & \\
Male & 39 & $33.9 \%$ \\
Female & 75 & $65.2 \%$ \\
Missing & 1 & $.9 \%$ \\
\hline
\end{tabular}




\begin{tabular}{lcc}
\hline Age & & \\
$25-34$ & 34 & $29.6 \%$ \\
$35-44$ & 32 & $27.8 \%$ \\
$45-54$ & 21 & $18.3 \%$ \\
$55-64$ & 17 & $14.8 \%$ \\
$65-74$ & 5 & $4.3 \%$ \\
Missing & 6 & $5.2 \%$ \\
\hline Ethnicity & & \\
African American (Black) & 4 & $3.5 \%$ \\
European-American (Caucasian) & 95 & $82.6 \%$ \\
Latino/a & 11 & $9.6 \%$ \\
Multiracial & 1 & $.9 \%$ \\
Other & 4 & $3.5 \%$ \\
European-Non-American & 1 & $.9 \%$ \\
International & 1 & $.9 \%$ \\
$\quad$ West-Indian American & 1 & $.9 \%$ \\
$\quad$ White \& Unknown & 1 & $.9 \%$ \\
\hline Total Number of Supervisors & 115 & $100 \%$ \\
\hline
\end{tabular}

Note. $\mathrm{N}=115$

Table 3

Clinical Information for Supervisors

\begin{tabular}{lcc}
\hline \multicolumn{1}{c}{ Clinical Information } & Number of & \\
\hline Years of Clinical Experience Post Doc & & Percentage \\
Less than 1 year & 6 & $5.2 \%$ \\
1-3 years & 22 & $19.1 \%$ \\
4-6 years & 23 & $20.0 \%$ \\
$7-9$ years & 9 & $7.8 \%$ \\
10-12 years & 16 & $13.9 \%$ \\
13-15 years & 5 & $4.3 \%$ \\
16 or more years & 34 & $29.6 \%$ \\
\hline Spiritual Identification & & \\
Yes & 76 & $66.1 \%$ \\
No & 39 & $33.9 \%$ \\
\hline Religious Identification & & \\
$\quad$ Yes & 43 & $37.4 \%$ \\
No & 72 & $62.6 \%$ \\
\hline At this time, would you be comfortable & & \\
addressing spiritual and religious material in & & \\
counseling? & & \\
Yes & 106 & $92.2 \%$
\end{tabular}




\begin{tabular}{lcc} 
No & 9 & $7.8 \%$ \\
\hline $\begin{array}{l}\text { Do you feel prepared by your graduate program } \\
\text { to include spiritual and religious issues in } \\
\text { counseling? }\end{array}$ & \\
$\quad$ Yes & 47 & $40.9 \%$ \\
$\quad$ No & 68 & $59.1 \%$ \\
\hline Are you familiar with ASERVIC's Spiritual & & \\
Competencies? & 5 & $4.3 \%$ \\
$\quad$ Yes & 110 & $95.7 \%$ \\
$\quad$ No & & \\
\hline
\end{tabular}

Note. $\mathrm{N}=115$

Student demographics. The 189 students in the analysis were comprised mostly of women $(68.8 \%)$. However, the student sample reported more gender diversity than the supervisor sample with $3.7 \%$ identifying as gender fluid/gender non-conforming and $0.5 \%$ identifying as transgender. The student sample ranged in age from 22 to 64 years with an average age of 30. The majority of students identified as European-American, Caucasian (73.5\%), with 7.9\% identifying as Asian and 5.8\% identifying as multiracial (See Table 4).

Students also more often reported being spiritual (61.9\%) than religious (29.1\%). As a group, $54.5 \%$ of students reported they did not feel adequately prepared by their graduate programs to work with a client's spiritual identity. However, 79.4\% reported that they would feel comfortable working with a client on spiritual concerns. Finally, $96.8 \%$ of students reported they were not aware of the ASERVIC spiritual competencies (See Table 5).

Table 4

Demographic Information of Students

\begin{tabular}{lcc}
\hline \multicolumn{1}{c}{ Demographics } & $\begin{array}{c}\text { Number of } \\
\text { Participants }\end{array}$ & Percentage \\
\hline Gender & 51 & $27.0 \%$ \\
Male & 130 & $68.8 \%$ \\
Female & 7 & $3.7 \%$ \\
Gender Fluid/Gender Non-Conforming & 1 & $.5 \%$ \\
Transgender (Male to Female) & & \\
\hline Age & 15 & $7.9 \%$
\end{tabular}




\begin{tabular}{lcc}
$25-34$ & 146 & $77.1 \%$ \\
$35-44$ & 17 & $9.0 \%$ \\
$45-54$ & 3 & $1.5 \%$ \\
$55-64$ & 2 & $1.0 \%$ \\
Missing & 6 & $3.5 \%$ \\
\hline Ethnicity & 8 & $4.27 \%$ \\
African American (Black) & 15 & $7.9 \%$ \\
Asian & 139 & $73.5 \%$ \\
European-American (Caucasian) & 6 & $3.2 \%$ \\
Latino/a & 11 & $5.8 \%$ \\
Multiracial & 1 & $.53 \%$ \\
Native American or Alaska Native & 8 & $4.27 \%$ \\
Other & 2 & $1.1 \%$ \\
$\quad$ Asian-White Biracial & 1 & $.5 \%$ \\
European-American and Alaska Native & 1 & $.5 \%$ \\
Irish American & 1 & $.5 \%$ \\
Jewish & 2 & $1.1 \%$ \\
Middle Eastern & 1 & .53 \\
Missing & 189 & $100 \%$ \\
\hline Total Number of Students & & \\
\hline
\end{tabular}

Note. $\mathrm{N}=189$

Table 5

Clinical Information for Students

\begin{tabular}{lcc}
\hline Clinical Information & $\begin{array}{c}\text { Number of } \\
\text { Participants }\end{array}$ & Percentage \\
\hline Spiritual Identification & & \\
Yes & 117 & $61.9 \%$ \\
No & 72 & $38.1 \%$ \\
\hline Religious Identification & & \\
Yes & 55 & $29.1 \%$ \\
No & 134 & $70.9 \%$ \\
\hline
\end{tabular}

At this time, would you be comfortable addressing spiritual and religious material in counseling?

Yes

150

$79.4 \%$

No

39

$20.6 \%$

Do you feel prepared by your graduate program to include spiritual and religious issues in counseling?

Yes 


\begin{tabular}{lcc} 
No & 103 & $54.5 \%$ \\
\hline Are you familiar with ASERVIC's Spiritual & & \\
Competencies? & 6 & $3.2 \%$ \\
Yes & 183 & $96.8 \%$ \\
No &
\end{tabular}

Note. $\mathrm{N}=189$

Both supervisors and students were asked if they felt prepared by their graduate programs to include spiritual and religious issues in counseling, with the option of selecting "yes" or "no." If a participant answered "yes," they were prompted to share how their program prepared them. If a participant answered "no," they were prompted to share perceptions of how their program should have prepared them. Tables 6 and 7 provide an overview of this information for supervisors and students.

Table 6

Supervisors: Were You Prepared by Your Graduate Program to Include Religious/Spiritual Issues in Counseling?

\begin{tabular}{lc}
\hline \multicolumn{1}{c}{ Answer } & Percentage \\
\hline Yes & $41 \%$ \\
Was a component of a class/es & $31.3 \%$ \\
Was a full course & $7.0 \%$ \\
Included in mentorship & $.9 \%$ \\
Discussion as issues came up & $.9 \%$ \\
Missing & $.9 \%$ \\
\hline No & $59 \%$ \\
Should be part of a class/es & $33 \%$ \\
Should have a full class devoted to these issues & $15 \%$ \\
They do not need to discuss these issues & $2 \%$ \\
Both: integrated into courses and specific course & $1.8 \%$ \\
Should be discussed in support group/colloquium/seminar/discussion groups & $2.7 \%$ \\
Should be discussed in supervision & $1.8 \%$ \\
Should meet the patient where they are at & $1.8 \%$ \\
Missing & $.9 \%$ \\
\hline
\end{tabular}

Table 7

Students: Were You Prepared by Your Graduate Program to Include Religious/Spiritual Issues in Counseling?

\begin{tabular}{lcc}
\hline & Answer & Percentage \\
\hline Yes & & $44.9 \%$
\end{tabular}




$\begin{array}{lc}\text { Was a component of a class/es } & 34.7 \% \\ \text { Was a full course } & 5.2 \% \\ \text { Both: was a component of a class/es and was a full course } & .5 \% \\ \text { Encouraged to engage in patient driven treatment planning } & .5 \% \\ \text { Discussed in supervision } & 2 \% \\ \text { Discussion as issues came up } & .5 \% \\ \text { Part of a research agenda } & 1 \% \\ \text { Missing } & .5 \% \\ \text { No } & 55.1 \% \\ \text { Should be part of a class/es } & 36 \% \\ \text { Should have a full class devoted to these issues } & 14.2 \% \\ \text { They do not need to discuss these issues } & 1.1 \% \\ \text { Both: integrated into courses and specific course } & 1 \% \\ \text { Should be discussed in supervision } & 1 \% \\ \text { Should meet the patient where they are at } & 1.8 \%\end{array}$

\section{Instrumentation}

Spiritual Issues in Supervision Scale (SISS; Miller, 2004). The SISS is a 30 -item selfreport survey that assesses the extent to which spiritual issues are discussed in clinical supervision. The items are rated using a Likert-type scale ranging from 1 to $5(1=$ Spiritual issues are never addressed; $3=$ Spiritual issues are occasionally addressed; $5=$ Spiritual issues are frequently addressed). Total composite scores can range from 30 to 150, with lower total scores indicating spiritual issues were addressed less frequently. The SISS utilized a sample of Marriage and Family Therapy graduate students as a part of the pilot and validation processes. The items were then analyzed for content validity by a panel of seven experts consisting of faculty and doctoral students in an accredited Marriage and Family Therapy program.

The use of a pilot study helped increase internal validity. The sample was composed of 51 students in a masters and doctoral Marriage and Family Therapy program. To analyze the findings, Principal Component Analysis (PCA) using orthogonal rotation was implemented. In order to determine the number of components present, eigenvalues greater than 1.0 and component loadings of .33 or higher were acceptable. Initially, seven components were found, 
accounting for $72.7 \%$ of the total variance. The first, second, and third components were comprised of six items, the second component contained six items, and the third component had six items respectively. The remaining four components contained three items each. The internal consistency reliability, as measured by Cronbach's alpha, was .94, suggesting that items were related and varied together. Miller (2004) reported the reliability coefficients for each of the seven components which follow: .87 for component one; .84 for component two; .89 for component three; .80 for component four; .87 for component five; .79 for component six; and .80 for component seven. When looking at variance accounted for, the first component accounted for $39.05 \%$ of the sample variance and the remaining components each accounted for less than $10 \%$ of the variance. This suggests that the SISS uni-dimensionally measures and assesses different aspects of supervision where spirituality may be part of the process (Miller, 2004). Following the pilot study, 153 participants were surveyed to further examine the robustness of the SISS. Student participants were asked to rate several supervisors which yielded 257 cases that were analyzed. Similar to the pilot study, PCA with orthogonal rotation was used. The same cutoff points were implemented as in the pilot study, which were eigenvalues greater than 1.0 and component loadings equal to .33 or higher. In contrast to the pilot study, four components were identified which accounted for $69.9 \%$ of the total variance. The first and largest component contained 14 items and accounted for $24.11 \%$ of the total variance, the second component had six items and accounted for $16.80 \%$ of the variance, the third component had five items and accounted for $15.11 \%$ of the variance, the fourth and final component contained four items and accounted for $13.90 \%$ of the variance. The internal consistency reliability, as measured by Cronbach's alpha, for the scale was .98 . The internal consistency for each of the components are as follows: .96 for component one; .90 for 
component two; .91 for component three; and .88 for component four. The internal consistency reliability of the SISS lends support for the uni-dimensionality of spirituality as a construct. The four-components, as corroborated by Hull, Suarez, Sells, and Miller (2013), were termed the Lens of Meaning and Value, the Supervisory System, the Client System, and the Diversity Lens.

Several limitations of the SISS were addressed by Weinstein (2006) and Garner (2014) and included the assumption that the components assessed in the scale had been discussed in supervision. Weinstein (2006) accounted for this limitation by adapting the SISS. Before each item participants are asked to indicate (Yes or No) as to whether each topic was discussed during supervision. If the participant answers "Yes" they will proceed to fill out the Likert portion of the question. If the participant answers "No" they will move to the next question. The additional question was scored by adding the ratings and dividing by the number of "yes," yielding an overall score of 1-5. This adjustment allowed for a more accurate representation of topics discussed. Using this adjusted form Weinstein (2006) reported internal consistency of .93 as measured by Cronbach's alpha.

A second limitation of the SISS discussed by Garner (2014) was the lack of consistency in the name of the measure. It is noted that the SISS is referred to as the Spiritual Issues in Supervision Scale as well as the Spirituality in Supervision Scale. To address this limitation this study used Spiritual Issues in Supervision Scale as that is the name used most often in the literature (Hull, Suarez, Sells, \& Miller, 2013; Miller, Korinek, \& Ivey, 2006).

Spiritual Competency Scale (SCS; Robertson, 2008). In addition to the SISS, the Spiritual Competency Scale (SCS; Robertson, 2008) was used to evaluate the proposed research questions. The SCS is a 21-item measure that uses a six-point Likert scale. Permission to use this scale was requested from the author and the granted permission is included in Appendix G. 
The SCS was subject to a pilot test as well as a national test to determine validity and utility of the scale. The SCS was developed by a seven-member panel of experts ( 1 clinician, 4 doctoral students, and 2 instructors) chosen for their knowledge and interest in spiritual and religious issues. The panel was given 263 items to sort into the ASERVIC category they felt best represented the item. Each panel member sorted the items and a minimum of 57 percent agreement had to be achieved in order for the item to be retained. Ninety items were retained with 10 items devoted to each of the nine competencies delineated by ASERVIC. Of the ninety items, 61 items had 100 percent agreement among the panel. Only one item had 57 percent agreement and was retained in order to ensure that each competency had 10 items.

Following the creation of the 90 -item scale it was administered to a different panel of five counselor education masters students who were asked to provide feedback. They were asked to review content and ease of use as a measure of face validity. The pilot test was administered to 100 students who completed the assessment in approximately 15-20 minutes. The assessment is scored on a 1 to 6 scale where participants can earn anywhere from 90 points, obtaining only one point per question, to 540 points, obtaining six points per question. Correct responses to questions were considered a score of five or six on each question. While four is above the half way mark it was not considered correct as it does not indicate mastery of the material. The mean of the pilot group was 387.5 with a standard deviation of 42 . The average individual item score was 4.25 , indicating deficient knowledge. In addition to the SCS, pilot participants were asked to complete a brief version of the Marlowe-Crown Social Desirability Scale (MCSDS) to assess for desirability in responding. The results of the pilot study indicated that there was no significant relationship between scores on the MCSDS and the SCS with less than 2 percent of the variance being attributed to desirable responding. Overall, the author concluded that social 
desirability did not factor into scores on the SCS. The Cronbach's alpha for the internal consistency reliability of the 90 items was .93 (Robertson, 2008).

The item analysis for the pilot study utilized item-to-total correlation to begin to eliminate items. Any item with less than $r=.3$ was eliminated, which resulted in the removal of 31 items. An additional five items were removed as they fell below the .3 threshold for subsequent analyses. Each of the removed items were reviewed for theoretical significance and one was returned to the instrument. The next step included removing four items that were better represented in content by a higher correlated item. Finally, any items that received extremely high or extremely low endorsement were deleted. The Cronbach's alpha for the remaining 46 items was .93. The validity of the SCS was measured in four different ways. First the scale was given to a panel of experts to evaluate that the items were accurate representations of the nine ASERVIC Spiritual Competencies. Secondly, the discriminant validity was assessed through the measure's ability to discern between religiously based schools and secular schools. When looking at the instrument's ability to discriminate behavior the SCS was paired with the Marlowe-Crowne Social Desirability Scale (MCSDS) and the two items failed to correlate, which demonstrates that the SCS is not measuring things it shouldn't be. Finally, looking at the concurrent validity with the ASERVIC Spiritual Competencies, factor analysis produced welldefined categories in the SCS that were congruent with the content in the competencies (Robertson, 2008).

The national study of the SCS included 499 participants across the country. The average score for the national sample was 393 with a standard deviation of 42.4. Principle components analysis was conducted on the 90 -item SCS to establish construct validity. In order to retain an item on the scale the author engaged in an eight criteria analysis. The resulting factor structure 
was six factors containing 28 items that accounted for $54 \%$ of the total variance. Factor one accounted for 27 percent of the total variance and the remaining factors accounted for between 3.6 and 6.5 percent of the variance in scores. The categories that the factors represent are "diagnosis and treatment, culture and worldview, counselor self-awareness, assessment, communication, and human and spiritual development" (Robertson, 2008). The Cronbach's alpha coefficient for the 28 -item revised version was .90 , indicating high internal consistency reliability.

Finally, when comparing groups based on religious affiliation the SCS was able to discriminate between religiously oriented participants and secular participants, indicating that religiously oriented participants scored higher than secular participants. Support for a six-factor structure was found by Dailey, Robertson, and Gill (2015). In addition, their study expanded the literature by offering a cut-off point for perceived competency that was not asserted by Robertson (2008). Dailey et al. (2008) suggested a score of 105 on the 21-item 6-factor solution that they used, which would translate to a score of 450 on the 90 -item full version of the SCS. The suggested cutoff score of 105 for perceived competence will be used as a benchmark in the current study. While the cutoff score offers a benchmark for perceived competence the limitation of individual's perception was considered as this is a self-report measure.

Demographic questionnaire. In the current study, demographic information (Appendices D \& E) was decided upon based on the work of Robertson (2008) and Miller (2004). Student participants were asked to provide information on 17 items about their age, sex, ethnicity, program type, theoretical orientation, current level of religiousness, influential nature of religious/spiritual beliefs on becoming a clinician, level of preparedness to include religious/spiritual issues into counseling, comfortability implementing religious and spiritual 
material into counseling, and familiarity with ASERVIC Spiritual Competencies. Supervisor participants were asked to provide information on 19 items about their age, sex, ethnicity, year in practice, degree type, accreditation status of their program, theoretical orientation, influential nature of religious/spiritual beliefs on becoming a clinician, level of preparedness to include religious/spiritual issues into counseling, comfortability implementing religious and spiritual material into counseling, and familiarity with ASERVIC Spiritual Competencies.

\section{Data Collection}

Sample procedures. In order to determine the necessary number of participants to address questions two, five, and six, a power analysis was conducted using the statistical program G*Power, version 3.1.5 (Faul, Erdfelder, Lang, \& Buchner, 2007). This study required the participation of at least 120 graduate student clinicians and 120 clinical supervisors to achieve a power of .80 . The power level of .80 was selected for the current study because of its prevalence within psychological research (Aron, Aron, \& Coups, 2014). The alpha error probability was set at .05 for a correlational analysis.

The researcher recruited participants in three ways following the West Virginia University Institutional Review Board (IRB) approval (Appendix F). First, the researcher created a list of APA-accredited clinical and counseling psychology programs. Once a list of programs was developed, the researcher identified the training director contact information for each school. Upon obtaining the contact information for each of the training directors, an overall invitation for participation (Appendix B) with a link to the study on Qualtrics was distributed. The electronic mail message explained the study, provided the purpose, and asked training directors to forward the link to their students and practicum clinical supervisors. 
Following Dillman's (1978) “Total Design Method,” the body of the email contained several components of a well-written letter. Firstly, the email described the usefulness of the study to the participant. The email also informed potential participants of their significance to the study. The email delineated confidentiality, as it is a key component in establishing trust according to Dillman (1978). Two reminder emails were sent; the first was sent two weeks after the initial email (Appendix K) and the second was sent four weeks after the initial email (Appendix L).

In order to accommodate the possibility of minimal response, participants were also recruited through the Association of Psychology Postdoctoral and Internship Centers (APPIC) website. Similar to APA-accredited institutions, internship training directors have access to supervisors and doctoral level interns who would be appropriate participants for this study. The same email and reminder email schedule were used when contacting training directors from APPIC internship sites.

Convenience sampling was used as the third recruitment method. A sharable, public post, including criteria for participation, was created to disseminate on social media platforms (e.g., Facebook). Possible participants were able to view the link to the study on Qualtrics where they were able to learn about the study (Appendix M). Individuals were also able to share or post the link to the study on their personal social media page. An additional effort to recruit participants was made by contacting organized groups on social media sites like Facebook (e.g., APA-American Psychology Association — an online community of APA members, Psychologists' World - an online community of psychologists who seek to empower each other and continue learning, and Research Methods in Psychology_an online community devoted to the advancement of research in the field of psychology). 
Regardless of the recruitment method, the risks and benefits were clearly outlined for the participants (see informed consent, Appendix A). In addition to risks and benefits, participants were offered an opportunity to receive an incentive (a drawing to receive one of 20, five-dollar gift cards to Starbucks ${ }^{\mathrm{TM}}$ ) for completing the study. An individual who chose to participate in the study clicked on the study link and was redirected to Qualtrics. Before beginning the study, participants were asked to complete the informed consent (Appendix A). Participants then indicated their role as either a supervisor or student. Based on their specification, the participant received either the supervisor (Appendix D) or supervisee (Appendix E) specific demographic questions. Upon completing the demographic information, if a participant remained eligible (information provided indicates they were at least 18 years of age and were in the role of supervisor or supervisee), the participant completed the following two measures in a randomized order: The Spiritual Competencies Scale (SCS, Appendix H), and the Spiritual Issues in Supervision Scale (SISS, Appendix I \& J).

If a participant failed to meet eligibility criteria based on their age or reported role, they were redirected to the debriefing page (Appendix C). This page thanked the participant for their time and willingness to provide information. Participants who completed the questionnaire received information about the opportunity to enter a drawing for one of 20 Starbucks $^{\mathrm{TM}}$ gift cards. The participant's email address was entered through a distinct link to ensure anonymity and privacy.

Following a pilot test of the two surveys, it was estimated that the total time to complete the survey was approximately 20-25 minutes. Once finished, a participant exited the window and did not have any further contact with the researcher, with the exception of participants chosen to receive the gift card incentive. The participants who chose to provide an email address 
were assigned a number, numbers were chosen via the random number generator

"www.random.org," and participants whose numbers were selected were emailed an electronic link for the gift card.

\section{Data Analysis}

Data were analyzed using the Statistical Package for Social Sciences (SPSS) software (IBM, 2016). Descriptive statistics and other appropriate statistical analyses were used in response to each research question. The analysis strategies will be described for each research question.

\section{Hypotheses.}

1. Fifty percent or more of supervisors would score in the competent range (minimum of 105 points) to implement spirituality as examined by the Spiritual Competency Scale (SCS).

2. Supervisors would score significantly higher on the SCS than supervisees.

3. Supervisors would report addressing issues of spirituality in less than $50 \%$ of the provided situations on the Spiritual Issues in Supervision Scale (SISS).

4. Constructs measured by the Spiritual Competency Scale (SCS) would map onto constructs discussed in the SACRED model of supervision.

5. There would be a significant, positive correlation between supervisors' scores on the Spiritual Competency Scale (SCS) and their reports of topics discussed in supervision as measured by the Spiritual Issues in Supervision Scale (SISS).

6. There would be a significant, positive correlation between supervisees' scores on the Spiritual Competency Scale (SCS) and their reports of topics discussed in supervision as measured by the Spiritual Issues in Supervision Scale (SISS). 


\section{SUMMARY}

This study sought to provide support for the connection between discussions of spirituality in supervision and feelings of competence. The present study used a descriptivecorrelational survey design, with solicited participants who held the role of supervisor and supervisee. Participants were recruited through training directors at American Psychological Association (APA)-accredited clinical and counseling psychology institutions, as well as training directors at the Association of Psychology Postdoctoral and Internship Centers (APPIC), through social media platforms, and convenience sampling. Participants were asked to provide demographic information, complete a measure of perceived competence to implement spiritual tenets, and complete a measure of spiritual issues addressed within the context of supervision. The estimated time to complete the survey was approximately 20-25 minutes. Upon completion of the study, participants were offered an opportunity to enter a drawing to receive one of twenty gift cards to Starbucks ${ }^{\mathrm{TM}}$. The collected data and hypotheses were analyzed using SPSS software (IBM, 2016). The addition of this information holds implications for the training of clinicians. The results serve to guide supervisors in their role of training competent clinicians. In addition, providing support for how a measure of perceived competence reflects theoretical components helps to bridge the gap between theory and practice. This quantitative study builds upon the findings of previous researchers to expand the literature surrounding supervision. The questions and methods were carefully designed in an attempt to get an accurate picture of feelings of competence based on the quantity of discussions of religion and spirituality in supervision. 


\section{CHAPTER 4: RESULTS}

This study examined the role of spirituality in supervision. Additionally, this study addressed supervisors' perceptions of competence to implement issues of spirituality with supervisees. Finally, this study expanded the literature by breaching a gap between theory and assessment through providing an assessment measure with a theoretical model of addressing spirituality in supervision.

The following research questions and accompanying hypotheses were addressed:

1. Do supervisors' scores on the Spiritual Competency Scale (SCS) fall within the competent range as examined by the SCS?

a. Hypothesis: $50 \%$ or more of supervisors would score in the competent range (at least 105 points) to implement spirituality as examined by the Spiritual Competency Scale (SCS). Analysis: Descriptive statistics

2. Are supervisors' scores on the SCS significantly different than students' scores on the SCS?

a. Hypothesis: Supervisors would score significantly higher on the SCS than students. Analysis: Independent samples t-test.

3. Are supervisors addressing issues pertaining to facets of spirituality, as measured by the Spiritual Issues in Supervision Scale (SISS) with supervisees?

a. Hypothesis: Supervisors would report addressing issues of spirituality in less than $50 \%$ of the provided situations on the Spiritual Issues in Supervision Scale (SISS). Analysis: Descriptive statistics.

4. How do the constructs in the SACRED model of supervision compare to the constructs measured on the SCS? 
a. Hypothesis: Constructs measured by the Spiritual Competency Scale (SCS) would map onto constructs discussed in the SACRED model of supervision. Analysis: Confirmatory factor analysis.

5. To what extent are supervisor scores on the SISS related to their scores on the SCS?

a. Hypothesis: There would be a significant, positive correlation between supervisors' scores on the Spiritual Competency Scale (SCS) and their reports of topics discussed in supervision as measured by the Spiritual Issues in Supervision Scale (SISS). Analysis: Pearson bivariate correlation.

6. To what extent are student scores on the SISS related to their scores on the SCS?

a. Hypothesis: There would be a significant, positive correlation between students' scores on the Spiritual Competency Scale (SCS) and their reports of topics discussed in supervision as measured by the Spiritual Issues in Supervision Scale (SISS). Analysis: Pearson bivariate correlation.

\section{Bivariate Correlations}

A bivariate correlation was conducted to understand the possible relationships between of the demographic variables for supervisors (Table 8) and students (Table 9). The clinically significant relationships are presented in Tables 8 and 9. The strength of the correlation coefficients was determined by the work of Aron, Aron, and Coups (2014). They identified "small effects as $r=.10$, medium effects as $r=.30$, and large effects as $r=.50$ " (p. 519). Results of the bivariate correlation indicated that there was a significant, large, positive association between supervisor's total score on the SCS and their total score on the SISS, $(r(111)=.50, p<$ .001). There was also a significant, large, positive association between supervisors who identified as religious and spiritual, $(r(111)=.53, p<.001)$. In addition to the positive 
associations the bivariate correlation indicated that there were several inverse relationships.

Supervisor's total score on the SCS were moderately, inversely associated with religious association $(r(111)=-.36, p<.001)$. Also, supervisor's total score on the SCS was moderately, negatively associated with spiritual affiliation $(r(111)=-.37, p<.001)$. Finally, there was a small, negative association between supervisor's total score on the SISS and spiritual affiliation $(r(111)=-.26, p<.001)$

The results of the bivariate correlation for students also yielded several significant findings. There was a significant, small, positive association between student's total score on the SCS and their total score on the SISS, $(r(182)=.29, p<.001)$. There were also significant, medium, positive associations between students who identified as religious and identified as spiritual $(r(182)=.40, p<.001)$. In addition to the positive associations, the Bivariate correlation indicated there were several negative relationships. There was a small, negative association between students' total score on the SCS and religious association $(r(182)=-.20, p<$ .001). Also, student total score on the SCS was moderately, negatively associated with spiritual affiliation $(r(182)=-.32, p<.001)$. For supervisors, there was a small, positive correlation between spiritual beliefs and comfortability $(r(113)=.18, p<.05)$. For students, there was a small, positive correlation between spiritual beliefs and comfortability $(r(187)=.24, p<.001)$. Finally, there was a small, negative association between student total score on the SISS and spiritual affiliation $(r(182)=-.26, p<.001)$.

Table 8

Correlations Among Supervisor Demographic Variables

\begin{tabular}{lcc}
\hline & SCS Total & SISS Total \\
\hline SISS Total & .503 & \\
\hline Age & & .250 \\
\hline Ethnicity & & .273 \\
\hline Program Type & .298 & .257 \\
\hline
\end{tabular}




\begin{tabular}{lcc}
\hline Number of Supervisees & & -.277 \\
\hline Spiritual ID & -.374 & .368 \\
\hline$\%$ of Time in Therapy & .346 & .405 \\
\hline \% of Time in Supervision & .333 & \\
\hline Religious ID & -.359 & .308 \\
\hline Religious Denomination & .261 & -.253 \\
\hline Impact of Beliefs on Career & -.429 & \\
\hline Prepared by Program & & -.261 \\
\hline Comfort & -.256 & \\
\hline
\end{tabular}

Note. SCS Total $=$ Spiritual Competency Scale Total Score for Supervisors; SISS Total $=$ Spiritual Issues in Supervision Scale Total Score for Supervisors; Program Type= What type of program did you graduate from (Public/Private Clinical psychology, Public/Private Counseling Psychology, or Other), Religious ID= Do you actively participate in a religious organization ("yes" or "no"); Spiritual ID= In general, do you consider yourself a spiritually minded person ("yes" or "no"), \% of Time in Therapy= Indicate the percentage of time you attend to spirituality and/or spiritual issues in therapy, \% of Time in Supervision= Indicate the percentage of time you attend to spirituality and/or spiritual issues in supervision, Impact of Beliefs on Career= Did your personal spiritual and religious beliefs play a role in your choice to become a clinician ("yes" or "no"), Prepared by Program= Do you feel you have been prepared by your graduate program to include spiritual and religious issues in counseling ("yes" or "no"), Comfort= At this time, would you be comfortable addressing spiritual and religious material in counseling ("yes" or "no"). $p<.01$

Table 9

Correlations Among Student Demographic Variables

\begin{tabular}{lcc}
\hline & SCS Total & SISS Total \\
\hline SISS Total & .294 & \\
\hline APA & & $-.147^{*}$ \\
\hline Theoretical Orientation & .242 & .273 \\
\hline Spiritual ID & -.324 & -.239 \\
\hline Religious ID & -.196 & \\
\hline Impact of Beliefs on Career & -.331 & .368 \\
\hline Prepared by Program & & -.297 \\
\hline Comfort & -.329 & -.274 \\
\hline
\end{tabular}

Note . SCS Total $=$ Spiritual Competency Scale Total Score for Students; SISS Total $=$ Spiritual Issues in Supervision Scale Total Score for Students; Religious ID= Do you actively participate in a religious organization ("yes" or "no"); Spiritual ID= In general, do you consider yourself a spiritually minded person ("yes" or "no"), Impact of Beliefs on Career= Did your personal spiritual and religious beliefs play a role in your choice to become a clinician ("yes" or "no"), Prepared by Program= Do you feel you have been prepared by your graduate program to include spiritual and religious issues in counseling ("yes" or "no"), Comfort= At this time, would you be comfortable addressing spiritual and religious material in counseling ("yes" or "no"). 
$p<.01, * p<.05$

In addition to gathering quantitative information about preparedness, this study gathered qualitative responses that addressed ways in which graduate programs adequately prepared those who felt prepared as well as ways in which participants wished their programs addressed religion and spirituality.

\section{Major Findings}

This section presents major findings organized around each of the six research questions associated with this study. Participants were provided a survey that included three sections. The first section requested demographic information including questions about age, gender identity, ethnicity, type of graduate program, accreditation status of graduate program, amount of postdoc practice if the participant was a supervisor, theoretical orientation, number of supervisors/ees, spiritual identity, religious identity, time attended to religion/spirituality in therapy and supervision, religious denomination, preparedness to include religious/spiritual issues in counseling, level of comfort addressing spiritual and religious material in counseling, and familiarity with ASERVIC's Spiritual Competencies. Section two contained the SISS and section three contained the SCS. Data were analyzed using SPSS 24.0 (IBM, 2016). What follows are sections devoted to the exploration of the major findings of this study through analysis of each of the six research questions.

\section{Research question one: Supervisors' scores on Spiritual Competency Scale (SCS).}

In order to address Research Question 1, Do supervisors'scores on the Spiritual Competency Scale (SCS) fall within the competent range as examined by the SCS?, the following hypothesis was tested: $50 \%$ or more of supervisors would score in the competent rage (at least 105 points) to implement spirituality as examined by the Spiritual Competency Scale (SCS). The responses 
to the SCS were totaled giving each participant a raw score between 21 and 126 with the cutoff for perceived competence at 105 (Dailey et al., 2015). On this assessment, participants were asked to rate their level of agreement with 21 statements. Participants were provided a Likert scale from one to six where 1= "Strongly disagree;" 2= "Disagree;" 3= "Somewhat disagree;" 4= "Somewhat agree;" 5= "Agree;" 6= "Strongly agree."

Of the 21 items on this portion of the survey, 113 supervisors completed the SCS. SPSS 24 was used to calculate a total SCS score variable which totaled the points associated with each selected response. If a participant skipped a question, they received zero points for that question. The mean, mode, and standard deviation for the total score was calculated. The average score on the SCS for supervisors was 104.5 with the most frequently occurring score being 111 . The median of the data fell at 107 points. A total of 60 supervisors $(54 \%)$ scored at or above the cutoff for perceived competence (105 points) (See Figure 1). The cutoff for competence asserted by Dailey et al. (2008) is 105 points. These results offer support for the initial hypothesis and suggest that $50 \%$ or more of supervisors scored in the competent range as measured by the SCS. 


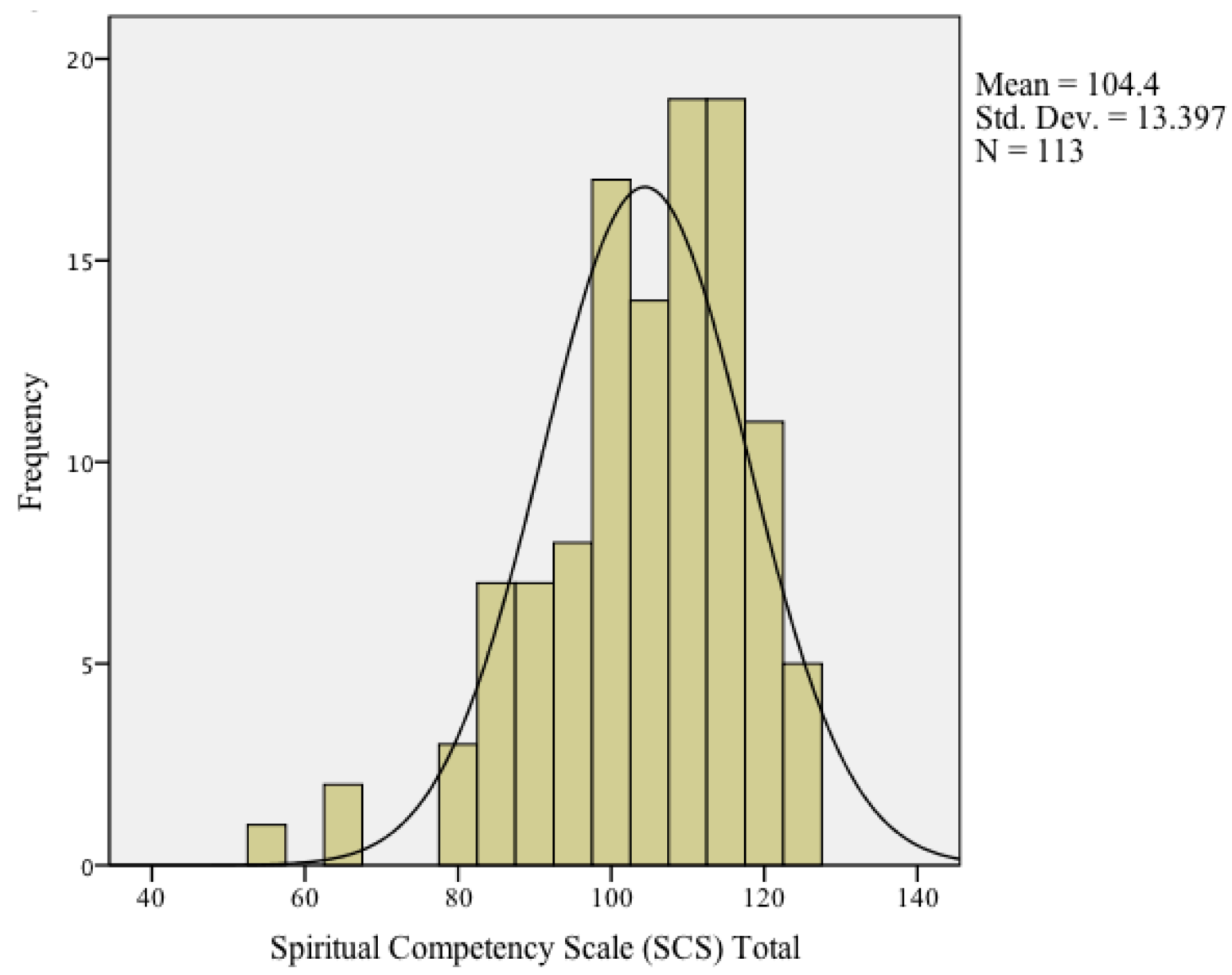

Figure 1. Frequency distribution for supervisor's scores on the Spiritual Competency Scale (SCS).

Research question two: Difference in Spiritual Competency Scale (SCS) scores. The SCS portion of the survey consisted of 21 items. One hundred eighty-four students completed the SCS. The mean, mode, and standard deviation for the total score was calculated (See Figure 2). The average score on the SCS for students was 103.72. The student distribution was trimodal with scores of 98,108 , and 110 occurring most frequently. The median of the data fell at 105.5 points. A total of 90 students (49\%) scored below the cutoff (105 points) for perceived 
competence.

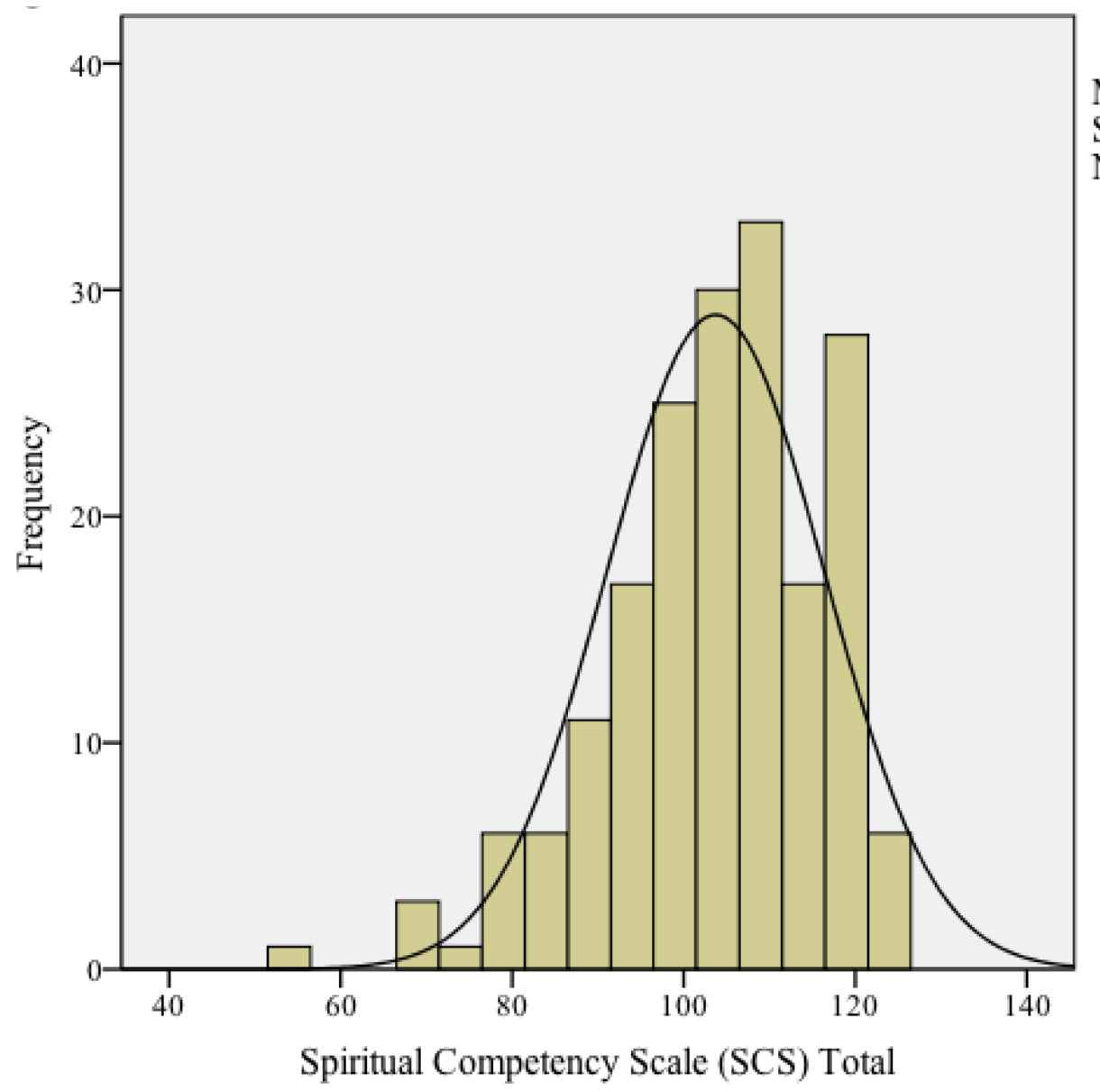

Mean $=103.72$

Std. Dev. $=12.699$

$\mathrm{N}=184$

Figure 2. Frequency distribution for student's scores on the Spiritual Competency Scale (SCS). The cutoff for competence asserted by Dailey et al. (2008) is 105 points.

In order to answer Research Question 2, Are supervisors' scores on the SCS significantly different than students' scores on the SCS? an independent samples $t$-test was used to test the hypothesis: supervisors would score significantly higher on the SCS than students. The findings do not offer support for the hypothesis. There were no significant differences in the scores for supervisors $(\mathrm{M}=104.40, \mathrm{SD}=13.397)$ and students $(\mathrm{M}=103.72, \mathrm{SD}=12.69) ; t(295)=-.439$, $p=.661$. These results suggest that students and supervisors did not perform differently on this self-report measure of spiritual competence. Additionally, the average SCS score for supervisors and students fell below the cutoff score of 105 (See Table 6). 
Research question three: Addressing spiritual issues in supervision. To address Research Question 3, “Are supervisors addressing issues pertaining to facets of spirituality, as measured by the Spiritual Issues in Supervision Scale (SISS) with supervisees?" descriptive data were collected to test the hypothesis: supervisors would report addressing issues of spirituality in less than $50 \%$ of provided situations on the Spiritual Issues in Supervision Scale (SISS). In order to ascertain if supervisors addressed facets of spirituality with supervisees in their clinical work, the presence of discussions needed to occur in $50 \%$ or more of the elements measured by the SISS. The SISS is comprised of 29 items with dichotomous ("yes" or "no") options to indicate if spirituality is addressed ("yes") or is not addressed ("no"). On 27 of the 29 items, the most frequently occurring answer was "yes," meaning supervisors reported addressing issues pertaining to facets of spirituality with supervisees in $93.1 \%$ of the situations measured by the SISS (See Table 10). This evidence offers support for the initial hypothesis. Of note, when comparing supervisors' reports of discussions to students' reports of discussions there were differences in the frequency of conversations (See Table 11).

Table 10

\begin{tabular}{|c|c|}
\hline \multicolumn{2}{|l|}{ Percentage of SISS Questions Addressed by Supervisors in Supervision } \\
\hline Question & Percentage "Yes" \\
\hline Is spirituality addressed when the assessment process is discussed? & $70 \%$ \\
\hline Is spirituality addressed in the areas of grief, loss, and death? & $94 \%$ \\
\hline Is spirituality addressed with issues concerning marriage? & $64 \%$ \\
\hline Is spirituality discussed with issues concerning divorce? & $55 \%$ \\
\hline Is spirituality discussed with issues concerning gender? & $64 \%$ \\
\hline $\begin{array}{l}\text { Is spirituality discussed with self-of-therapist issues, including your own } \\
\text { family-of-origin issues? }\end{array}$ & $75 \%$ \\
\hline Is spirituality discussed when talking about the treatment plan? & $64 \%$ \\
\hline $\begin{array}{l}\text { Is spirituality discussed when conceptualizing the case (e.g., integrating theory } \\
\text { of therapy)? }\end{array}$ & $80 \%$ \\
\hline Is spirituality discussed with substance abuse issues? & $62 \%$ \\
\hline Is spirituality discussed in the area of trauma (including abuse)? & $76 \%$ \\
\hline Is spirituality discussed when self-esteem issues emerge? & $56 \%$ \\
\hline
\end{tabular}


Is spirituality discussed when themes of morality and/or values emerge? $\quad 95 \%$

Is spirituality discussed in the area of culture? $\quad 93 \%$

Is spirituality discussed when addressing ethnicity? $\quad 77 \%$

Is spirituality discussed when addressing race? $\quad 70 \%$

Is spirituality discussed when addressing parenting issues? $\quad 56 \%$

Is spirituality discussed when addressing other issues concerning children? $\quad 56 \%$

Is spirituality discussed when addressing the area of identity? $\quad 91 \%$

Is spirituality discussed when talking about the supervisory relationship? $\quad 49 \%$

Is spirituality discussed with issues about sexual intimacy? $\quad 62 \%$

Is spirituality discussed with ethical concerns? $\quad 58 \%$

Is spirituality discussed when addressing issues of power and hierarchy? $\quad 44 \%$

Is spirituality discussed with issues surrounding abortion? $\quad 70 \%$

Is spirituality discussed with issues concerning contraception or fertility? $\quad 57 \%$

Is spirituality discussed in the area of suicide/suicidal ideation? $\quad 90 \%$

Is spirituality discussed within the theme of a personal network or support $\quad 85 \%$ group for the clients?

Is spirituality discussed about your own persona, network/support group? $\quad 52 \%$

Is spirituality discussed when talking about hope of a greater purpose in life? $\quad 84 \%$

Is spirituality discussed when talking about religion? $\quad 97 \%$

Table 11

\begin{tabular}{lcc}
\hline \multicolumn{1}{c}{ Percentage of SISS Questions Above 50\% for Supervisors and Below 50\% for Students } \\
\hline & $\begin{array}{c}\text { Supervisors } \\
\text { Percentage } \\
\text { "Yes" }\end{array}$ & $\begin{array}{c}\text { Students } \\
\text { Percentage } \\
\text { "Yes" }\end{array}$ \\
\hline Is spirituality addressed when the assessment process is discussed? & $70 \%$ & $42 \%$ \\
\hline Is spirituality addressed with issues concerning marriage? & $64 \%$ & $46 \%$ \\
\hline Is spirituality discussed with issues concerning divorce? & $55 \%$ & $35 \%$ \\
\hline Is spirituality discussed with issues concerning gender? & $64 \%$ & $40 \%$ \\
\hline Is spirituality discussed with self-of-therapist issues, including your own & $75 \%$ & $46 \%$ \\
family-of-origin issues? & & \\
\hline Is spirituality discussed when talking about the treatment plan? & $64 \%$ & $45 \%$ \\
\hline Is spirituality discussed with substance abuse issues? & $62 \%$ & $34 \%$ \\
\hline Is spirituality discussed in the area of trauma (including abuse)? & $76 \%$ & $43 \%$ \\
\hline Is spirituality discussed when self-esteem issues emerge? & $56 \%$ & $32 \%$ \\
\hline Is spirituality discussed when addressing parenting issues? & $56 \%$ & $32 \%$ \\
\hline Is spirituality discussed when addressing other issues concerning children? & $56 \%$ & $27 \%$ \\
\hline Is spirituality discussed with issues about sexual intimacy? & $62 \%$ & $42 \%$ \\
\hline Is spirituality discussed with ethical concerns? & $58 \%$ & $40 \%$ \\
\hline Is spirituality discussed with issues concerning contraception or fertility? & $57 \%$ & $44 \%$ \\
\hline
\end{tabular}


Is spirituality discussed about your own persona, network/support group?

$52 \%$

$30 \%$

\section{Research question four: Comparing constructs measured by the Spiritual}

Competency Scale (SCS) to the SACRED model of supervision. To address Research

Question 4, "How do the constructs in the SACRED model of supervision compare to the

constructs measured on the SCS? " the following hypothesis was tested: constructs measured by the SCS would map onto constructs discussed in the SACRED model of supervision, utilizing confirmatory factor analysis. Based on the results of Dailey et al. (2015) it was expected that six factors would emerge from the SCS. Consistent with the literature, six factors were found. Upon analyzing the results of the orthogonally rotated component matrix for supervisors compared to students there are differences in factor structure.

First, the factors for supervisors and students will be named, next comparisons will be drawn between supervisor and student factor structures, finally the factors as measured by the SCS will be compared to the constructs delineated in the SACRED model to determine overlap as overlapping themes would suggest the utility of the SCS as a measure of effectiveness for implementation of the SACRED model of supervision.

The final six-factor solution for supervisors included 22 items that loaded at .50 or higher, with the exception of item 50 (.45), item 56 (.46), item 59 (.47), and item 61 (.38) (see Table 12). These items remained a part of the analysis as they have garnered previous empirical support (Dailey et al., 2015). The solution accounted for $67.1 \%$ of the total variance. Factor 1 , named "role of religion/spirituality in the room" (six items, variance $=33.2 \%$ ), highlighted the importance of addressing religion/spirituality during the counseling session. Factor 2, named "spirituality at intake" (three items, variance $=9.3 \%$ ), highlighted inquiry about spiritual beliefs during the intake process. Factor 3, named "importance of self-exploration" (four items, 
variance $=7.4 \%$, highlighted the importance of clinicians' understanding of their own beliefs and value systems. Factor 4, named "worldview" (two items, variance $=6.4 \%$ ), highlighted the importance of considering religion/spirituality within a multicultural framework. Factor 5, named "religion/spirituality as a strength" (three items, variance $=5.9 \%$ ), highlighted the positive possibilities of incorporating religion/spirituality into treatment. Factor 6, named "importance of human development" (three items, variance $=4.9 \%$ ), highlighted the relationship between human development and religious/spiritual development. The emerging factors of “worldview," "intake," "self-exploration," and "human development" from the current sample also emerged in Robertson (2010) lending support for the consistency of the Spiritual Competency Scale.

The six-factor structure for the students contained the same 22 items that loaded at .5 or higher with the exception of Item $46(.38)$, Item $56(.37)$, and Item 58 (.47). These items remained a part of the analysis as they have garnered previous empirical support (Dailey et al., 2015). The solution accounted for $66.6 \%$ of the total variance. Factor 1 , labeled "religious symbols as interventions in therapy" (three items, variance $=31.7 \%$ ), highlighted the importance of using religious symbols as interventions in treatment. Factor 2, labeled "spirituality at intake" (three items, variance $=8.8 \%$, highlighted inquiry about spiritual beliefs during the intake process. Factor 3, labeled "importance of self-exploration" (four items, variance $=7.4 \%$ ), highlighted the importance of clinicians' understanding of their own beliefs and value systems. Factor 4, labeled "worldview" (four items, variance 6.9\%), highlighted the importance of considering religion/spirituality within a multicultural framework. Factor 5, labeled "importance of human development" (three items, variance $=6.9 \%$ ), highlighted the relationship between human development and religious/spiritual development. Factor 6, labeled "religion/spirituality 
as a strength" (four items, variance $=6.9 \%$ ), highlighted the positive possibilities of incorporating religion/spirituality into treatment.

Upon comparing supervisors and students, three factors were identical, meaning they contained the same questions. Those factors were, "spirituality at intake," "importance of selfexploration," and the "importance of human development." The remaining three factors between supervisors and students contained variation. Overall, the item distribution for students contained fewer extremes than for supervisors with between 3-4 items per factor as opposed to 26 items per factor. Factor one accounted for the most variance for supervisors and students with $33.2 \%$ and $31.7 \%$ respectively. For the supervisors, factor one contained six items and broadly captured the use of religion/spirituality in the therapy session as compared to factor one for students which contained three items that looked specifically at the use of religious symbols as interventions in treatment.

The SACRED model of supervision contains six domains that should be attended to as a way to ensure competent supervision. The six domains that should be focused on are safety, assessment, conceptualization, reflection, emerging congruence, and development. The SCS contains factors that pertain to "assessment" (Factor 2), "reflection" (Factor 3), and “development" (Factor 5 for students and Factor 6 for supervisors). The results of the current study have identified three factors from the SCS that map directly onto domains of the SACRED model. Of note, while there are not six factors from the SCS that directly map onto the six domains asserted by the SACRED model, there are individual items on the SCS that address each of the six critical domains in the SACRED model. These will be discussed in greater detail in the discussion section. 
Table 12

\begin{tabular}{|c|c|c|c|c|c|c|c|c|c|c|c|c|}
\hline \multirow{3}{*}{$\begin{array}{c}\text { SCS } \\
\text { Question } \\
\end{array}$} & \multicolumn{12}{|c|}{ Participants } \\
\hline & \multicolumn{6}{|c|}{ Supervisor Factors } & \multicolumn{6}{|c|}{ Student Factors } \\
\hline & 1 & 2 & 3 & 4 & 5 & 6 & 1 & 2 & 3 & 4 & 5 & 6 \\
\hline Q1 & & & 689 & & & & & & .81 & & & \\
\hline $\mathrm{Q} 2$ & & .88 & & & & & & .86 & & & & \\
\hline Q3 & & & & & 580 & & & & & .682 & & \\
\hline Q4 & & & & & 806 & & & & & .383 & & \\
\hline Q5 & .745 & & & & & & .83 & & & & & \\
\hline Q6 & & & & & & 873 & & & & & 797 & \\
\hline Q7 & & & & .757 & & & & & & & & .768 \\
\hline $\mathrm{Q} 8$ & & & & & 446 & & & & & & & .586 \\
\hline Q9 & & & 692 & & & & & & .72 & & & \\
\hline Q10 & & .681 & & & & & & .70 & & & & \\
\hline Q11 & & & & .726 & & & & & & .767 & & \\
\hline Q12 & & & & & & 818 & & & & & 79( & \\
\hline Q13 & .657 & & & & & & .84 & & & & & \\
\hline Q14 & .460 & & & & & & & & & & & .367 \\
\hline Q15 & & & .687 & & & & & & .62 & & & \\
\hline Q16 & .622 & & & & & & & & & & & .470 \\
\hline Q17 & .466 & & & & & & & & & .785 & & \\
\hline Q18 & .760 & & & & & & .76 & & & & & \\
\hline Q19 & & & & & & 384 & & & & & 591 & \\
\hline Q20 & & .856 & & & & & & .86 & & & & \\
\hline Q21 & & & .793 & & & & & & .73 & & & \\
\hline
\end{tabular}

Table 12. Supervisor and student, orthogonally rotated, item loadings for each factor represented on the Spiritual Competency Scale (SCS).

Table 13

\begin{tabular}{|l|l|}
\hline SACRED Domains & SCS Overlap \\
\hline 1. Safety & 1. Does not overlap \\
\hline 2. Assessment & 2. Formal and Informal Applications \\
\hline 3. Conceptualization & 3. Specific Questions Overlap \\
\hline 4. Reflection & 4. Direct Overlap \\
\hline 5. Emerging Congruence & 5. Direct Overlap \\
\hline 6. Development & 6. Formal and Informal Applications \\
\hline
\end{tabular}

Table 13. Ways in which the SCS factors and questions overlap or do not overlap the SACRED domains.

\section{Research question five: Relationship between Spiritual Issues in Supervision Scale}

(SISS) Scores and Spiritual Competency Scale (SCS) Scores for supervisors. To address

Research Question 5, "To what extent are supervisor scores on the SISS related to their scores

on the SCS? " a Pearson product-moment correlation coefficient was computed to assess the 
relationship between supervisor's SCS Total scores and SISS Total scores. The following hypothesis was tested: there would be a significant, positive correlation between supervisors' scores on the SCS and their reports of topics discussed in supervision as measured by the SISS. SISS Total scores were computed according to the protocol described by Miller (2004) in the scale development text. There was a correlation between the two variables, $(r(113)=.503, p<$ .001). Overall, there was a large, positive correlation between supervisor's total scores on the SCS and their total scores on the SISS. Increases in total score on the SCS were correlated with increases in scores on the SISS. The results offer support for the hypothesis suggesting that increases in perceived competence correlate with more conversations about spirituality.

\section{Research question six: Relationship between Spiritual Issues in Supervision Scale} (SISS) Scores and Spiritual Competency Scale (SCS) Scores for students. To address Research Question 6, "To what extent are student scores on the SISS related to their scores on the SCS? ” A Pearson product-moment correlation coefficient was computed to assess the relationship between student's SCS Total scores and SISS Total scores. The following hypothesis was tested: there would be a significant, positive correlation between students' scores on the SCS and their reports of topics discussed in supervision as measured by the SISS. SISS Total scores were computed according to the protocol described by Miller (2004) in the scale development text. There was a correlation between the two variables, $(r(177)=.294, p<.001)$. Overall, there was a positive correlation between student's total scores on the SCS and their total scores on the SISS. Increases in total score on the SCS were correlated with increases in scores on the SISS. The results offer support for the hypothesis suggesting that increases in perceived competence correlate with more conversations about spirituality. 


\section{SUMMARY}

The results of this study offer explanations for the role of spirituality in supervision. Additionally, the results addressed supervisors' perceptions of competence to implement issues of spirituality with supervisees. Finally, this study expanded the literature by breaching a gap between theory and assessment through providing an assessment measure with a theoretical model of addressing spirituality in supervision. The results of hypothesis one indicated that $49.5 \%$ of the 113 supervisors in this sample scored below the cutoff for perceived competence of 105 points on the SCS. Hypothesis two suggested there is no significant difference between SCS scores achieved by supervisors and students. Additionally, the average SCS score for supervisors and students fell below the cutoff for perceived competence of 105 . The third hypothesis suggested that supervisors discussed $93.1 \%$ of the situations measured by the SISS with their supervisees. Hypothesis four found six factors present on the SCS, three of those factors were the same as the factors identified by Robertson (2010). All six factors found in the current study were named and compared to the dimensions asserted in the SACRED model. Three of the factors found in this sample (spirituality at intake, importance of self-exploration, and importance of human development) map onto three dimensions of the SACRED model (assessment, reflection, and development). Hypothesis five found a relationship between supervisors' total scores on the SCS and their total scores on SISS. As scores increase on the SCS, scores also increase on the SISS. Additionally, hypothesis six found the same relationship between the SCS and SISS for students. Increases in total score on the SCS were correlated with increases in scores on the SISS. Chapter five provides both conclusions and recommendations based on the data presented in chapter four. 


\section{CHAPTER 5: DISCUSSION}

The results of this study expand the literature around the role of religion and spirituality in supervision. Prior to this study there was no known published research on supervisors' perceived level of competence to teach supervisees about religion and spirituality. The results of this study highlight the importance of fostering competent practice around the topic of spirituality. Clients, students, and supervisors have expressed the importance of this topic in treatment (Diallo, 2013; Frazier \& Hansen, 2009; Gockel, 2011; Knox et al., 2005; Morrison et al., 2009; Plumb, 2011; Post \& Wade, 2014; Rose et al., 2008). Without proper attention and training, there is a risk of clinicians imposing their values onto clients, avoiding the conversations completely, and practicing in an ethically inappropriate manner. The results from each of the six research questions will be discussed with regard to how they complement and expand the current body of literature. Limitations of this study will also be examined. Finally, the chapter concludes with an exploration of future directions in which researchers may choose to engage in an effort to expand this topic.

\section{Demographics Discussion}

Several elements of this sample were consistent with findings across the literature on religion and spirituality. A review of the literature revealed an assertion that clinicians tend to be less religious overall (Delaney, Miller, \& Bisonó, 2013). The data collected in this study supported this hypothesis; both supervisors (see Table 2) and students (see Table 4) are less religious than spiritual. Looking at reported confidence to address a client's religious and spiritual beliefs, Cummings et al. (2014) found that clinicians' own religious and spiritual beliefs correlated with confidence. In the current sample of supervisors and students, only spiritual beliefs correlated with comfortability to address spiritual and religious material in counseling. 
Plumb (2011) assessed comfortability addressing religion and spirituality with clients if the client initiated the conversation. Their results suggested that $98 \%$ of the 341 participants would feel comfortable. The current study found that, absent of the client initiating the conversation, $92 \%$ of supervisors and $79 \%$ of students would feel comfortable addressing religious and spiritual material in session. The literature suggests clinicians feel confident and comfortable to discuss religion and spirituality when they have their own set of beliefs as well as when the client initiates the conversation (Cummings et al., 2014; Delaney et al., 2013; Plumb, 2011). This study supported these hypotheses, suggesting that a spiritual belief system leads to comfortability and overall significantly more than half of supervisors and student clinicians reported feeling comfortable talking about religious and spiritual material in session.

This finding could hold implications for the supervisory relationship as well as for the treatment of clients. Within the supervisory relationship, supervisors have the opportunity to help increase their supervisee's level of comfortability addressing religious and spiritual material in session through dialogue about the supervisee's beliefs. Assessing and helping the supervisee understand their personal beliefs would likely lead to increased comfortability talking with clients. While Plumb (2011) found comfortability was increased when the client initiated the conversation, the current study did not measure initiation, and still supervisors and students reported comfortability. This would suggest that supervisors have an opportunity to initiate a conversation in supervision to help increase their supervisees' comfortability. Within the therapy setting, clients might benefit from a clinician who has engaged in self-reflection around their religious/spiritual beliefs. A clinician might be less likely to avoid conversations around religion and spirituality if they are more comfortable. 
Another central theme that emerges across the literature is the lack of training for clinicians to implement religion and spirituality into counseling (Adams, 2012; Burke, Hackney, Hudson, Miranti, Watts, \& Epp, 1999; Hall, Dixon, \& Mauzey, 2004; Saunders, Petrik, \& Miller, 2013; Walker, Gorsuch, \& Tan, 2004; Wiggins-Frame, \& Cashwell, 2007; Young, van Asselt, \& Senstock, 2009). In the current study, supervisors and students were asked if they felt their graduate program prepared them to include spiritual and religious issues in counseling. More than half of the sample (59\% of supervisors and 54\% of students) felt inadequately prepared by their training programs.

A comparison of supervisors' responses to students' responses revealed that students reported more opportunities to discuss religious/spiritual issues in counseling in their training programs. For example, students cited seven different ways in which their graduate programs prepared them as opposed to supervisors who cited only four different ways in which programs prepared them. The number of available opportunities could be reflective of increased emphasis on diversity factors in doctoral curriculum, meaning that some improvements have already been made to doctoral curriculum to include religion/spirituality as topics of discussion. Additionally, both supervisors and students suggested that religious/spiritual issues qualify as issues of diversity and should be addressed in diversity courses. Many authors allude to a lack of training (Adams, 2012; Burke et al., 1999; Delaney et al., 2013; Hall et al., 2004; Saunders et al., 2013; Walker et al., 2004; Wiggins-Frame \& Cashwell, 2007; Young et al., 2009). However, few studies have asked clinicians how they would like to be trained. This study offers suggestions about how to address training deficits. While supervision is one area participants felt training would be appropriate, the majority of participants, 283 out of the 304 total, indicated that issues of religion/spirituality should be addressed academically, as a part of relevant diversity courses 
or as separate courses. This suggests that deferring and relying on supervisors to fill in learning gaps before licensure is inconsistent with student expectations. Students reported that they need to learn about ways to include religious/spiritual topics in clinical work during their time in the classroom.

Finally, the literature suggests that clinicians agree on the utility of religious and spiritual discussions in therapy (Diallo, 2013; Gockel, 2011; Knox et al., 2005; Morrison et al., 2009; Post \& Wade, 2014; Rose et al., 2008) This is synonymous with the findings of this study. Only four of the 304 participants indicated that issues of religion and spirituality do not need to be addressed in treatment. Young, Wigging-Frame, and Cashwell (2007) asserted that knowledge of ASERVIC's Spiritual competencies is the gold standard for fostering competence in the area of addressing religious and spiritual issues in clinical work. However, the participants in this study did not endorse they had knowledge of ASERVIC's spiritual competencies. In this study, 95.7\% of supervisors and $96.8 \%$ of students reported not being familiar with ASERVIC's spiritual competencies. More than half $(n=171)$ of the supervisors and students in this sample indicated no formal, in class training related to religion/spirituality, and even more $(n=293)$ reported not being familiar with the foundational ASERVIC document that helps foster competence. To recap, supervisors and students alike endorsed the idea that issues of religion and spirituality should be addressed in treatment, but those same clinicians lack knowledge and awareness of the one guiding document that fosters competence in this area. This calls into question where participants developed the perceived competence to address religious and spiritual concerns. These results demonstrate a disconnect between the standards designed to help foster competence and clinician's self-perception. It is possible that other factors are contributing to a perceived sense of competence (e.g., self-identification as spiritual). However, 
awareness of the spiritual competencies delineated by ASERVIC is not one of the factors contributing to this sample's perceived competence.

\section{Supervisors' Scores on Spiritual Competency Scale (SCS) Discussion}

It was hypothesized that at least $50 \%$ of supervisors would score in the competent range (105 points or above) on the SCS, thus indicating that they perceived themselves as competent to implement religion/spirituality into their clinical work. The results of the current study showed that more than half of the supervisors (53\%) scored 105 points or above, lending support for this hypothesis. A possible explanation for why more than half of the supervisors scored in the competent range is due to their own personal belief system. Walker, Gorsuch, and Tan (2004), as well as Cummings (2014) suggested that, due to a lack of training in religious/spiritual topics, clinicians will rely on their personal experiences to guide feelings of competence. As previously discussed, the majority of participants in the current study (59\% of supervisors and $55 \%$ of students) felt inadequately prepared by their graduate program to competently address spirituality in session. While many of the participants did not get the necessary training from their programs, many participants in the current sample (53\%) identified as spiritual, which could have been a factor in their perceptions of competence. This could suggest that clinicians are basing their understanding of their competence on their personal beliefs, which could negatively impact the therapeutic relationship. Clinicians who hold a different belief system than their clients might act differently when engaging in a conversation about religion and spirituality; or they might avoid conversations about religion/spirituality because of the difference in beliefs.

In addition to these findings, several correlations were conducted to ascertain if other variables correlated with overall SCS score as a means of offering future directions to explore. For supervisors, years of experience, religious affiliation, and age did not significantly correlate 
with increased SCS scores. Of note, the percentage of time spent attending to spirituality and/or spiritual issues in both therapy and supervision moderately correlated with scores on the SCS. This correlation is consistent with the hypothesis that discussing spiritual topics in supervision and therapy is helpful in fostering a sense of competence.

For students, similar correlations were conducted to ascertain if other variables correlated with overall SCS score. Upon analyzing age, religious affiliation, and time spent discussing spirituality in supervision, there were no significant relationships with SCS scores. However, there was a small, positive correlation between SCS score and time spent discussing spiritual issues in therapy. This correlation suggests that the more time a student spends addressing spiritual issues in therapy, the greater their perceived level of competence. For both students and supervisors these results highlight the importance of having conversations about spiritual issues in therapy with the client as well as in supervision.

\section{Difference in Supervisor and Student Spiritual Competency Scale (SCS) Score Discussion}

A comparison of supervisor and student scores on the SCS revealed no statistically significant difference between scores of the two groups. Additionally, the average score on the SCS was below the cutoff of 105 delineated by Dailey et al. (2008), with supervisors scoring 104.4 and students scoring 103.7 on average. These results lend support to the hypothesis that experience does not equate to competence (Goldberg et al., 2016). Overall, the lack of significant difference in scores between supervisors and students lends support for an increased need for both initial training and continuing education opportunities.

Both supervisors and students endorsed the importance of integrating spirituality into treatment, when appropriate, and have specified ways in which training programs could address these diversity factors. Based on the current sample, the topics of religion and spirituality should 
be discussed across several different settings such as through specific courses, didactics, round table discussions, and lunch and learn seminars; supervision is not the only place responsible for fostering competence.

\section{Spiritual Issues in Supervision Scale Discussion}

A closer examination of the different ways in which supervisors integrate spirituality into supervision illuminates some surprising frequencies. The Spiritual Issues in Supervision Scale (SISS) presents different clinical topics that arise in session. Supervisors were asked to consider if they discussed the different topics in supervision with their supervisees. The scale contains 29 items. More than $50 \%$ of the supervisors indicated that they addressed 27 out of the 29 items with their supervisees. The two items supervisors failed to address were, talking about spirituality when talking about the supervisory relationship (49\%), and talking about spirituality when discussing issues of power and hierarchy (44\%). A closer examination of the results revealed several questions that were addressed by $80 \%$ or more of supervisors. The overarching theme of this group of questions dealt with challenges to spiritual beliefs (e.g., issues of morality, death, and suicide). Additionally, several of the categories are representative of a more holistic conceptualization of a client (e.g., culture and conceptualization).

As stated in the beginning of this chapter, clients see value in addressing their religious/spiritual beliefs in treatment (Diallo, 2013; Gockel, 2011; Knox et al., 2005; Morrison et al., 2009; Post \& Wade, 2014; Rose et al., 2008). The results of this study suggested that supervisors addressed spirituality in supervision in several areas that clients find important, specifically with regard to existential concerns such as meaning and purpose (Knox et al., 2005).

The results of this study also served to support the work of Weinstein (2006), whose results suggested a correlation existed between religious affiliation and scores on the SISS. The 
students represented in this sample lend support for this finding. For students, there was a small positive correlation between religiosity and SISS score. While the student data were consistent with previous research results, a small negative correlation existed between supervisors' scores on the SISS and both religious and spiritual identification. Overall, the results of this research question lend support to the hypothesis that supervisors reported having conversations about how spirituality impacts their supervisee's client's lives holistically.

Of note, upon analyzing students' reports of conversations about spirituality with supervisors there are significant differences in the students' reports compared to the supervisors' reports. As depicted in Table 11 there were several domains in which supervisors reported having conversations about spirituality and students indicated that conversations about spirituality were not occurring. One possible explanation for this finding is the lack of a social desirability measure in the SISS. It is possible that supervisors responded to the SISS in a socially desirable way whereas social desirability was less of a factor for students.

\section{Spiritual Competency Scale (SCS) as a Measure for SACRED Model Implementation}

The SACRED model of supervision is a theoretical model that can be implemented by supervisors to help foster students' competence to work with a client's religious/spiritual issues as they arise in treatment. However, the SACRED model is not the only theoretical model of supervision for issues of religion and spirituality. Fowler's model of faith development (Parker, 2009), the developmental model (Gingrich \& Worthington, 2007; Ripley et al., 2007), and the integrative developmental model (Aten \& Hernandez, 2004, Ogden \& Sias, 2011; Tan, 2009) are all models discussed in the literature. However, the SACRED model was chosen for this study because it is an amalgamation of the theoretical literature. Ross et al. (2013) offered six domains to which a supervisor should attend to insure competent supervision: safety, assessment, 
conceptualization, reflection, emerging congruence, and development. While the SACRED model offers a strong theoretical foundation, there is currently no way to test the effectiveness of its use in supervision as it relates to fostering competent practitioners.

The SCS is the only measure, to date, that evaluates an individual's perceived competence to address issues related to spirituality in session. The goal of this research question was to examine factors in the SCS and assess how they compared to the six domains contained in the SACRED model, with the intent of understanding if the SCS could be used as a measure of effectiveness for the SACRED model.

The foundation to answer this question was to first ascertain if the SCS would produce the same factor loadings in this sample as it did in the work of Dailey et al. (2015). It was expected from previous results that six factors would emerge. Consistent with this expectation, this sample produced six factors. Factor analysis was completed for students and supervisors separately, and the factor structures were compared. Although there were six factors present for students and supervisors, there was variability between questions loading on each factor (See Tables $12 \& 13)$. One possibility for the variability in distribution could be shifts in the structure of doctoral teaching. With a growing emphasis on the importance of multicultural competence it is possible that the consistency across student categories is reflective of increased focus on multiculturalism in academia.

Looking more closely at the factors that emerged from the data in this study and how they map onto constructs proposed by the SACRED model, the SCS contains three factors that map directly onto SACRED constructs. For both students and supervisors, the "assessment" and "reflection" factors were identical. These two factors also map directly onto the "assessment" 
and "reflection" domains of the SACRED model, although it is important to understand the nuances of what is being measured by the SCS and how that translates to the SACRED model.

The "assessment" domain within the SACRED model emphasizes the importance of the supervisor understanding the supervisee's knowledge of spirituality. In essence, it is important to establish a spirituality knowledge baseline. Supervisors are encouraged to gather information about their supervisee through formal and informal means. The results of this study determined the SCS could serve as a formal means of assessing the supervisee's perceived competence to work with spiritual issues at the beginning of supervision, and again at the end of supervision with discussion about changes over time. Additionally, this study postulates the results of the SCS could serve as a guide for a more informal discussion between the supervisor and supervisee as goals for supervision are set. The "assessment" domain, as measured by the SCS, questions the importance of assessing a client's religious/spiritual beliefs. This factor is comprised of questions asking specifically about the importance of assessing a client's belief systems during the intake process. The use of "assessment" as measured by the SCS reflects the importance of proper assessment with the client compared to the assessment construct delineated by the SACRED model that pertains to the use of assessment to gauge knowledge about spirituality.

The "reflection" domain within the SACRED model has four components: a diversity component, a parallel process component, an ideological integration component, and a selfexamination component. The diversity component of the model emphasizes that supervisors should assist supervisees as they process their increased awareness of the cultural complexity that surrounds issues of religion and spirituality. The "parallel process" component highlights the importance of the supervisory relationship and how supervision processes can be applied to 
clinical work. The ideological integration component delves into the importance of understanding the ways in which a supervisee's theoretical orientation accommodates religion and spirituality. The self-examination component involves self-reflection and integration to "teach the counselor how to be a caring person" (Ross et al., 2013, p. 79). The "reflection" factor as measured by the SCS overlaps nicely with the SACRED model. The results of this study determined the four SCS questions that make up this factor focus on the importance of self-reflection, self-awareness, the clinician's spiritual development, and integration into therapy. The results of this study determined there is overlap between the SCS and SACRED model with regard to the "reflection" domain. As a result of these findings the SCS could be used as a measure of effectiveness for the "reflection" domain of the SACRED model.

Another component of the SACRED model that maps directly onto a factor in the SCS, as determined by the results of this study, is the emphasis on "development." Within the SACRED model, development pertains to the importance of life-long learning and continued growth as it relates to spiritual understanding, both personally and professionally. The "development" factor on the SCS suggests the importance of knowing and understanding human development as it affects spiritual development. The SCS “development” factor, while different than the SACRED explanation for development, could be useful in understanding the supervisee's baseline. Again, based on the supervisee's answers to questions in the “development” factor, a supervisor could incorporate more or less didactic information about human development as it pertains to spiritual development.

The conceptualization component of the SACRED model includes awareness of the many relationships present in supervision, self-reflection (specifically as it pertains to countertransference), and holistic case conceptualization. Based on the results of this study, the 
SCS does not have a factor that maps directly onto this component. However, the SCS has specific questions about the importance of self-reflection and its impact on the therapeutic relationship (Factor 3). Similarly, the SACRED model offers the safety component which does not map directly onto the SCS. The safety component of the SACRED model emphasizes establishing an open, safe environment in which supervisees can discuss spirituality.

The emerging congruence component of the SACRED model emphasizes the importance of finding a balance between a client's presenting concerns and their spiritual beliefs. This component focuses on tailoring the interventions used in treatment to the individual. Factor 1 for both students and supervisors maps most closely onto this component. The factor assesses the role of religion/spirituality in the room, whether that be discussions or interventions.

A strength of the SCS is its short design as well as its broad overview of perceived spiritual competence. The results of this study expand the literature around the SCS as an instrument in a couple of ways. First, this study found a similar factor structure as Dailey et al. (2015) which lends support for the reliability of the instrument. Further, based on the results of this study it is likely that the SCS could be a helpful measure to use in supervision. Upon comparing the content assessed by the SCS to the components of the SACRED model the SCS would likely serve as an adequate measure to accompany the implementation of the SACRED model. The SCS could serve as a measure of pre-to-post supervision growth, as an informal supervision goal setting tool, or as a means of gathering information about a supervisee's knowledge base.

\section{Relationship between SISS Scores and SCS Scores for Supervisors Discussion}

Upon comparing the relationship between supervisors' scores on the SISS and SCS, there was a large positive correlation between the scores $(r(113)=.503, p<.001)$. This would 
suggest that the higher the score for perceived competence, as measured by the SCS, the more conversations supervisors have with their supervisees about issues of spirituality, as measured by the SISS. These findings combined with the positive correlations between SISS score, SCS score, and time spent discussing spirituality in supervision suggest that the act of having conversations about spirituality fosters feelings of competence. These findings hold implications for ways in which training can be implemented. Across the literature, there is consensus that clients want to discuss their religious/spiritual identities (Diallo, 2013; Gockel, 2011; Knox et al., 2005; Morrison et al., 2009; Post \& Wade, 2014; Rose et al., 2008) and clinicians endorse the importance of having these conversations (Frazier and Hansen, 2009; Morrison et al., 2009; Plumb, 2011). However, according to the findings in studies by Mrdjenovich et al. (2012), Shafranske and Malony (1990), Souza (2002) and Young et al., (2007), there is breakdown with regard to feeling competent to have the conversations. The results of this study suggest that increased conversation about issues of spirituality relates to increased perceptions of competence.

\section{Relationship between SISS Scores and SCS Scores for Students Discussion}

A comparison revealed a large, positive correlation between students' scores on the SISS and SCS. This suggests that the higher the score for perceived competence, as measured by the SCS, the more conversations students had with their supervisors about issues of spirituality, as measured by the SISS. There was no significant relationship $(r(184)=.045, p>.05)$ between the amount of time spent discussing spirituality in supervision and perceived competence. These findings suggest that students' perceived competence is associated with discussions in therapy, as opposed to supervisors whose perceived competence is associated with discussions in supervision. 
There are several possible explanations for the relationship between time spent discussing spirituality in therapy and perceived competence, as opposed to time spent discussing spiritualty in supervision and perceived competence. One possibility, as described by Adams (2012), is that due to implicit and explicit messages students receive from faculty about religion and spirituality, students have to decide for themselves how to deal with religious and spiritual issues as they arise. It is possible that the messages expressed in training programs are generalized to all clinical settings, making students less likely to discuss issues of religion and spirituality in supervision.

Another explanation for this relationship as described by Walker, Gorsuch, and Tan (2004) is that when clinicians are not taught how to implement religion and spirituality into sessions they are more likely to rely on intrapersonal experiences as a way to work with clients. This phenomenon was corroborated by van Asselt and Senstock (2009) who found clinicians' personal beliefs impacted their choice of interventions. Overall, it is important to ensure supervisors and students receive the training they need to competently work with their clients' religious/spiritual identities. Without proper training, it is possible that the clinician's beliefs could unknowingly influence the therapeutic dynamic. The APA code of ethics (2017) cites the importance of self-awareness around one's physical and mental health, as well as maintaining competence. This study has captured the training experiences of students and supervisors as well as their suggestions for improved training.

There are several implications for training that can be gleaned from the results of this study. First, across age and experience the clinicians in this study identified as less religious than spiritual. It is possible that confidence to discuss religion/spirituality might be influenced by an individual's beliefs. Training programs should emphasize self-reflection and exploration around 
one's religious/spiritual beliefs and how that impacts the clinical work in which they engage. As with other facets of diversity, self-awareness is critical to building competence and working with religion/spirituality should be no different.

Additionally, the findings of this study suggest greater emphasis needs to be placed on coursework related to religious/spiritual competence. Many participants in this study emphasized the importance of time being spent on religion/spirituality in multicultural classes. Ensuring that courses offer more of a balance between facets of diversity as opposed to emphasis on race and gender with limited time spent on other factors could be helpful. The results of this study also lend support for the hypothesis that multicultural competence as a topic cannot be covered in one course over one semester. Attending to intersectionality as well as individual identities warrants time and attention. The participants in this study advocated for separate classes devoted to religion/spirituality, emphasizing a deficit in current training.

Another way this study contributes to the literature is through attending to measurement in supervision. The implementation of measurement-based care in individual therapy is becoming increasingly important (King et al., 2017). It offers a way for providers to assess progress as well as for clients to reflect on the work they are doing in treatment. Measurementbased care offers transparency to the therapeutic process. This same logic was applied in the study to the supervision process. Through providing supervisors with a tool to measure the effectiveness of supervision around one content area they could assess the growth and development of supervisees in the area of spiritual competence.

Finally, this study offers some perspective about the achievability of spiritual competence. Despite the deficits in training, $51 \%$ of students and $53 \%$ of supervisors scored in the competent range on the SCS. This suggests that with some attention given to the topics of 
religion/spirituality, competence can be increased. The results of this study offer a tangible perspective on helping to increase competence among clinicians.

\section{IMPLICATIONS}

The next section will discuss various limitations to the current study. Additionally, this section will delve into ideas for directions for future research.

\section{Limitations}

There are several limitations of this study that offer the opportunity for future research. Consideration should be given to the instrumentation and design that was used. More generally, Coughlan, Cronin, and Ryan (2009) discussed the major drawbacks to using electronic means to collect data as well as limitations to survey research in general. They suggested that poor response rate is a major disadvantage to online survey administration. In addition, while they recommended the use of personalization to increase response rate, they recognized that decreased anonymity is the resulting limitation. Another way to combat low response rate is to initiate frequent contacts, offer monetary compensation, and personalize the contacts. All three of those suggestions were deployed in this study. Despite implementing the suggestions made by Coughlan, Cronin, and Ryan (2009) more students participated in this study than supervisors. Additionally, despite obtaining an adequate number of participants a larger sample size would increase generalizability of the results. The authors also cautioned against item non-response. This occurs when participants skip items on the survey. To combat item non-response, it is recommended that questionnaires be short with clear and concise items. This study attempted to provide a clear and concise survey. One way of ensuring the survey was clear was to utilize Qualtrics, an online survey creator that allowed for control over the display of questions. Additionally, it is possible that due to the nature of the questions asked in the survey, participants 
could have responded in a socially desirable way or in a way that they thought they should answer. An example of the potential for socially desirable responding might be seen in the discrepancy between students' and supervisors' results on the SISS. It is possible that supervisors responded in a socially desirable way. Finally, the authors suggested that sample bias is another inherent limitation to survey research that is applicable to this study. It is possible that supervisors and students self-selected out of this study based on their interests. Additionally, it is possible that training director personal beliefs could have had an effect on the distribution of this survey.

\section{Future Research}

Future researchers should consider several additional areas on which to focus their efforts. First, future studies should consider using supervisor-supervisee dyads as more dyadic comparisons could be asserted with this type of design. Through the use of dyads, pre-and postmeasures could be conducted. For example, supervisors could administer the SCS to supervisees at the beginning of supervision and again at the end of supervision to assess growth.

Additionally, through the use of dyads other factors such as the therapeutic relationship could be measured. Future research could delve into the relationship between students and supervisors and the impact that has on competence. Additionally, a strength of using pairs of students and supervisors would be in the comparisons that could be made; not only assessing the strength of the relationship but the impact of similarity (e.g., style or theoretical orientation) on outcomes.

With regard to instruments, there are very few instruments available to measure the topics of religion/spiritualty in supervision. Through the development and implementation of additional instruments, this body of research could be diversified. For example, development of an objective measure of competence as opposed to a perceived measure of competence could be 
informative. The literature suggests that clinicians' self-perceptions of multicultural competence do not correlate with their clients' perceptions, indicating a mismatch between self-perception and the perceptions of others (Dillon et al., 2016). An objective measure of spiritual competence might provide a more accurate picture of clinical practice. Additionally, development of a measure to help facilitate a clinician's self-exploration process could be helpful and synonymous with what participants in this study discussed.

Finally, utilizing different methodologies, such as qualitative or Delphi Studies, could provide additional information to this body of literature. Qualitative studies could delve into student and supervisor experiences addressing religion/spirituality in session. Additionally, a qualitative approach to this topic could help inform future measures of spiritual competence. In a similar way, a Delphi Study could help hone in on what groups of expert professionals deem most relevant with regard to fostering religious and spiritual competence.

\section{CONCLUSION}

This study expanded the literature around the issue of spiritual competence in several ways. First, the results of this study suggest that there is room for growth for both supervisors and students when it comes to discussing topics of religion and spirituality. Additionally, experience, according to the findings of this study, does not guarantee competence; this study demonstrated that students and supervisors were no different with regard to perceived competence. One place where growth can occur is within the context of supervision. Based on this study, the majority of supervisors in the sample endorsed discussing spirituality with their supervisees across a multitude of different clinical issues. The act of having conversations about spirituality served as an important facet to perceived competence. Of note, the majority of the participants in this study felt underprepared by their doctoral programs and some offered 
suggestions of ways in which training could be improved. A common assertion was that religion/spirituality are facets of diversity and should be given adequate attention in multicultural courses. Participants also recommended that elective courses, didactics, support groups, and colloquia integrate religious/spiritual topics. Finally, this study lends support for the SACRED model and the use of the SCS as a tool to bolster further empirical support for the model. This study provides information to supervisors, students, and even training programs in the hope of increasing holistic, competent care for clients that includes acknowledgment of the importance of religion and spirituality in treatment. 


\section{References}

Abu-Raiya, H., Sasson, T., Palachy, S., Mozes, E., \& Tourgeman, A. (2016). The relationships between religious coping and mental and physical health among female survivors of intimate partner violence in Israel. Psychology of Religion and Spirituality, doi: $10.1037 /$ rel0000107

Adams, J. R. (2012). Spiritual issues in counseling: What do students perceive they are being taught? Counseling and Values, 57(1), 66-80. doi:10.1002/j.2161-007X.2012.00009.x

Adams, C. M., Puig, A., Baggs, A., \& Wolf, C. P. (2015). Integrating religion and spirituality into counselor education: Barriers and strategies. Counselor Education and Supervision, 54(1), 44-56. doi:10.1002/j.1556-6978.2015.00069.x

Ankrah, L. (2002). Spiritual emergency and counselling: An exploratory study. Counselling and Psychotherapy Research, 2(1), 55-60. doi:10.1080/14733140212331384988

American Psychological Association (2002). Guidelines for clinical multicultural education, training, research, practice and organizational change. Retrieved November 18, 2016, from http://www.apa.org/practice/guidelines/

Aron, A., Aron, E., \& Coups, E. J. (2014). Statistics for psychology (6th ed.). Harlow: Pearson. Association for Spiritual, Ethical, and Religious Values in Counseling. (2009). Spiritual competencies. Retrieved December 07, 2016, from http://www.aservic.org/resources/spiritual-competencies/

Aten, J. D., \& Hernandez, B. C. (2004). Addressing religion in clinical supervision: A model. Psychotherapy: Theory, Research, Practice, Training, 41(2), 152-160. doi:10.1037/00333204.41.2.152 
Bergin, A. E., \& Jensen, J. P. (1990). Religiosity of psycho-therapies: A national survey. Psychotherapy, 27, 3-7. doi: 10.1037/0033-3204.27.1.3

Berkel, L. A., Constantine, M. G., \& Olson, E. A. (2007). Supervisor multicultural competence: Addressing religious and spiritual issues with counseling students in supervision. Clinical Supervisor, 26(1), 3-15. doi:10.1300/J001v26n01.02

Bernard, J. M., \& Goodyear, R. K. (2014). Fundamentals of clinical supervision. (5th ed.). Upper Saddle River, NJ: Pearson.

Bishop, D. R., Avila-Juarbe, E., \& Thumme, B. (2003). Recognizing spirituality as an important factor in counselor supervision. Counseling \& Values, 48(1), 34. doi: 10.1002/j.2161007x.2003.tb00273.x

Blando, J. A. (2006). Spirituality, religion, and counseling. Counseling \& Human Development, 39(2), 1-14.

Burke, M., Hackney, H., Hudson, P., Miranti, J., Watts, G. A., \& Epp, L. (1999). Spirituality, religion, and CACREP curriculum standards. Journal of Counseling \& Development, 77(3), 251. doi: 10.1002/j.1556-6676.1999.tb02448.x

Coughlan, M., Cronin, P., \& Ryan, F. (2009). Survey research: Process and limitations. International Journal of Therapy and Rehabilitation, 16(1), 9-15. doi:10.12968/ijtr.2009.16.1.37935

Coyle, A., \& Lochner, J. (2011). Religion spirituality and therapeutic practice. The Psychologist, 24(4), 264-266.

Crossley, J. P., \& Salter, D. P. (2005). A question of finding harmony: A grounded theory study of clinical psychologists' experience of addressing spiritual beliefs in therapy. Psychology 
and Psychotherapy: Theory, Research and Practice, 78(3), 295-313.

doi:10.1348/147608305X26783

Cummings, J. P., Ivan, M. C., Carson, C. S., Stanley, M. A., \& Pargament, K. I. (2014). A systematic review of relations between psychotherapist religiousness/spirituality and therapy-related variables. Spirituality in Clinical Practice, 1(2), 116-132. doi:10.1037/scp0000014

Dailey, S. F., Robertson, L. A., \& Gill, C. S. (2015). Spiritual competency scale: Further analysis. Measurement and Evaluation in Counseling and Development, 48(1), 15-29. doi: $10.1177 / 0748175614544688$

Delaney, H. D., Miller, W. R., \& Bisonó, A. M. (2013). Religiosity and spirituality among psychologists: A survey of clinician members of the American Psychological Association. Spirituality in Clinical Practice, 1(S), 95-106.

doi:10.1037/2326.4500.1.S.95

Diallo, A. (2013). Clients' willingness to incorporate religion or spirituality in counseling: A brief report. Rehabilitation Counseling Bulletin, 56(2), 120-122. doi: $10.1177 / 0034355212439425$

Dillman, D. A. (1978). Mail and telephone surveys: The total design method. New York, NY: Wiley-Interscience.

Dillon, F. R., Odera, L., Fons-Scheyd, A., Sheu, H., Ebersole, R. C., \& Spanierman, L. B. (2016). A dyadic study of multicultural counseling competence. Journal of Counseling Psychology, 63(1), 57-66. doi:10.1037/cou0000118 
Faul, F., Erdfelder, E., Lang, A. G., \& Buchner, A. (2007). G*Power 3: A flexible statistical power analysis program for the social, behavioral, and biomedical sciences. Behavior Research Methods, 39, 175-191. doi: 10.3758/bf03193146

Fowler, J. (1981). Stages of faith. San Francisco, CA: Harper \& Row.

Frazier, R. E., \& Hansen, N. D. (2009). Religious/spiritual psychotherapy behaviors: Do we do what we believe to be important? Professional Psychology: Research and Practice, 40(1), 81-87. doi:10.1037/a0011671

Gall, T., Malette, J., \& Guirguis-Younger, M. (2011). Spirituality and religiousness: A diversity of definitions. Journal of Spirituality in Mental Health, 13(3), 158-181. doi:10.1080/19349637.2011.593404

Gallup, G. H., Jr., \& Lindsay, D. M. (1999). Surveying the religious landscape. Harrisburg, PA: Morehouse.

Garner, C. M. (2014). Overview of the spiritual issues in supervision scale. International Forum for Logotherapy, 37(2), 82-84. doi:0191-3379

Gartner, J., Larson, D. B., \& Allen, G. D. (1991). Religious commitment and mental health: A review of the empirical literature. Journal of Psychology and Theology, 19(1), 6-25. doi:10.1037/10199-007

Gilliam, T. H., \& Armstrong, S. A. (2012). Spirituality and counseling supervision: Current practices of board-approved supervisors. The Clinical Supervisor, 31(1), 25-41. doi: $10.1080 / 07325223.2012 .671718$

Gingrich, F., \& Worthington, E. R. (2007). Supervision and the integration of faith into clinical practice: Research considerations. Journal of Psychology and Christianity, 26(4), 342355. 
Gockel, A. (2011). Client perspectives on spirituality in the therapeutic relationship. Humanistic Psychologist, 39(2), 154-168. doi:10.1080/08873267.2011.564959

Gubi, P. M. (2007). Exploring the supervision experience of some mainstream counsellors who integrate prayer in counselling. Counselling \& Psychotherapy Research, 7(2), 114-121. doi:10.1080/14733140701342544

Hall, C. R., Dixon, W. A., \& Mauzey, E. D. (2004). Spirituality and religion: Implications for counselors. Journal of Counseling and Development, 82(4), 504. doi: 10.1002/j.15566678.2004.tb00339.x

Heydari-Fard, J., Bagheri-Nesami, M., Shirvani, M. A., \& Mohammadpour, R. (2014). Association between quality of life and religious coping in older people. Nursing Older People, 26(3), 24-30. doi:10.7748/nop2014.03.26.3.24.e496

Hull, C. E., Suarez, E. C., Sells, J. N., \& Miller, M. M. (2013). Addressing spiritual dialogue in supervision: comparing supervisor and supervisee perceptions. Journal of Psychology and Christianity, 32(1), 30-42.

Hull, C. E., Suarez, E. C., \& Hartman, D. (2016). Developing spiritual competencies in counseling: A guide for supervisors. Counseling and Values, 61(1), 111-126. doi:10.1002/cvj.12029

IBM Corp. Released 2016. IBM SPSS Statistics for Macintosh, Version 24.0. Armonk, NY: IBM Corp.

Kelly, E. W., Jr., (1994). Counselor preparation: The role of religion and spirituality in counselor education: A national survey. Counselor Education and Supervision, 33, 227-237.

King, P. R., Beehler, G. P., Vair, C. L., Gass, J., Funderburk, J. S., Lilienthal, K. R., \& Novi, J. H. (2017). Identifying measurement-based care practices of VHA co-located 
collaborative care providers. Professional Psychology: Research and Practice, 48(4), 236-242. doi:10.1037/pro0000048

Knox, S., Catlin, L., Casper, M., \& Schlosser, L. Z. (2005). Addressing religion and spirituality in psychotherapy: Clients' perspectives. Psychotherapy Research, 15(3), 287-303. doi:10.1080/10503300500090894

Koenig, H. G. (2009). Research on religion, spirituality, and mental health: A review. Canadian Journal of Psychiatry, 54, 283-291.

Magaldi-Dopman, D. (2014). An "Afterthought": Counseling trainees' multicultural competence within the spiritual/religious domain. Journal of Multicultural Counseling \& Development, 42(4), 194-204. doi:10.1002/j.2161-1912.2014.00054.x

McCullough, M. E., Hoyte, W. T., Larson, D. B., Koenig, H. G., \& Thoresen, C. (2000). Religious involvement and mortality: A meta-analytic review. Health Psychology, 19, 211-222. doi: 10.1037/0278-6133.19.3.211

Miller, M. M. (2004). Spirituality, gender, and supervisory style in supervision (Doctoral dissertation, Texas Tech University, 2003). Dissertation Abstracts International, 64(10A), 3861 .

Miller, M. M., Korinek, A. W., \& Ivey, D. C. (2006). Integrating spirituality into training: The spiritual issues in supervision scale. American Journal of Family Therapy, 34(4), 355372. doi: $10.1080 / 01926180600553811$

Morrison, J. Q., Clutter, S. M., Pritchett, E. M., \& Demmitt, A. (2009). Perceptions of clients and counseling professionals regarding spirituality in counseling. Counseling \& Values, 53(3), 183-194. doi: 10.1002/j.2161-007x.2009.tb00124.x 
Mrdjenovich, A., Dake, J., Price, J., Jordan, T., \& Brockmyer, J. (2012). Providing guidance on the health effects of religious/spiritual involvement: A national assessment of university counseling professionals. Journal of Religion and Health, 51(1), 198-214. doi:10.1007/s10943-010-9345-8

Ogden, K. R. W., \& Sias, S. M. (2011). An integrative spiritual development model of supervision for substance abuse counselors-in-training. Journal of Addictions \& Offender Counseling, 32(1-2), 84-96. doi:10.1002/j.2161-1874.2011.tb00209.x

Olson, M. M., Trevino, D. B., Geske, J. A., \& Vanderpool, H. (2012). Religious coping and mental health outcomes: An exploratory study of socioeconomically disadvantaged patients. Explore, 8(3), 172-176. doi:10.1016/j.explore.2012.02.005

Parker, S. (2009). Faith development theory as a context for supervision of spiritual and religious issues. Counselor Education \& Supervision, 49(1), 39-53. doi: 10.1002/j.15566978.2009.tb00085.x

Pearce, M. J., Medoff, D., Lawrence, R. E., \& Dixon, L. (2016). Religious coping among adults caring for family members with serious mental illness. Community Mental Health Journal, 52(2), 194-202. doi:10.1007/s10597-015-9875-3

Plumb, A. M. (2011). Spirituality and counselling: Are counsellors prepared to integrate religion and spirituality into therapeutic work with clients? Canadian Journal of Counselling and Psychotherapy, 45(1), 1-16.

Ponterotto, J. G., Gretchen, D., Utsey, S. O., Rieger, B. P., \& Austin, R. (2002). A revision of the Multicultural Counseling Awareness Scale. Journal of Multicultural Counseling and Development, 30, 153-180. doi: 10.1002/j.2161-1912.2002.tb00489.x 
Post, B. C., \& Wade, N. G. (2014). Client perspectives about religion and spirituality in group counseling. Counseling Psychologist, 42(5), 601-627. doi:10.1177/0011000014524601

Puente, C. P., Morales, D. M., \& Monge, F. C. (2015). Religious coping and locus of control in normal pregnancy: Moderating effects between pregnancy worries and mental health. Journal of Religion and Health, 54(5), 1598-1611. doi:10.1007/s10943-014-9881-8

Richards, P., Bartz, J. D., \& O'Grady, K. A. (2009). Assessing religion and spirituality in counseling: Some reflections and recommendations. Counseling and Values, 54(1), 6579. doi: 10.1002/j.2161-007x.2009.tb00005.x

Ripley, J. S., Jackson, L. D., Tatum, R. L., \& Davis, E. B. (2007). A developmental model of supervisee religious and spiritual development. Journal of Psychology and Christianity, $26(4), 298-306$.

Robertson, L. A. (2008). The spiritual competency scale: A comparison to the ASERVIC Spiritual Competencies, University of Central Florida: Electronic Thesis \& Dissertations, (CFE0002422).

Robertson, L. A. (2010). The spiritual competency scale. Counseling \& Values, 55(1), 6-24. doi: 10.1002/j.2161-007x.2010.tb00019.x

Rogers, D., Skidmore, S., Montgomery, G., Reidhead, M., \& Reidhead, V. (2012). Spiritual integration predicts self-reported mental and physical health. Journal of Religion \& Health, 51(4), 1188-1201. doi:10.1007/s10943-010-9425-9

Rose, E. M., Westefeld, J. S., \& Ansley, T. N. (2008). Spiritual issues in counseling: Clients' beliefs and preferences. Psychology of Religion and Spirituality, 5(1), 18-33. doi:10.1037/1941-1022.S.1.18 
Ross, D. K., Suprina, J. S., \& Brack, G. (2013). The spirituality in supervision model (SACRED): An emerging model from a meta-synthesis of the literature. Practitioner Scholar: Journal of Counseling \& Professional Psychology, 2(1), 68-83.

Russell, S. R., \& Yarhouse, M. A. (2006). Training in religion/spirituality within APA-accredited psychology predoctoral internships. Professional Psychology: Research and Practice, 37(4), 430-436. doi: 10.1037/0735-7028.37.4.430

Saunders, S. M., Petrik, M. L., \& Miller, M. L. (2013). Psychology doctoral students’ perspectives on addressing spirituality and religion with clients: Associations with personal preferences and training. Psychology of Religion and Spirituality, 6(1), 1-8. doi:10.1037/a0035200

Schafer, R. M., Handal, P. J., Brawer, P. A., \& Ubinger, M. (2011). Training and education in religion/spirituality within APA-accredited clinical psychology programs: 8 years later. Journal of Religion and Health, 50, 232-239. doi:10.1007/s10943-009-9272-8

Shafranske, E. P., \& Malony, H. N. (1990). Clinician psychologists' religious and spiritual orientations and their practice of psychotherapy. Psychotherapy, 27, 72-78. doi: $10.1037 / 0033-3204.27 .1 .72$

Soheilian, S. S., Inman, A. G., Klinger, R. S., Isenberg, D. S., \& Kulp, L. E. (2014). Multicultural supervision: Supervisees' reflections on culturally competent supervision. Counselling Psychology Quarterly, 27(4), 379-392. doi:10.1080/09515070.2014.961408

Souza, K. Z. (2002). Spirituality in counseling: What do counseling students think about it? Counseling \& Values, 46(3), 213. doi: 10.1002/j.2161-007x.2002.tb00214.x

Sperry, L. (2014). Effective spiritually oriented psychotherapy practice is culturally sensitive practice. Spirituality in Clinical Practice, 1(4), 245-247. doi:10.1037/scp0000048 
Tan, S. (2009). Developing integration skills: The role of clinical supervision. Journal of Psychology \& Theology, 37(1), 54-61.

Tinsley, H. E. A., \& Tinsley, D. J. (1987). Uses of factor analysis in counseling psychology research. Journal of Counseling Psychology. 34. 414-424. doi: 10.1037/00220167.34.4.414

Ulmer, G. J. (2012). The association of religion data archives: Quality data on religion. Retrieved May 10, 2017, from http://www.thearda.com/

van Asselt, K., \& Senstock, T. (2009). Influence of counselor spirituality and training on treatment focus and self-perceived competence. Journal of Counseling \& Development, 87(4), 412-418. doi:10.1002/j.1556-6678.2009.tb00125.x

Walker, D. F., Gorsuch, R. L., \& Tan, S. (2004). Therapists' integration of religion and spirituality in counseling: A meta-analysis. Counseling and Values, 49(1), 69. doi: 10.1002/j.2161-007X.2004.tb00254.X

Weinstein, C. (2006). An exploration of trainees' multicultural counseling competence, supervisory working alliance, and discussing spiritual issues in supervision (Order No. 3243430). Available from ProQuest Dissertations \& Theses Full Text. (305303161). Retrieved from https://search.proquest.com/docview/305303161?accountid=2837

Worthington, E. L. Jr., Hook, J. N., Davis, D. E., \& McDaniel, M. A. (2011). Religion and spirituality. Journal of Clinical Psychology, 67(2), 204-214. doi:10.1002/jclp.20760

Worthington, E. R., \& Sandage, S. J. (2001). Religion and spirituality. Psychotherapy: Theory, Research, Practice, Training, 38(4), 473-478. doi:10.1037/0033-3204.38.4.473

Wulff, D. M. (1996). The psychology of religion: An overview. In Religion and the Clinical Practice of Psychology (1st ed., pp. 43-70). American Psychological Association. 
Young, J., Wiggins-Frame, M., \& Cashwell, C. S. (2007). Spirituality and counselor competence: A national survey of American counseling association members. Journal of Counseling \& Development, 85(1), 47-52. doi: 10.1002/j.1556-6678.2007.tb00443.x 


\title{
Appendix A: Informed Consent
}

\section{WestVirginiaUniversity.}

Human Research Protocol

Only Minimal Risk Consent Form

Without HIPAA

\author{
Only Minimal Risk \\ Consent Information Form (without HIPAA) \\ Principal Investigator \\ Brittany J. Shannon \\ Department \\ Department of Counseling, Rehabilitation Counseling, and \\ Counseling Psychology \\ Protocol Number \\ Study Title \\ Co-Investigator(s) \\ Click here to enter text. \\ Spiritual Issues in Supervision Scale Applied to Supervisors \\ Christine Schimmel Ed.D.
}

\section{Contact Persons}

In the event you experience any side effects or injury related to this research, you should contact Dr. Christine Schimmel at (304) 293-2266. If you have any questions, concerns, or complaints about this research, you can contact Dr. Christine Schimmel (304) 293-2266 or Brittany Shannon at (513) 255-7486.

For information regarding your rights as a research subject, to discuss problems, concerns, or suggestions related to the research, to obtain information or offer input about the research, contact the Office of Research Integrity and Compliance at (304) 293-7073.

In addition, if you would like to discuss problems, concerns, have suggestions related to research, or would like to offer input about the research, contact the Office of Research Integrity and Compliance at 304-293-7073.

\section{Introduction}

This study is being conducted by Brittany Shannon M.S. and supervised by Christine Schimmel, Ed.D., in the Department of Counseling, Rehabilitation Counseling, and Counseling Psychology at West Virginia University.

\section{Purpose(s) of the Study}

The purpose of this study is to determine how religion and spirituality are being addressed in supervision and if supervisors feel competent to engage in the teaching process of their supervisees to foster competent clinicians. In addition, this study will provide empirical support for clinicians' feelings of competence to implement religious and spiritual discussions into session. Finally, this study will expand the literature further by breaching a gap between theory and assessment through providing an assessment measure with a theoretical model of addressing religion and spirituality in supervision.

\section{Description of Procedures}

This study involves answering several demographic questions about yourself, and then answering a longer survey. It will take approximately 15-20 minutes for you to complete. You will be asked to fill out a questionnaire regarding your feelings of competence to work with a client's 
spiritual beliefs in session, in addition you will be asked to reflect on your supervision experience and identify how spirituality is addressed within the context of your supervision/supervisory experience. You do not have to answer all the questions.

\section{Discomforts}

There are no known or expected risks from participating in this study.

\section{Benefits}

You may choose to provide your email address to receive 1 of $20, \$ 5$ Starbucks $^{\mathrm{TM}}$ gift cards. Should you choose to provide your email it will not be linked in any way to your questionnaire responses.

\section{Financial Considerations}

There are no special fees for participating in this study.

\section{Confidentiality}

Any information about you that is obtained as a result of your participation in this research will be kept as confidential as legally possible. Your research records and test results, just like hospital records, may be subpoenaed by court order or may be inspected by the study sponsor or federal regulatory authorities (including the FDA if applicable) without your additional consent.

In addition, there are certain instances where the researcher is legally required to give information to the appropriate authorities. These would include mandatory reporting of infectious diseases, mandatory reporting of information about behavior that is imminently dangerous to your child or to others, such as suicide, child abuse, etc.

In any publications that result from this research, neither your name nor any information from which you might be identified will be published without your consent.

\section{Voluntary Participation}

Participation in this study is voluntary. You are free to withdraw your consent to participate in this study at any time by simply closing the window.

Refusal to participate or withdrawal will result in no penalty to you.

I willingly agree to be in the study.
$\circ$ Yes
○ No 
Appendix B: Participant Invitation Request

(email sent to Training Directors of APA accredited clinical and counseling psychology programs as well as Training Directors of APPIC accredited internship sites):

Dear (Training Director Name),

This letter is a request for you to forward this research project opportunity to your clinical supervisors and students. This project is exploring the role of spirituality in supervision and variables related to competence and clinical work. This dissertation is being conducted by Brittany Shannon, M.S., a doctoral candidate in counseling psychology in the College of Education and Human Services at West Virginia University along with Dr. Christine Schimmel Ed.D, Assistant Department Chairperson, Associate Professor and Coordinator of the School Counseling Program. Your participation in this project is greatly appreciated and will take approximately 20-25 minutes to fill out the attached questionnaire.

You will have the opportunity to enter to win one of twenty $\$ 5$ gift cards to Starbucks ${ }^{\mathrm{TM}}$ as a thank you for your participation! We ask that you complete the survey by September $30^{\text {th }}$. To enter to win a gift card, just click the link provided on the last page of the survey and provide your email. Please note, for your privacy, email addresses are not linked with survey results.

Your involvement in this project will be kept as private as legally possible. All data will be reported in the aggregate. You must be 18 years of age or older and either a student enrolled in an APA accredited clinical or counseling doctoral program OR a doctoral level supervisor. We will not ask any information that should lead back to your identity as a participant. Your participation is completely voluntary. You may skip any question that you do not wish to answer, and you may discontinue at any time. West Virginia University's Institutional Review Board acknowledgement of this project is on file.

We hope that you will participate in this research project, as it will be beneficial in understanding relevant components of clinical training and professional development during graduate school. Thank you very much for your time. Should you have any questions about this letter or the research project, please feel free to contact Brittany Shannon at bjcatania@mix.wvu.edu.

If you are willing to participate in this study, please click here:

http://wvu.qualtrics.com/jfe/form/SV 8jqkPtrjw5peYvj

Sincerely,

Brittany Shannon M.S. 


\section{Appendix C: Debriefing Form}

Thank you for your participation in this study! Your responses to the survey questions are greatly appreciated.

If you would like to be redirected to an external link for the opportunity to enter a drawing for one of twenty, five-dollar, electronic Starbucks ${ }^{\mathrm{TM}}$ gift cards, please click here.

\section{Anonymity and Confidentiality:}

If you choose to enter the drawing for one of several small, Starbucks ${ }^{\mathrm{TM}}$ gift cards, please be aware that your name and email address as having completed the study will be provided to the researcher. While your name and email address will not be directly associated with your answers, complete anonymity is not possible due to entering the drawing; instead your answers still remain strictly confidential and will be secured stored.

If you choose not to enter the drawing from one of several small, Starbucks ${ }^{\text {TM }}$ gift cards, your responses are completely anonymous as no identifying information has been requested from you. In addition, the secure survey software (Qualtrics) that collected your responses has been programmed to anonymize all data by removing respondents' IP addresses.

In order to maintain the quality of this study, please do not disclose research procedures to anyone who might participate in this study in the future as this could bias the results.

\section{Final Report:}

If you would like to receive a copy of a summary of the findings of this study when it is completed, please feel free to contact me at bjcatania@mix.wvu.edu. 


\section{Appendix D: Demographic Information Questionnaire}

\section{(Supervisors)}

1. Please enter your age in years below. (You must be 18 years of age to participate)

2. Which of the following describes your gender identity?

- Woman

- Man

- Gender fluid/gender non-conforming

- Transgender (Female $\rightarrow$ Male)

- Transgender (Male $\rightarrow$ Female)

- Other

3. Which of the following describes your ethnicity?

- Native American or Alaska Native

- Asian

- African-American (Black)

- Multiracial

- Latino/a

- European-American (Caucasian)

- Other

4. What type of program did you graduate from?

- Clinical psychology, public school

- Clinical psychology, private school

- Counseling psychology, public school

- Counseling psychology, private school

- Other

5. Was your program accredited by the American Psychological Association (APA)?

- Yes

- No

6. How long have you been practicing post doctorate?

- Less than 1 year

- 1-3 years

- 4-6 years

- 7-9 years

- 10-12 years

- 13-15 years

- 15 or more years

7. In general, how would you describe your primary theoretical orientation?

- Behavioral 
- Biological

- Cognitive

- Cognitive/Behavioral

- Developmental

- Family

- Humanistic/Existential

- Integrative

- Interpersonal

- Psychodynamic/Psychoanalytic

- Systems

- Other

Please choose ONE supervisee you have had in your current practice.

8. In general, how would you describe your supervisee's primary theoretical orientation?

- Behavioral

- Biological

- Cognitive

- Cognitive/Behavioral

- Developmental

- Family

- Humanistic/Existential

- Integrative

- Interpersonal

- Psychodynamic/Psychoanalytic

- Systems

- Other

9. Including your current supervisee, approximately how many supervisees have you had during your post-doctoral clinical work?

- 1

- 2

- 3

- 4

- 5

- 6

- 7

- 8

- 9

- $10+$

10. In general, do you consider yourself a spiritually minded person?

- Yes

- No 
11. Using the following continuum, indicate the percentage of time you attend to spirituality and/or spiritual issues in therapy:

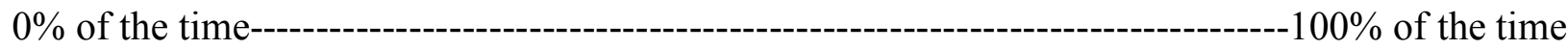

12. Using the following continuum, indicate the percentage of time you attend to spirituality and/or spiritual issues in supervision:

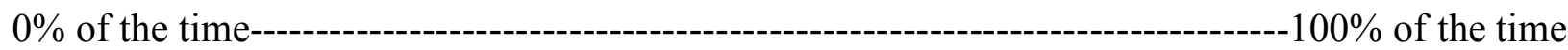

13. Do you actively participate in a religious organization?

- Yes

- No

14. Describe your current level of religiousness

- Not religious

- Not very religious

- Somewhat religious

- Very religious

15. What religious denomination do you identify with?

- None

- Agnostic

- Other

- Catholic

- Jewish

- Baptist

- Methodist

- Lutheran

- Presbyterian

- Protestant

- Mormon

- Islam

- Buddhism

- Hinduism

- Atheist

16. Did your personal spiritual and religious beliefs play a role in your choice to become a clinician?

- Yes

- No

17. Do you feel you were prepared by your graduate program to include spiritual and religious issues in counseling?

- Yes 
- No

- If yes, how did your graduate program expose you to spiritual and religious issues?

- Spirituality/religion were components of a class(s)

- My program offered a spirituality/religion in counseling class

o Other

- If no, how should your graduate program address spiritual and religious issues?

- They should be addressed as part of a class

- They should have a class devoted solely to these issues

- They do not need to address these issues

o Other:

18. At this time, would you be comfortable addressing spiritual and religious material in counseling?

- Yes

- No

19. Are you familiar with ASERVIC's Spiritual Competencies?

- Yes

- No 


\section{Appendix E: Demographic Information Questionnaire}

\section{(Students)}

1. Please enter your age in years below. (You must be 18 years of age to participate)

2. Which of the following describes your gender identity?

- Woman

- Man

- Gender fluid/gender non-conforming

- Transgender (Female $\rightarrow$ Male)

- Transgender (Male $\rightarrow$ Female)

- Other

3. Which of the following describes your ethnicity?

- Native American or Alaska Native

- Asian

- African-American (Black)

- Multiracial

- Latino/a

- European-American (Caucasian)

- Other

4. What type of American Psychological Association (APA) accredited program will you graduate from?

- Clinical psychology, public school

- Clinical psychology, private school

- Counseling psychology, public school

- Counseling psychology, private school

- Other

5. In general, how would you describe your primary theoretical orientation?

- Behavioral

- Biological

- Cognitive

- Cognitive/Behavioral

- Developmental

- Family

- Humanistic/Existential

- Integrative

- Interpersonal

- Psychodynamic/Psychoanalytic

- Systems

- Other 
Please choose ONE supervisor you have had in your doctoral practice.

6. In general, how would you describe your supervisor's primary theoretical orientation?

- Behavioral

- Biological

- Cognitive

- Cognitive/Behavioral

- Developmental

- Family

- Humanistic/Existential

- Integrative

- Interpersonal

- Psychodynamic/Psychoanalytic

- Systems

- Other

7. Counting your current supervisor, approximately how many supervisors have you had during your doctoral clinical work?

- 1

- 2

- 3

- 4

- 5

- 6

- 7

- 8

- 9

- $10+$

8. In general, do you consider yourself a spiritually minded person?

- Yes

- No

9. Using the following continuum, indicate the percentage of time you attend to spirituality and/or spiritual issues in therapy:

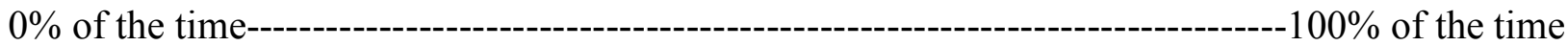

10. Using the following continuum, indicate the percentage of time you attend to spirituality and/or spiritual issues in supervision:

0\% of the time----

11. Do you actively participate in a religious organization? 
- Yes

- No

12. Describe your current level of religiousness

- Not religious

- Not very religious

- Somewhat religious

- Very religious

13. What religious denomination do you identify with?

- None

- Agnostic

- Other

- Catholic

- Jewish

- Baptist

- Methodist

- Lutheran

- Presbyterian

- Protestant

- Mormon

- Islam

- Buddhism

- Hinduism

- Atheist

14. Did your personal spiritual and religious beliefs play a role in your choice to become a clinician?

- Yes

- No

15. Do you feel you have been prepared by your graduate program to include spiritual and religious issues in counseling?

- Yes

- No

- How did your graduate program expose you to spiritual and religious issues?

- Spirituality/religion were components of a class(s)

○ My program offered a spirituality/religion in counseling class

o Other:

- How should your graduate program address spiritual and religious issues?

- They should be addressed as part of a class(s)

- They should have a class devoted solely to these issues

- They do not need to address these issues

o Other: 
16. At this time, would you be comfortable addressing spiritual and religious material in counseling?

- Yes

- No

17. Are you familiar with ASERVIC's Spiritual Competencies?

- Yes

- No 


\title{
Appendix F: IRB Approval
}

\section{W. West VirginiaUniversity. \\ Office of Research Integrity and Compliance \\ 886 CHESNUT RIDGE ROAD MORGANTOWN, WV 26506 \\ Acknowledgement Letter Exempt Initial Protocol Review}

\author{
Action Date \\ 06/07/2017 \\ To \\ Christine Schimmel \\ From \\ WVU Office of Research Integrity and Compliance \\ Approval Date \\ 06/07/2017 \\ Expiration Date \\ $06 / 06 / 2020$ \\ Subject \\ Acknowledgement Letter Exempt Initial Protocol Review \\ Protocol Number \\ 1705592127 \\ Title \\ Increasing Perceived Clinician Competence to Work with Spiritual Issues Through \\ Competent Supervision
}

The above-referenced study was reviewed by the West Virginia University Institutional Review Board IRB and was granted exemption in accordance with 45 CFR 46.101.

- This research study was granted an exemption because the Research involves educational tests, survey procedures, interview procedures or observation of public behavior and (i) information obtained is recorded in such a manner that human subjects cannot be identified, directly or through identifiers linked to the subjects; and (ii) any disclosure of the human subjects responses outside the research could not reasonably place the subjects at risk of criminal or civil liability or be damaging to the subjects financial standing, employability, or reputation [45 CFR 46.101(2)]. All exemptions are only good for three years. If this research extends more than three years beyond the approved date, then the researcher will have to request another exemption. The following documents have been acknowledged for use in this study and are available in the WVU+kc system:

Documents reviewed and/or approved as part of this submission:

Informational Cover Letter:Advertisement for Survey.pdf: 2017-05-23-04:00

Facebook Advertisement.pdf: 2017-05-31-04:00

Survey Questions Final.pdf: 2017-05-31-04:00 
Documents for use in this study have been acknowledged and are available in the WVUkc system in the Notes and Attachments section of your protocol.

The Office of Research Integrity and Compliance is here to provide assistance to you from the initial submission of an IRB protocol and all subsequent activity. Please feel free to contact us by phone at 304.293.7073 with any question you may have. Thank you.

WVU Office of Research Integrity and Compliance

Date:06/07/2017

Signed:

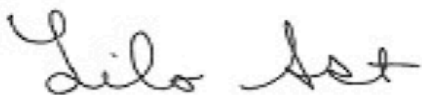

Lilo Ast

Senior Program Coordinator 


\section{Appendix G: Permission to Use the Spiritual Competency Scale}

November 14, 2016

Brittany Shannon

West Virginia University

Dear Ms. Shannon,

Thank you for your interest in the Spiritual Competency Scale (SCS). I hereby offer this letter including a formal request for permission to administer the SCS as a component of your study.

Note that there are presently 2 versions of this instrument:

1. (SCS; 2009) Hardcopy (pencil \& paper): full (90 item) version; I can also provide you with the 90-item version that includes 7 items from a brief Marlowe-Crowne SD scale that I used in my original study (i.e., dissertation).

2. (SCS-R-II; 2011) Hardcopy: The latest version, which was developed from a factor analytical study of ASERVIC members' responses (i.e., this more recent group was more "spiritually competent" than the original group). Many of the same items loaded as in former studies (See: Robertson, L. A. (2008). The spiritual competency scale: A comparison to the ASERVIC Spiritual Competencies, University of Central Florida: Electronic Thesis \& Dissertations, (CFE0002422); Robertson, L. A. (2010). The spiritual competency scale. Counseling \& Values, 55, 6-24; Robertson, L. A., \& Young, M. E. (2011). The revised ASERVIC spiritual competencies. In C. S. Cashwell \& J. S. Young's (Eds.) Integrating Spirituality and religion into counseling (2nd ed., pp. 25-42). Alexandria, VA: American Counseling Association). However, a few items were replaced, and the final instrument included 21 items. (See Daily, S. F., Robertson, L. A., \& Gill, C. S. (2015). Spiritual competency scale: Further analysis. Measurement \& Evaluation in Counseling. 48:15-29.)

This latest study also produced empirically supported cut off scores for both the 90-item version (SCS) and the 21-item factored version (SCS-R-II). This is important because the cut off scores for the original student group study were arbitrarily vs. empirically assigned (i.e., there was no data in existence at the time of the original study to determine the scores that would be expected of a spiritually competent counselor). The cut off scores for all versions are noted below.

There is currently no charge for using any of the hardcopy versions; beginning in 2017 , the fee will be $\$ 50$ to reproduce the number of copies required for the project described in the Statement of Agreement (see below).

Please send a formal letter explaining your study to the extent that you have developed it at the time of your request. The letter should also include a request for the version you are interested in and a signed copy of the Statement of Agreement for using the SCS (see last page of this document). I will send you the version that you request upon receipt of your letter. 
The basic criteria for using any of these versions are as follows:

1. You are permitted to produce a copy for each anticipated participant in your sample.

2. Please maintain the copyright notation and my name (as shown at the top of the SCS or the SCS-R-II in the Word documents) on each of your questionnaires, including in any published / printed / electronic versions.

To further protect the copyright, please do NOT include a copy of the instrument in any publication of your study.

3. Please do not alter the instrument without permission. In particular, please note that the response/scoring protocols are unique - that is, neither the SCS nor the SCS-R-II includes a traditional Likert scale. Therefore, to maintain continuity relevant to the development of this instrument, please use the response format as it is shown in the hardcopy. Note that reproduction of this response format has historically presented challenges for several online survey programs. If you are able to successfully create the response format in a publicly available online survey program, please let me know so I can share this information with future researchers.

4. Please do not distribute any version of the SCS to other researchers/individuals who have not obtained permission for its use. I request that any version you place online have an expiration date that corresponds to the time frame of your research (i.e., please do not leave it online indefinitely). Please include the projected time frame of your study in your letter of request.

5. Please send me a copy of your results at the conclusion of your study.

Scoring:

SCS (90-item) and SCS-R-II (21-item):

Low Agreement: 4

Low Disagreement: 3
Mid-range Agreement: 5 High Agreement: 6

Mid-range Disagreement: 2 High Disagreement: 1

Additionally, the 90-item SCS (i.e., \#6, 7, 30, 31, 34, 46, 47, 66, 69, and 83). Points are to be assigned to these items as follows:

Low Agreement: 3

Low Disagreement: 4

Low Agreement: 4

Low Disagreement: 3
Mid-range Agreement: 2 High Agreement: 1

Mid-range Disagreement: 5 High Disagreement: 6

Mid-range Agreement: 5 High Agreement: 6

Mid-range Disagreement: 2 High Disagreement: 1

There are no items requiring reverse scoring on the SCS-R-II versions.

For all versions: sum the item scores to obtain the total score. Spiritual competency is indicated by a total score of 105 for the SCS-R-II and 450 for the SCS.

If your project and/or use of the SCS changes, please advise. Feel free to contact me if you have questions about the SCS during the course of your project. Best wishes! I look forward to hearing from you. 
Sincerely,

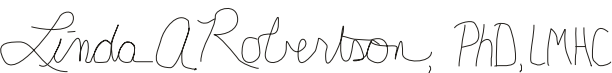

Linda A Robertson, $\mathrm{PhD}$

870 Clark Street, Suite 1030

Oviedo, Florida 32876

407-583-7979 
Appendix H: Spiritual Competency Scale

SCS-R-II

Copyright $(2011 *$ L. A. Robertson

\begin{tabular}{|c|c|c|c|c|c|c|c|}
\hline \multicolumn{8}{|c|}{$\begin{array}{l}\text { INSTRUCTIONS: Please familiarize yourself with the unique response format before you } \\
\text { begin. } \\
\text { Indicate your level of agreement or disagreement with the following by selecting } \underline{O N E} \\
\text { response for each item. }\end{array}$} \\
\hline Begin Here & \multicolumn{3}{|c|}{ Agreement } & & \multicolumn{3}{|c|}{ Disagreement } \\
\hline $\begin{array}{l}\text { EXAMPLE: } \\
\quad \text { I am ready to begin this questionnaire. (High } \\
\text { Agreement) }\end{array}$ & $\square$ & $\square$ & $\mathbf{X}$ & & $\square$ & $\square$ & $\square$ \\
\hline $\begin{array}{l}\text { 1. Counselors who have not examined their } \\
\text { spiritual/religious values risk imposing those values } \\
\text { on their clients. }\end{array}$ & $\square$ & $\square$ & $\square$ & & $\square$ & $\square$ & $\square$ \\
\hline 2. Religious beliefs should be assessed at intake. & $\square$ & $\square$ & $\square$ & & $\square$ & $\square$ & $\square$ \\
\hline $\begin{array}{l}\text { 3. Coping strategies are influenced by religious } \\
\text { beliefs. }\end{array}$ & $\square$ & $\square$ & $\square$ & & $\square$ & $\square$ & $\square$ \\
\hline $\begin{array}{l}\text { 4. A counselor's task is to be in tune to } \\
\text { spiritual/religious expressions in client } \\
\text { communication. }\end{array}$ & $\square$ & $\square$ & $\square$ & & $\square$ & $\square$ & $\square$ \\
\hline $\begin{array}{l}\text { 5. Sacred scripture readings are appropriate } \\
\text { homework assignments. }\end{array}$ & $\square$ & $\square$ & $\square$ & & $\square$ & $\square$ & $\square$ \\
\hline $\begin{array}{l}\text { 6. It is essential to know models of human } \\
\text { development before working with a client's } \\
\text { spiritual/religious beliefs. }\end{array}$ & $\square$ & $\square$ & $\square$ & & $\square$ & $\square$ & $\square$ \\
\hline 7. Cultural practices are influenced by spirituality. & $\square$ & $\square$ & $\square$ & & $\square$ & $\square$ & $\square$ \\
\hline $\begin{array}{l}\text { 8. A client's perception of God or a higher power } \\
\text { can be a resource in counseling. }\end{array}$ & $\square$ & $\square$ & $\square$ & & $\square$ & $\square$ & $\square$ \\
\hline $\begin{array}{l}\text { 9. Counselors are called by the profession to } \\
\text { examine their own spiritual/religious beliefs. }\end{array}$ & $\square$ & $\square$ & $\square$ & & $\square$ & $\square$ & $\square$ \\
\hline $\begin{array}{l}\text { 10. It is essential to determine a client's spiritual } \\
\text { functioning during an intake assessment. }\end{array}$ & $\square$ & $\square$ & $\square$ & & $\square$ & $\square$ & $\square$ \\
\hline $\begin{array}{l}\text { 11. Spiritual/religious beliefs impact a client's } \\
\text { worldview. }\end{array}$ & $\square$ & $\square$ & $\square$ & & $\square$ & $\square$ & $\square$ \\
\hline
\end{tabular}




\begin{tabular}{|c|c|c|c|c|c|c|c|}
\hline $\begin{array}{l}\text { 12. Understanding human development helps a } \\
\text { counselor work with spiritual material. }\end{array}$ & $\square$ & $\square$ & $\square$ & & $\square$ & $\square$ & $\square$ \\
\hline $\begin{array}{l}\text { 13. Including religious figures in guided imagery is } \\
\text { an appropriate counseling technique. }\end{array}$ & $\square$ & $\square$ & $\square$ & & $\square$ & $\square$ & $\square$ \\
\hline $\begin{array}{l}\text { 14. Spiritual/religious terms are often infused in } \\
\text { clients' disclosures. }\end{array}$ & $\square$ & $\square$ & $\square$ & & $\square$ & $\square$ & $\square$ \\
\hline $\begin{array}{l}\text { 15. Counselors who can describe their own spiritual } \\
\text { development are better prepared to work with } \\
\text { clients. }\end{array}$ & $\square$ & $\square$ & $\square$ & & $\square$ & $\square$ & $\square$ \\
\hline $\begin{array}{l}\text { 16. Addressing a client's spiritual or religious } \\
\text { beliefs can help with therapeutic goal attainment. }\end{array}$ & $\square$ & $\square$ & $\square$ & & $\square$ & $\square$ & $\square$ \\
\hline $\begin{array}{l}\text { 17. A client's worldview is affected by religious } \\
\text { beliefs. }\end{array}$ & $\square$ & $\square$ & $\square$ & & $\square$ & $\square$ & $\square$ \\
\hline 18. Prayer is a therapeutic intervention. & $\square$ & $\square$ & $\square$ & & $\square$ & $\square$ & $\square$ \\
\hline $\begin{array}{l}\text { 19. There is a relationship between human } \\
\text { development and spiritual development. }\end{array}$ & $\square$ & $\square$ & $\square$ & & $\square$ & $\square$ & $\square$ \\
\hline $\begin{array}{l}\text { 20. Inquiry into spiritual/religious beliefs is part of } \\
\text { the intake process. }\end{array}$ & $\square$ & $\square$ & $\square$ & & $\square$ & $\square$ & $\square$ \\
\hline $\begin{array}{l}\text { 21. If counselors do not explore their own spiritual } \\
\text { beliefs, they risk damaging the therapeutic alliance. }\end{array}$ & $\square$ & $\square$ & $\square$ & & $\square$ & $\square$ & $\square$ \\
\hline
\end{tabular}




\section{Appendix I: Spiritual Issues in Supervision Scale}

\section{(Supervisors)}

Please consider your experience of one academic year of supervision ( $2+$ consecutive semesters) with one supervisee.

Below are several circumstances in which spirituality could be addressed in supervision. This measure examines your perceptions of the supervision experience with a particular supervisee.

Spirituality is defined in the broadest sense as an overarching construct that includes a personal journey of transcendent beliefs and a sense of connection with other people, experienced either within or outside of formal religious structures.

According to the following scale, please indicate whether or not the following topics are addressed during supervision (Yes/No) and for those topics that have been discussed (Yes), please rate how often spirituality is addressed when these issues have arisen in supervision.

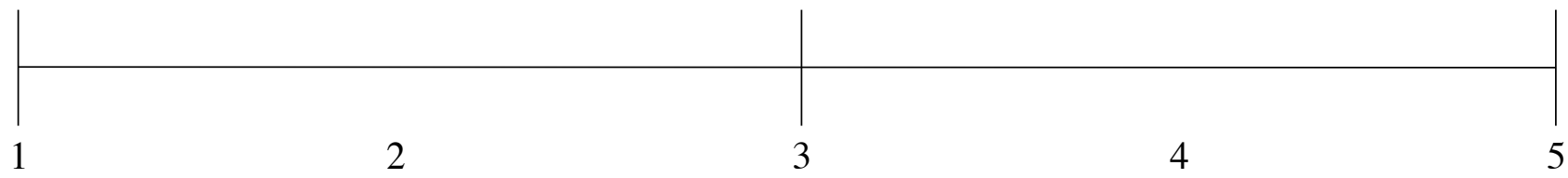

Spiritual issues

are never

addressed
Spiritual issues

are occasionally

addressed
Spiritual issues are frequently addressed

\begin{tabular}{|c|c|c|c|c|c|c|c|}
\hline \multirow{2}{*}{$\begin{array}{l}\text { Is spirituality } \\
\text { addressed... }\end{array}$} & Yes/No & \multirow{2}{*}{$\begin{array}{c}\text { If Yes How } \\
\text { much... }\end{array}$} & & & & & \\
\hline & & & $\begin{array}{l}1 \\
\text { Spiritual } \\
\text { issues are } \\
\text { never } \\
\text { addressed }\end{array}$ & 2 & \begin{tabular}{l}
\multicolumn{1}{c}{3} \\
Spiritual \\
issues are \\
occasionally \\
addressed
\end{tabular} & 4 & $\begin{array}{l}\quad 5 \\
\text { Spiritual } \\
\text { issues are } \\
\text { frequently } \\
\text { addressed }\end{array}$ \\
\hline \multirow{2}{*}{$\begin{array}{l}\text { When the assessment } \\
\text { process is discussed? }\end{array}$} & \multirow[t]{2}{*}{$\mathrm{Y} \quad \mathrm{N}$} & & & & t & & \\
\hline & & & 1 & 2 & 3 & 4 & 5 \\
\hline \multirow{2}{*}{$\begin{array}{l}\text { In the area of grief, } \\
\text { loss, and death }\end{array}$} & \multirow[t]{2}{*}{ Y N } & & & & | & & \\
\hline & & & 1 & 2 & 3 & 4 & 5 \\
\hline \multirow{2}{*}{$\begin{array}{l}\text { With issues } \\
\text { concerning marriage }\end{array}$} & \multirow[t]{2}{*}{$\mathrm{Y} \quad \mathrm{N}$} & & & & & & \\
\hline & & & 1 & 2 & 3 & 4 & 5 \\
\hline \multirow{2}{*}{$\begin{array}{l}\text { With issues } \\
\text { concerning divorce }\end{array}$} & \multirow[t]{2}{*}{$\mathrm{Y} \quad \mathrm{N}$} & & & & & & \\
\hline & & & 1 & 2 & 3 & 4 & 5 \\
\hline
\end{tabular}




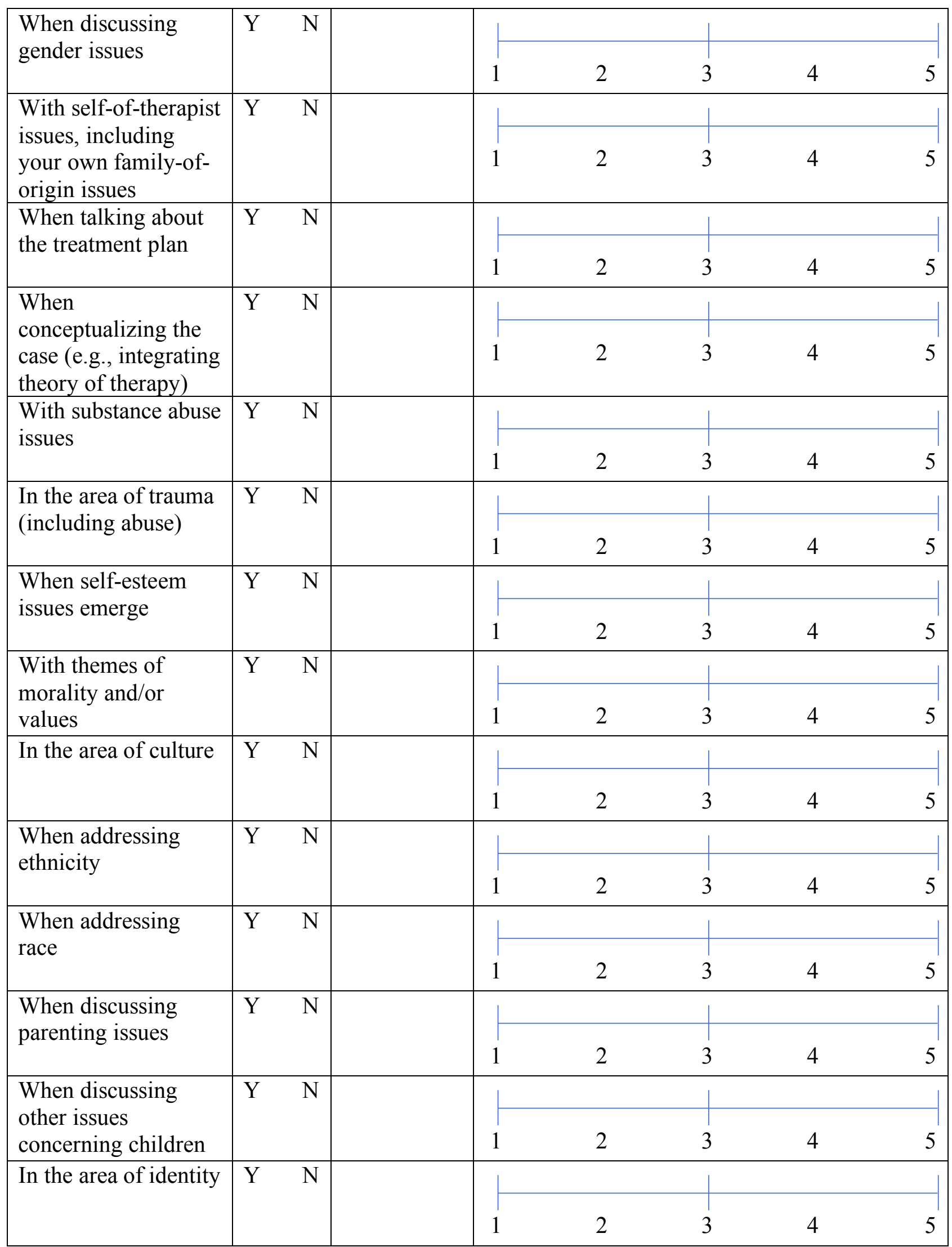




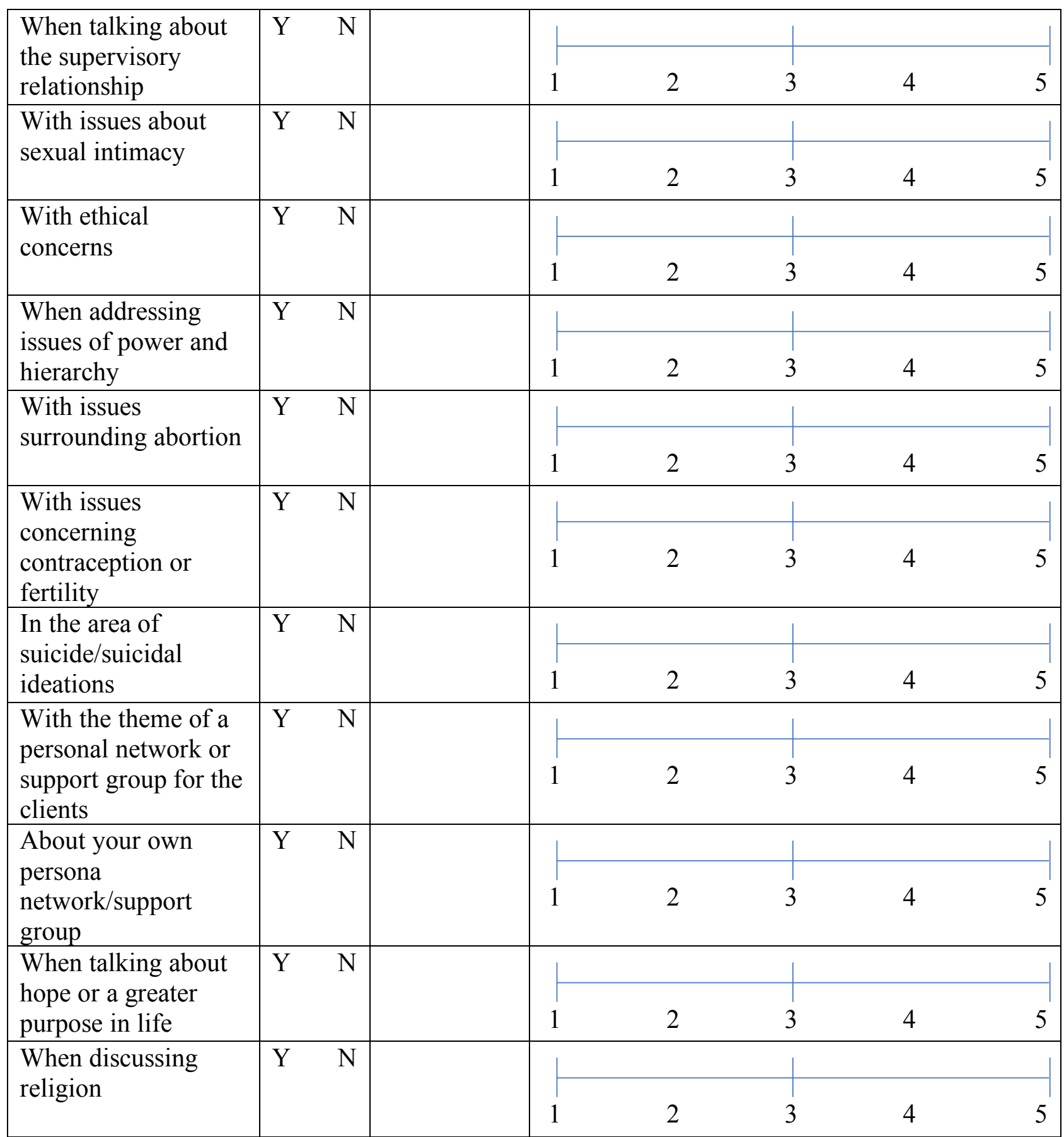




\section{Appendix J: Spiritual Issues in Supervision Scale}

\section{(Students)}

Please consider your experience of one academic year of supervision ( $2+$ consecutive semesters) with one supervisor.

Below are several circumstances in which spirituality could be addressed in supervision. This measure examines your perceptions of the supervision experience with a particular supervisor.

Spirituality is defined in the broadest sense as an overarching construct that includes a personal journey of transcendent beliefs and a sense of connection with other people, experienced either within or outside of formal religious structures.

According to the following scale, please indicate whether or not the following topics are addressed during supervision (Yes/No) and for those topics that have been discussed (Yes), please rate how often spirituality is addressed when these issues have arisen in supervision.

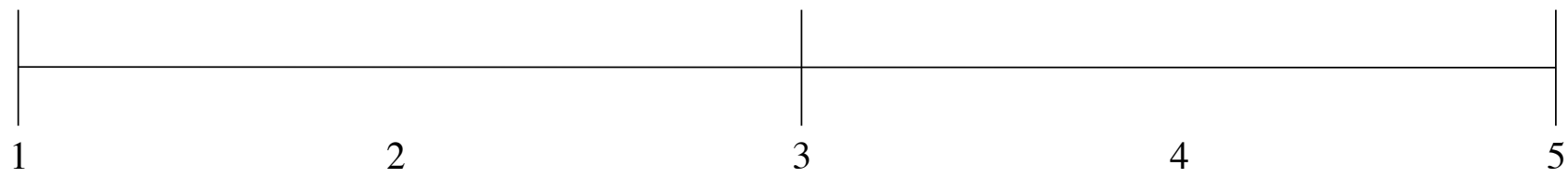

Spiritual issues

are never

addressed
Spiritual issues

are occasionally

addressed
Spiritual issues are frequently addressed

\begin{tabular}{|c|c|c|c|c|c|c|c|}
\hline \multirow{2}{*}{$\begin{array}{l}\text { Is spirituality } \\
\text { addressed... }\end{array}$} & Yes/No & \multirow{2}{*}{$\begin{array}{l}\text { If Yes How } \\
\text { much... }\end{array}$} & \multirow{2}{*}{$\begin{array}{l} \\
1 \\
\text { Spiritual } \\
\text { issues are } \\
\text { never } \\
\text { addressed }\end{array}$} & \multirow[b]{2}{*}{2} & & \multirow[b]{2}{*}{4} & \multirow[b]{2}{*}{$\begin{array}{l}\text { Spiritual } \\
\text { issues are } \\
\text { frequently } \\
\text { addressed }\end{array}$} \\
\hline & & & & & \begin{tabular}{l}
\multicolumn{1}{c}{3} \\
Spiritual \\
issues are \\
occasionally \\
addressed
\end{tabular} & & \\
\hline \multirow{2}{*}{$\begin{array}{l}\text { When the assessment } \\
\text { process is discussed? }\end{array}$} & $\mathrm{Y}$ & & | & & 1 & & \\
\hline & & & 1 & 2 & 3 & 4 & 5 \\
\hline \multirow{2}{*}{$\begin{array}{l}\text { In the area of grief, } \\
\text { loss, and death }\end{array}$} & $\mathrm{N}$ & & 1 & & 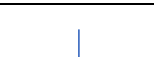 & & \\
\hline & & & 1 & 2 & 3 & 4 & 5 \\
\hline \multirow{2}{*}{$\begin{array}{l}\text { With issues } \\
\text { concerning marriage }\end{array}$} & $\mathrm{N}$ & & 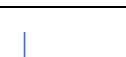 & & 1 & & \\
\hline & & & 1 & 2 & 3 & 4 & 5 \\
\hline \multirow{2}{*}{$\begin{array}{l}\text { With issues } \\
\text { concerning divorce }\end{array}$} & $\mathrm{Y} \quad \mathrm{N}$ & & & & 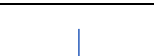 & & \\
\hline & & & 1 & 2 & 3 & 4 & 5 \\
\hline
\end{tabular}




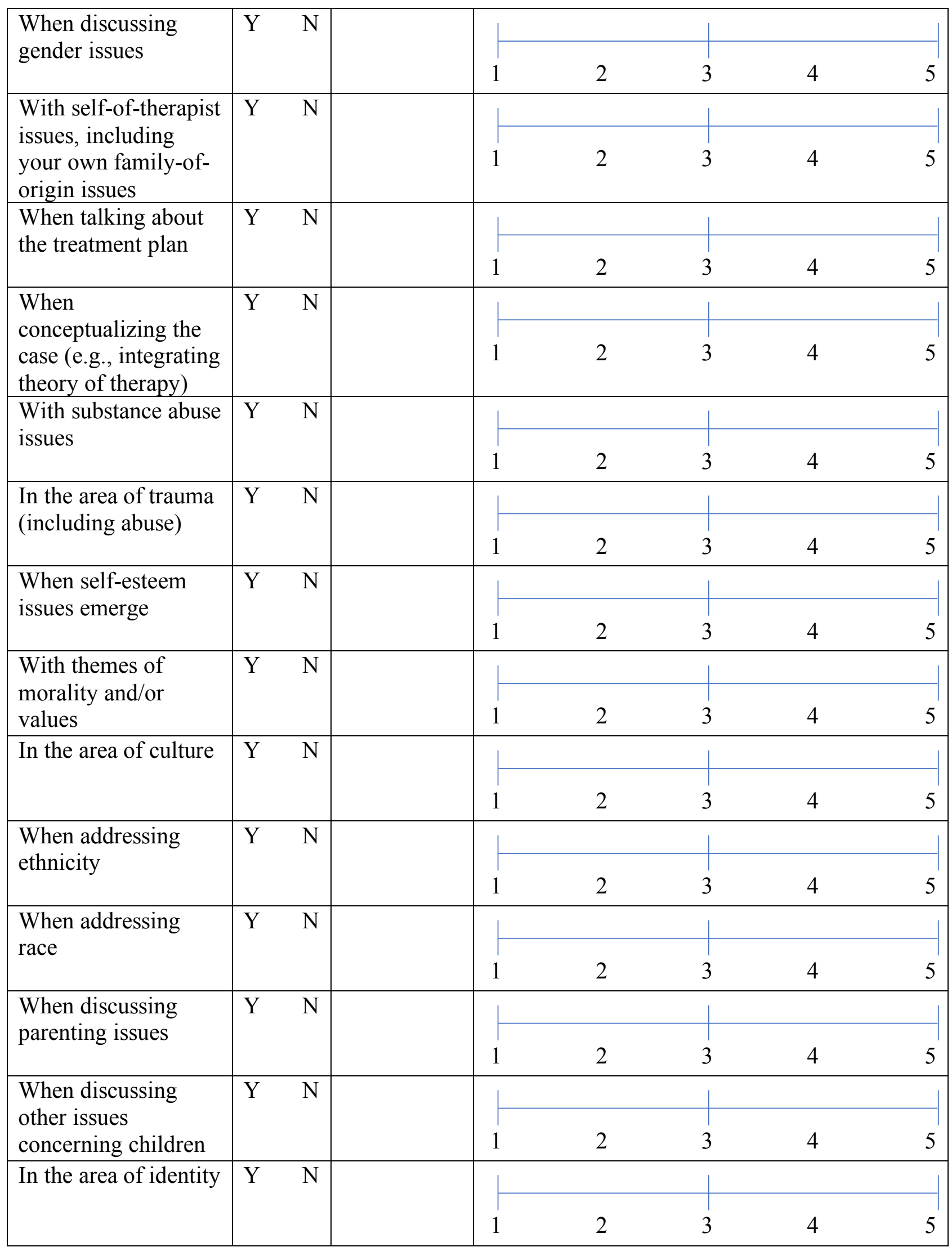




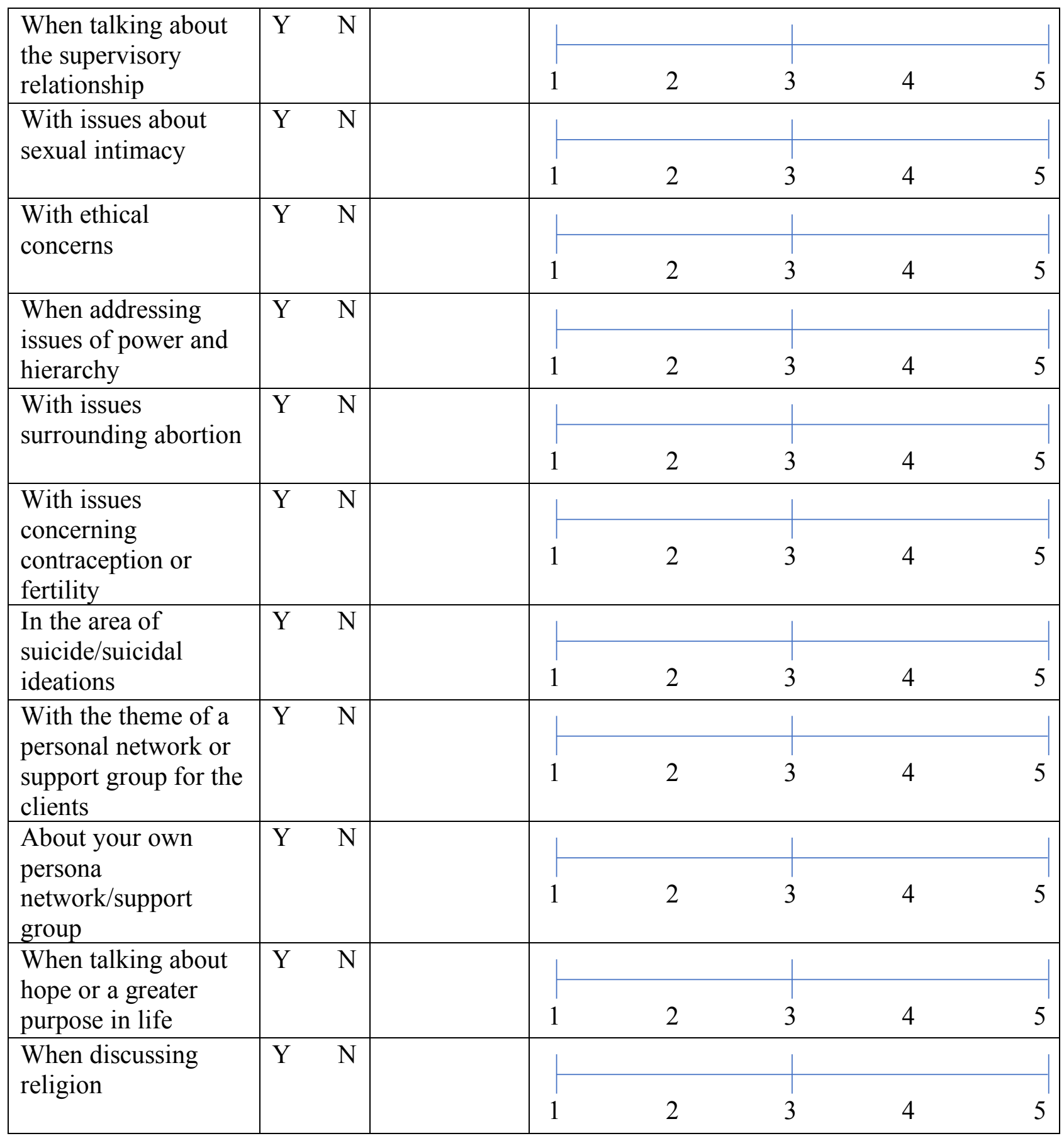




\section{Appendix K: 2 Week Participation Reminder}

Hello,

Approximately two weeks ago, I wrote asking for your support of and participation in a survey examining the role of religion and spirituality in supervision and how the implementation impacts perceived competence. Our hope is to survey as many students and clinical supervisors as possible.

Again, I appreciate that your time is limited and ask if you could send this invitation to students in your program, as well as your practicum supervisors? Please click on the following URL to be taken to the survey:

http://wvu.qualtrics.com/ife/form/SV 8jqkPtriw5peYvi

If you find that the above link does not work, you may copy and paste it to your browser. Thank you for your time and willingness to participate in this study.

Sincerely,

Brittany Shannon, M.S.

Doctoral Candidate

West Virginia University 


\section{Appendix L: 4 Week Participation Reminder}

Dear Dr. (Training Director Name),

Approximately four weeks ago, I wrote asking for your support of and participation in a survey examining the role of religion and spirituality in supervision and how the implementation impacts perceived competence. Our hope is to survey as many students and clinical supervisors as possible.

Again, I appreciate that your time is limited and ask if you could send this invitation to students in your program, as well as your practicum supervisors? Please click on the following URL to be taken to the survey:

\section{http://wvu.qualtrics.com/ife/form/SV 8jqkPtriw5peYvi}

If you find that the above link does not work, you may copy and paste it to your browser. This will be the final survey reminder and responses will be welcomed until (insert date of data collection completion).

Sincerely,

Brittany Shannon, M.S.

Doctoral Candidate

West Virginia University 


\section{Appendix M: Facebook Advertisement}

Are you a clinical/counseling doctoral student or a doctoral level supervisor?

Researchers are exploring the role of spirituality in supervision and variables related to competence and clinical work. This dissertation is being conducted by Brittany Shannon, M.S., a doctoral candidate in counseling psychology in the College of Education and Human Services at West Virginia University along with Dr. Christine Schimmel Ed.D, Assistant Department Chairperson, Associate Professor and Coordinator of the School Counseling Program. West Virginia University's Institutional Review Board acknowledgement of this project is on file. You must be 18 years of age or older and either a student enrolled in an APA accredited clinical or counseling doctoral program OR a doctoral level supervisor. You will have the opportunity to enter to win 1 of 20, \$5 gift cards to Starbucks ${ }^{\mathrm{TM}}$ as a thank you for your participation! Your participation in this project is greatly appreciated and will take approximately 20-25 minutes to fill out the attached questionnaire. If you are willing to participate in this study, please click here:

\section{http://wvu.qualtrics.com/jfe/form/SV 8jqkPtrjw5peYvi}


CURRICULUM VITAE

Brittany Catania Shannon

Mailing Address: 6172 Contreras rd. Oxford, $\mathrm{OH} 45056$

Telephone: 513-255-7486

Email: bjcatania@mix.wvu.edu

\section{Education}

West Virginia University

Fall 2014-Present

Morgantown, West Virginia

Counseling Psychology (APA Accredited Program)

Doctor of Philosophy

GPA: 4.0

Indiana State University

Summer 2011-July 2013

Terre Haute, Indiana

Clinical Mental Health Counseling (CACREP Accredited Program)

July 2011- Summer 2013

Master of Science

GPA: $4.0 / 4.0$

Miami University of Ohio

Fall 2007-Spring 2011

Oxford, Ohio

Bachelor of Arts in Psychology

GPA: $3.4 / 4.0$

\section{John E. Doulobois Center}

Fall 2010

Differdange, Luxembourg

Study Abroad

GPA: $3.9 / 4.0$

\section{Clinical Experience}

\section{Dayton VA Medical Center, Internship, APA Accredited}

July 2017-Present

Total Direct Contact Hours as of 11/24/17: 184

Total Hours as of 11/24/17: 700

Projected Direct Contact Hours: 600

Projected Total Hours: 2000

- Rotations included: PTSD Clinic (6 months), Substance Use (6 months), Mental Health Clinic (12 months)

- Completed CPT training and case consultation, STAIR, CBT-I, CBT-D and CAPS-5 training

- Facilitated process and CPT groups in the residential PTSD program

- Implemented professional knowledge and clinical skills with an integrated CBT and Adlerian approach.

Supervisors: Brian Macobin PsyD 
Angelique Teeters PsyD

\section{Louis A. Johnson VA Medical Center, Practicum}

July 2016-May 2017

Clinical Hours: 230

Total Hours: 524

- Facilitated process and trauma focused groups in a rural residential VA hospital.

- Completed VA 101 training, Motivational Interviewing training, and Cognitive Processing Therapy Training.

- Maintained an individual client caseload to facilitate trauma processing and achievement of treatment goals.

- Received 2 hours a week of individual supervision.

- Utilized CPRS for electronic record keeping as well as billing.

- Implemented professional knowledge and clinical skills with an Adlerian approach.

Supervisors: Angelo Giolzetti PsyD (Maryland Psychologist License \#05133)

Amanda Charlton-Fryer PsyD (Pennsylvania Psychologist License \# PS016963)

\section{Norwood Behavioral Health Systems, Practicum}

August 2015-August 2016

Clinical Hours: 524

Total Hours: 963

- Facilitated process and psychoeducation groups on the Crisis Stabilization Unit in addition to an anger management intensive outpatient group in a rural community mental health center.

- Maintained a diverse outpatient caseload.

- Received 1 hour a week of individual supervision and 1 hour of group supervision.

- Utilized Provider for electronic record keeping as well as billing.

- Implemented professional knowledge and clinical skills with an Adlerian approach.

Supervisor: Perry Stanley Ed.D (West Virginia Psychologist License \#596)

Ridge Behavioral Health Center

Youth Chemical Dependency Therapist

October 2013- June 2014

- Facilitated substance abuse groups for adolescent clients.

- Groups utilized the Seven Challenges Model to address substance abuse as well as co-occurring mental illness.

- Received Verbal De-Escalation Training, Nonviolent Crisis Intervention Training, and CPR Training.

- Received 1 hour a week of individual supervision.

Supervisor: Jason Staats LPCC (Kentucky License \#102110), CADC (Kentucky License

\#ADCLAD00224864)

\section{Vermillion Parke Community Health Center (FQHC) \& North Vermillion High School, Internship}

Fall 2012- Spring 2013

Clinton \& Cayuga, Indiana

Clinical Hours: 618.5

Internship Hours: 1248.8

- Worked with a variety of clients ranging in age from 4-50 years old within the Clinton community 
as well as High School students in the Cayuga community.

- Facilitated psychoeducational groups on stress management, and anger management (2 sixweek groups).

- Carried a diverse caseload of approximately 20 individual clients.

- Therapeutic aid to the onsite psychologist in adjunctive therapy with 3 families.

- Received 3 hours of supervision (individual supervision by site supervisor, and group supervision) per week.

- Utilized the Electronic Medical Record for all documentation.

- Attended quarterly medical provider meetings.

- Implemented professional knowledge and clinical skills with an Adlerian approach.

Supervisor: Jonathan Leggett Ph.D. HSPP (New Mexico License \#1279)

\section{Rose Hulman Institute of Technology, Internship}

Spring 2013

Terre Haute, Indiana

Clinical Hours: 19

Total Hours: 132

- Worked with Rose Hulman undergraduate students one day per week for five hours.

- Carried a caseload of 4 students.

- Received 1 hour a week of individual supervision.

- Implemented professional knowledge and clinical skills with an Adlerian approach.

Faculty Supervisor: Bridget Roberts-Pittman, Ph.D. HSPP LMFT LCAC (Indiana License \# 20042100A)

\section{Ryves Hall Community Center, Practicum/Internship}

Spring 2012- Spring 2013

Clinical Hours: 40

- Facilitated group Theraplay at a Catholic Charities pre-school, with the goals of improved selfregulation, self-calming and soothing.

- Group consisted of between 6-10 children ages 3-5 years of diverse and varied backgrounds.

- Collaborated with co-facilitator to plan and document the weekly group.

- Received 1 hour a week of individual supervision.

Faculty Supervisor: Catherine Tucker, PhD, LMHC, Registered Play Therapist-Supervisor

\section{University Hall Counseling Clinic at Indiana State University, Practicum}

Fall 2012- Fall 2013

Terre Haute, Indiana

Total Clinical Hours: 156.5

Total Practicum Hours: 273.9

- Supervised counseling experience in a professional setting working with children, adolescents, and adults.

- Directly experienced individual, couples, and group counseling, crisis intervention, and assessment (Level A \& B).

- Advocated for a client by testifying in family court.

- Completed documentation electronically under supervision.

- Implemented professional knowledge and clinical skills with an Adlerian approach.

Faculty Supervisor: Catherine Tucker, Ph.D., LMHC, Registered Play Therapist-Supervisor 


\section{Professional Experience}

\section{Graduate Student Instructor, West Virginia University}

Morgantown, West Virginia

Fall 2015- Spring 2017

Course Titles: Counseling 303: Introduction to the Helping Profession Counseling 410: Interpersonal Communications

Counseling 400: Diversity \& Human Relations

Counseling 405: Career \& Lifespan Development

Supervisor: Regina Burgess, PhD, Certified Rehabilitation Counselor, LPC, Certified Vocational Evaluator

\section{Student Advisor, West Virginia University}

Morgantown, West Virginia

Summer 2015

- Assisted first year students with course scheduling, academic planning, and setup orientation presentation.

\section{Graduate Student Instructor, Indiana State University}

Terre Haute, Indiana

Fall 2012 \& Spring 2013

Course Title: Counseling 135: Career and Life Planning

Supervisor: Catherine Tucker, PhD, LMHC, Registered Play Therapist-Supervisor

\section{Graduate Assistant, Indiana State University}

Terre Haute, Indiana

Fall 2011- Fall 2012

- Assistant in the Communication Disorders and Counseling, School and Educational Psychology office.

- University Hall Clinic reception, responsible for counseling filing system and labeling process.

\section{Student Helper, Division TEACCH}

\section{Chapel Hill, North Carolina}

Summer 2010

- Assisted trainers in working with children on the Autism Spectrum.

- Worked with program participants to learn the TEACCH method to implement with children in their classrooms.

\section{Research}

\section{Law Enforcement Officers Killed \& Assaulted (LEOKA)}

Research Assistant

2014-2017

- Utilizing a Consensual Qualitative Research (CQR) methodology, blocked, coded, and collated interview results.

\section{Publications \& Presentations}

Shaw, J.L.A., Shannon, B.J., Molder, A., Latorre, C., Berkey Milam, S...Greenbaum, H. (2016). Demystifying Human Trafficking in the United States. Symposium conducted at the 2016 Great Lakes Regional 
Counseling Psychology Conference, Bloomington, Indiana.

Shannon, B.J., \& Shaw, J.L.A. (2016). Shedding light on religious privilege. Poster presented at Great Lakes Regional Counseling Psychology Conference, Bloomington, Indiana.

Shaw, J.L.A., Shannon, B.J., Greenbaum, H., \& Taylor, J. (2016). Infusing multiculturalism and social justice from college to community: Speak Out, Reach Out. In M.G. Hickey (Ed.), Service Learning in Higher Education. New York, NY: Peter Lang Publishing.

Greenbaum, H., Webb, B., Scott, O., Shaw, J., Shannon, B., \& Taylor, J. (2015). Speak out reach out (SORO): Student-led group affirming diversity at WVU and in our local community. Poster session presented at West Virginia Psychological Association Conference, Morgantown, West Virginia.

Daniels, J. (Director) (2015, August 8). Law Enforcement Officer Ambushes: The Psychology of Officers and Offenders. American Psychological Association Annual Conference. Lecture conducted from American Psychological Association, Toronto.

Tucker, C., Catania, B. (2013). Group theraplay in a pre-school for at-risk children and children of a homeless shelter. $6^{\text {th }}$ International Theraplay Conference, Evanston, Illinois.

Catania, B., Collins, S., Nelson, S. (2013). Child sex trafficking in Southeast Asia: Implications for counselors. The American Counseling Association 2013 Conference, Cincinnati, Ohio.

\section{Leadership and Advocacy}

Speak Out Reach Out- Treasurer

Morgantown, West Virginia

Fall 2014-2017

- Founding member and active treasurer of a student lead organization designed to promote multicultural and social justice engagement at West Virginia University and within the broader community.

- Organized trainings, workshops, presentations, or other community outreach programs.

- Created and fostered a supportive environment for students of diverse cultural backgrounds and for those interested in multiculturalism and diversity promote awareness about multicultural issues within the Morgantown community.

\section{Alzheimer's Association}

Morgantown, West Virginia

Fall 2014-Summer 2015

- Assisted with organization and preparation for psychoeducation conferences within the community.

\section{Human Trafficking a Global Perspective}

Thailand \& Cambodia

Summer 2013

- Traveled to Thailand and Cambodia to gain a greater understanding of the history, economic, and mental health impact of human trafficking.

- Expanded understanding of cultural differences, gender issues, and power dynamics, which is directly applied to clinical work.

\section{John E. Doulobois Center}

\section{Differdange, Luxembourg}

Fall 2010

- Learned multicultural sensitivity in interactions with diverse cultures. 


\section{Cincinnati Children's Hospital, College Hill Campus}

Cincinnati, Ohio

January 2008-May 2010

- Organized activities with psychiatric inpatients during activity hour.

- Shadowed a Child Life Specialist in preparing patients for upcoming procedures.

\section{Cross Cultural Solutions}

Tanzania, Africa

Summer 2009

- Taught English to twenty-five local orphans ranging from age three to age eight in Boma, Tanzania.

\section{Additional Training}

Enhancing Providers' Effectiveness with Transgender Clients: Risk and Stigma Reduction Dr. Colt Meier

Morgantown, West Virginia

September 2014

\section{International Theraplay Conference}

Evanston, Illinois

July 2013

\section{Techniques in Crisis Counseling}

Indianapolis, Indiana

April 2013

American Counseling Association Conference- Military Counseling Academy Certificate Cincinnati, Ohio

April 2013

\section{Pediatric Mental Health Symposium Conference}

Cincinnati, Ohio

October 2012

\section{Domestic Minor Sex Trafficking in Indiana}

Presenter: Anita Carpenter, Indiana Coalition Against Sexual Assault

Terre Haute, Indiana

October 2012

\section{American Counseling Association Conference}

San Francisco, California

March 2012 
Healing, Resiliency and Hope for Childhood Trauma, Indiana State University

Presenter: Mary U. Vicario, LPCC-S of St. Aloysius Orphanage and Finding Hope Clinical

Consulting, LLC

Terre Haute, Indiana

December 2011

\section{Professional Memberships}

American Psychological Association

Student Member

American Psychological Association Division 17

Student Member

\section{Honors and Recognition}

\section{University Provost Fellowship Recipient}

Academic Year 2014

\section{Ethos Award}

Spring 2013

- Awarded for high-quality and balanced contributions in the areas of teaching, research, and service

- Recognizes those who embrace the university mission, embody the values of graduate education at Indiana State University, and have arguably served as the standard for excellence within a given degree program.

\section{Delta Theta Tau Counseling Scholarship Award}

Spring 2013, Spring 2012; Awarded to graduate students in the Counseling field. 